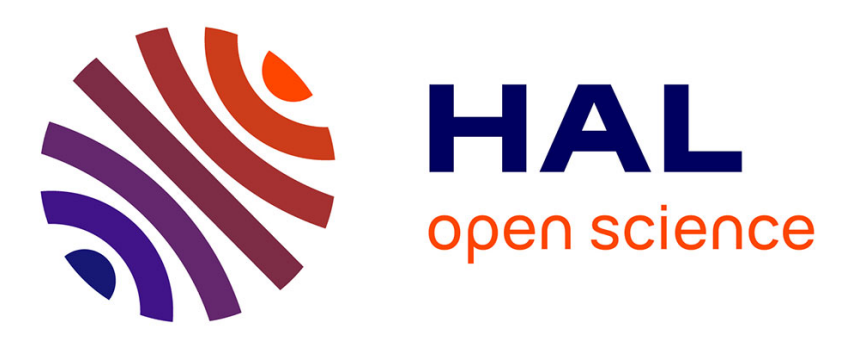

\title{
Validation of Soil Moisture Data Products From the NASA SMAP Mission
}

Andreas Colliander, Rolf Reichle, Wade T Crow, Michael H Cosh, Fan Chen, Steven Chan, Narendra Narayan Das, Rajat Bindlish, J. Chaubell, Seungbum Kim, et al.

\section{To cite this version:}

Andreas Colliander, Rolf Reichle, Wade T Crow, Michael H Cosh, Fan Chen, et al.. Validation of Soil Moisture Data Products From the NASA SMAP Mission. IEEE Journal of Selected Topics in Applied Earth Observations and Remote Sensing, 2022, 15, pp.364-392. 10.1109/JSTARS.2021.3124743. meteo-03512208

\section{HAL Id: meteo-03512208}

\section{https://hal-meteofrance.archives-ouvertes.fr/meteo-03512208}

Submitted on 5 Jan 2022

HAL is a multi-disciplinary open access archive for the deposit and dissemination of scientific research documents, whether they are published or not. The documents may come from teaching and research institutions in France or abroad, or from public or private research centers.
L'archive ouverte pluridisciplinaire HAL, est destinée au dépôt et à la diffusion de documents scientifiques de niveau recherche, publiés ou non, émanant des établissements d'enseignement et de recherche français ou étrangers, des laboratoires publics ou privés. 


\title{
Validation of Soil Moisture Data Products From the NASA SMAP Mission
}

\author{
Andreas Colliander ${ }^{(}$, Senior Member, IEEE, Rolf H. Reichle (i), Wade T. Crow ${ }^{(1)}$, \\ Michael H. Cosh ${ }^{\circledR}$, Senior Member, IEEE, Fan Chen ${ }^{\circledR}$, Steven Chan ${ }^{\circledR}$, Senior Member, IEEE, \\ Narendra Narayan Das ${ }^{\circledR}$, Rajat Bindlish ${ }^{\circledR}$, Senior Member, IEEE, Julian Chaubell ${ }^{\circledR}$, Seungbum Kim ${ }^{(1)}$, \\ Qing Liu, Peggy E. O’Neill ${ }^{\circledR}$, Fellow, IEEE, R. Scott Dunbar, Land B. Dang, John S. Kimball ${ }^{\circledR}$, \\ Thomas J. Jackson ${ }^{\circledR}$, Fellow, IEEE, Hala Khalid Al-Jassar ${ }^{\circledR}$, Jun Asanuma ${ }^{\circledR}$, Bimal K. Bhattacharya, \\ Aaron A. Berg ${ }^{(1)}$, David D. Bosch ${ }^{\circledR}$, Laura Bourgeau-Chavez ${ }^{\circledR}$, Todd Caldwell ${ }^{\circledR}$, Jean-Christophe Calvet, \\ Chandra Holifield Collins, Karsten H. Jensen, Stan Livingston, Ernesto Lopez-Baeza ${ }^{\circledR}$, José Martínez-Fernández ${ }^{\circledR}$, \\ Heather McNairn ${ }^{\circledR}$, Mahta Moghaddam ${ }^{\circledR}$, Fellow, IEEE, Carsten Montzka ${ }^{\circledR}$, Member, IEEE, \\ Claudia Notarnicola ${ }^{\circledR}$, Member, IEEE, Thierry Pellarin, Isabella Greimeister-Pfeil ${ }^{\circledR}$, Jouni Pulliainen ${ }^{\circledR}$, \\ Judith Gpe. Ramos Hernández ${ }^{\circledR}$, Mark Seyfried, Patrick J. Starks ${ }^{\circledR}$, Zhongbo Su, R. van der Velde ${ }^{(0)}$, \\ Yijian Zeng ${ }^{(\mathbb{0}}$, Marc Thibeault ${ }^{\circledR}$, Mariette Vreugdenhil ${ }^{\circledR}$, Jeffrey P. Walker ${ }^{\mathbb{1}}$, Fellow, IEEE, Mehrez Zribi, \\ Dara Entekhabi ${ }^{\circledR}$, Fellow, IEEE, and Simon H. Yueh, Fellow, IEEE
}

\begin{abstract}
The National Aeronautics and Space Administration Soil Moisture Active Passive (SMAP) mission has been validating its soil moisture (SM) products since the start of data production on March 31, 2015. Prior to launch, the mission defined a set of criteria for core validation sites (CVS) that enable the testing of the key mission SM accuracy requirement (unbiased root-meansquare error $<0.04 \mathrm{~m}^{3} / \mathrm{m}^{3}$ ). The validation approach also includes other ("sparse network") in situ SM measurements, satellite SM products, model-based SM products, and field experiments. Over the past six years, the SMAP SM products have been analyzed with respect to these reference data, and the analysis approaches themselves have been scrutinized in an effort to best understand the products' performance. Validation of the most recent SMAP Level 2 and 3 SM retrieval products (R17000) shows that the $L$-band $(1.4 \mathrm{GHz})$ radiometer-based $\mathrm{SM}$ record continues to meet mission requirements. The products are generally consistent with SM retrievals from the European Space Agency Soil Moisture Ocean Salinity mission, although there are differences in some regions. The high-resolution (3-km) SM retrieval product, generated by combining Copernicus Sentinel-1 data with SMAP observations, performs within expectations. Currently, however, there is limited availability of 3-km CVS data to support extensive validation at this spatial scale. The most recent (version 5) SMAP Level 4 SM data assimilation product providing surface and root-zone SM with complete spatio-temporal coverage at $9-\mathrm{km}$ resolution also meets performance requirements. The SMAP SM validation program
\end{abstract}

Manuscript received May 30, 2021; revised September 20, 2021; accepted October 15, 2021. Date of publication November 2, 2021; date of current version December 29, 2021. This work was supported in part by the NASA SMAP mission; in part at the Jet Propulsion Laboratory, California Institute of Technology, under a contract with the National Aeronautics and Space Administration; in part by the Spanish Ministry of Science, Innovation and Universities (Project ESP2017-89463-C3-3-R and PID2020-114623RB-C33), the Castilla y León Government (Projects SA112P20 and CLU-2018-04), and the European Regional Development Fund; and in part by the U.S. Department of Agriculture, Agricultural Research Service. Long-Term Agroecosystem Research was supported by the U.S. Department of Agriculture. (Corresponding author: Andreas Colliander.)

Please see the Acknowledgment section of this article for the author affiliations.

Digital Object Identifier 10.1109/JSTARS.2021.3124743 will continue throughout the mission life; future plans include expanding it to forested and high-latitude regions.

Index Terms - Core validation sites (CVS), soil moisture (SM), Soil Moisture Active Passive (SMAP), validation.

\section{INTRODUCTION}

$\mathbf{T}$ HE National Aeronautics and Space Administration (NASA) Soil Moisture Active Passive (SMAP) mission has produced global soil moisture (SM) measurements since March 2015 [1]. SMAP uses the $L$-band $(1.413 \mathrm{GHz})$ frequency to carry out the SM measurements because of its sensitivity to SM changes in the surface $(\sim 0-5 \mathrm{~cm})$ soil layer and its relative insensitivity to confounding effects of surface roughness and vegetation [2]. As with other remotely sensed data products, the scientific value of these SM products is determined, in part, by how well their performance characteristics are known. The process of assessing the accuracy of a data product by independent means is called validation [3], [4]. The SMAP mission established a rigorous validation program to verify that mission requirements are met and to provide information on the quality of the products to the community. The mission recognized the importance of the calibration and validation program early on, resulting in a comprehensive plan of validation activities during the prelaunch phase [5]. In particular, the mission started engaging external partners and conducting validation exercises years before the launch. Moreover, the SMAP validation strategy benefited from two earlier missions that had a considerable focus on the validation of SM products: the Japan Aerospace Exploration Agency Advanced Microwave Scanning Radiometer-Earth Observing System (AMSR-E) instrument launched by NASA on the Aqua satellite in 2002 [6], and the Soil Moisture and Ocean Salinity (SMOS) satellite launched by European Space Agency (ESA) in 2009 [7]. AMSR-E validation efforts spurred the development 
of locally dense observation networks with surface SM measurements in hydrologic research watersheds for SM validation at the footprint scale of these satellites (tens of kilometers) (e.g., [8]-[14]). This trend continued with SMOS (e.g., [15]-[19]). Consequently, when SMAP was launched in 2015, there was already a significant infrastructure of locally dense networks in place with respect to the remote sensing footprint size, due to these earlier efforts and active international cooperation.

The SMAP project evaluated these existing locally dense networks for their suitability as so-called SMAP core validation sites (CVS) and called for expanding these kinds of observations as much as possible, while also incorporating sparse networks (typically providing just one point-scale observation location within a footprint), other satellite data products, model-based products, and field experiments into the SM validation plan [5]. The AMSR-E and SMOS validation efforts utilized these components as well. In the US, the AMSR-E community led a series of field experiments that also included airborne observations (e.g., [20]-[22]). The experience gained from these experiments was invaluable for the subsequent SMAP validation experiments (see Section III-F). SMOS SM validation plans [23] similarly included field experiments (e.g., [24]), sparse networks (e.g., [25]), and other approaches (e.g., [26]) in addition to dense networks (e.g., [27], [28], [18], [29]). In the 1990s, an effort was started to collect global SM measurements in a single database called the Global Soil Moisture Data Bank [30]. ESA and SMOS continued the development of a centralized repository via the ongoing collection of in situ SM observations into the International Soil Moisture Network (ISMN) [31].

The SMAP project required the release of beta and validated versions of the SM data products after 6 and 12 months, respectively, from the start of science observations [5]. This timeline drove many decisions in the development of the validation plan and tools. Obviously, only reference data for the period after the start of the SMAP science observations on March 31, 2015 could be used for SMAP validation. Moreover, reference measurements needed to be available to SMAP with short temporal latency to facilitate validation of the beta and validated product versions in time for their public release. The mission's emphasis on this point ensured that there were data available during the first months of the validation period to meet the challenging timeline. This is also the main reason the SMAP validation team connected directly to the data providers and operated outside of established repositories, such as the ISMN, that do not have such strict latency requirements. Furthermore, the bulk of the data processing tools were developed and the data formats, transfer protocols, etc., were agreed upon before the launch of SMAP. This arguably reduced the flexibility to include datasets that did not meet the constraints during the first year of the validation. However, once the most intensive phase of the validation was completed, the mission was able to increase flexibility and relax its previous requirements on the latency of the validation data.

A unique aspect of the SMAP SM validation is the need to assess SM estimates for the nested "surface" $(0-5 \mathrm{~cm})$ and "root-zone" (0-100 cm) soil layers from the SMAP Level 4 (L4) product, which is based on the assimilation of SMAP brightness temperature (TB) observations into a land surface model [39]. To the extent possible, the SM validation strategy for the L4 product is similar to that of the directly retrieved Level 2 (L2) and Level 3 (L3) surface-only SM products (see Section II), which were based on CVS, sparse networks, and other data sources. However, adaptation to the unique characteristics of the L4 product resulted in some differences between the validation of the L4 and L2/L3 products (see Sections III and IV).

The Committee on Earth Observation Satellites (CEOS) has advanced a four-stage validation hierarchy, which has been adopted by many providers of satellite data product (https: //lpvs.gsfc.nasa.gov). The validation stages increase with the breadth of the validation effort (see Appendix A). SMAP was operating at validation Stage 1 during the first year of the mission, which implied that the assessment was conducted based on comparisons to in situ reference data collected at a small set of locations and over relatively short time periods. The SM products achieved Stage 2 shortly thereafter with the extension of the spatial and temporal scope and the publication of the first validation results in the peer-reviewed literature. Since then, SMAP has continued to expand the analysis, with significant contributions from the community, to achieve Stage 3 maturity. Stage 4 (the final stage) requires the Stage 3 level analysis to be updated systematically over time. Many of the SMAP validation analyses are currently updated on a yearly basis and released in the data product assessment reports (e.g., [32], [33]), which satisfies the key aspect of Stage-4 validation.

The experience of the AMSR-E, SMOS, and SMAP SM validation efforts contributed to two important community reference documents that outline best practices for SM validation along with guidance for future development of these practices [34], [35]. The SMAP SM validation approach is largely in line with these recommendations. This article lays out the SMAP SM validation approach, describes the use of the different methodologies, discusses the uncertainty estimates associated with the validation analyses (see Section III), and presents updated validation results for the most recent versions (R17000 for L2/L3 and Vv5030 for L4) of the SMAP SM products (see Section IV). In Section V, we discuss the reliability of the validation approach, its shortcomings, and how to improve on the current approach as well as results from other validation studies and future directions for the SMAP SM products and their validation.

\section{SMAP SM DATA PRODUCTS}

Since March 31, 2015, the SMAP mission has delivered data products containing instrument measurements (Level 1), geophysical SM retrievals (swath-based, L2, and daily composite, L3), and SM estimates from data assimilation of the instrument measurements into a land surface model (L4). On July 7, 2015, the SMAP radar malfunctioned and ceased operation. Prior to the radar malfunction, SMAP provided four different surface SM products and one root-zone SM product [1]: radiometer-based surface SM on a 36-km grid [36], radar-based surface SM on a 3-km grid [37], radiometer and radar combined surface SM on a 9-km grid [38], and surface and root-zone SM based on the assimilation of SMAP TB observations into the NASA Goddard Earth Observing System (GEOS) Catchment land surface model on a $9-\mathrm{km}$ grid [39]. The grid used by the SMAP products is the 
TABLE I

SMAP SM DATA PRODUCTS

\begin{tabular}{|c|c|c|c|c|c|}
\hline $\begin{array}{l}\text { Data Product } \\
\text { Name }\end{array}$ & Abbr. & Short Description & Resolution & $\begin{array}{c}\text { EASEv2 } \\
\text { Grid } \\
\end{array}$ & Time Period \\
\hline [L2/L3]SMPE & $\mathrm{PE}$ & Enhanced radiometer-based & $33 \mathrm{~km}$ & $9 \mathrm{~km}$ & March 31,2015 - present \\
\hline$[\mathrm{L} 2 / \mathrm{L} 3] \mathrm{SMP}$ & $\mathrm{P}$ & Radiometer-based & $36 \mathrm{~km}$ & $36 \mathrm{~km}$ & March 31, 2015-present \\
\hline$[\mathrm{L} 2 / \mathrm{L} 3] \mathrm{SMA}$ & A & Radar-based & $3 \mathrm{~km}$ & $3 \mathrm{~km}$ & April $13-$ July 7, 2015 \\
\hline [L2/L3]SMAP & AP & Combined SMAP radiometer and radar & $9 \mathrm{~km}$ & $9 \mathrm{~km}$ & April 13 - July 7, 2015 \\
\hline L2SMSP & SP & Combined SMAP radiometer and Sentinel-1 radar & $3 \mathrm{~km}$ & $3 \mathrm{~km}$ & March 31, 2015-present \\
\hline L4SM & L4 & Model assimilation product (surface and root-zone SM) & $9 \mathrm{~km}$ & $9 \mathrm{~km}$ & March 31, 2015 - present \\
\hline
\end{tabular}

The resolution column indicates the effective spatial resolution and the EASEv2 grid column indicates the spacing of the posting grid.

version 2 Equal Area Scalable Earth (EASEv2) grid system [40], [41].

Following the failure of the radar, the mission introduced a new TB sampling approach and two new SM products. The SMAP $40^{\circ}$ angle TB measurements have a $38-\mathrm{km}$ resolution (defined by the half-power footprint on the earth's surface of the radiometer antenna pattern); the radiometric resolution of the gridded TB is better than $0.5 \mathrm{~K}$, and the measurements filter out radio frequency interference (RFI) [42]-[44]. The original radiometer sampling averaged the TB measurements over the 36-km EASEv2 grid cells using inverse distance weighting [45]. The enhanced TB processing developed after the radar malfunction, using a Backus-Gilbert approach to sample measurements on the 9-km EASEv2 grid [46]. A new SM product was developed based on the enhanced TB product, which was also sampled onto the 9-km grid [47]. Because the spatial resolution of the TB measurement is considerably larger than the 9-km spacing of the sampling grid, the enhanced passive radiometer-based SM product (henceforth, PE) inverts the TB from a given 9-km grid cell into an SM estimate using ancillary data and parameters for a 33-km "aggregation domain" centered on the 9-km grid cell, thereby approximating the spatial resolution of the TB measurement. The second SM product introduced after the radar malfunction uses observations from the $C$-band radar on the Copernicus Sentinel-1a and $1 \mathrm{~b}$ satellites to downscale the SMAP $L$-band radiometer TB measurements with an algorithm similar to that used by the original SMAP radar/radiometer combined product [38], and then derives SM from the downscaled TB field [48]. The SMAP/Sentinel-1 product (henceforth, SP) provides $\mathrm{SM}$ on 1-km and 3-km grids. The product uses the SMAP observations only when the Sentinel-1 measurements are available; therefore, the product covers the earth in about 12-days (based on Sentinel-1 repeat cycle), but the combined revisit interval of the two satellites is less for certain areas where data collection is prioritized (over Europe, for example) [48]. Table I summarizes the SMAP SM products.

The radiometer-based products (P and PE) include SM retrieved using three different algorithms: single-channel vertical polarization $(\mathrm{SCA}-\mathrm{V})$, single-channel horizontal polarization (SCA-H), and dual-channel algorithms (DCA) [49]. Besides adding the enhanced and the SMAP/Sentinel-1 products described above, the mission has broadly improved all products over the years. Key improvements include the processing of ancillary data, such as the surface temperature [49], updating the SM retrieval algorithm for the DCA [50], and improving the modeling parameterization for the L4 product [51]. New versions of the SMAP SM products have been released approximately yearly with various enhancements and always accompanied by updated assessment reports (e.g., [32], [33]), plus a complete reprocessing of the data.

The SMAP baseline validation domain is defined by the product accuracy requirements of the mission. Surfaces with permanent ice and snow, urban areas, wetlands, and areas with above-ground vegetation water content (VWC) greater than 5 $\mathrm{kg} / \mathrm{m}^{2}$ are excluded from the formal accuracy requirements and identified with a nonzero retrieval quality flag [1]. In recent years, the SMAP SM algorithm research has included improving the quality of SM retrievals in more densely vegetated regions, which has resulted in validation activities in forested areas [52], [53].

\section{SMAP SM VALidation STRATEGy AND METHOdOlogiES}

The SMAP SM validation strategy is driven by the mission validation requirements, the characteristics of the measured SM (accounting for natural variability in the horizontal, vertical, and time dimensions), and the availability of high-quality reference data [5]. NASA required the SMAP mission to measure SM to within $0.04 \mathrm{~m}^{3} / \mathrm{m}^{3}$ accuracy-in an average aggregate senseacross the entire SM validation domain [1], [54], where accuracy is defined as the standard deviation of the error or unbiased root-mean-square error (ubRMSE) (see Appendix B). Because the locally dense CVS SM monitoring networks provide the best available measurements of SM at the SMAP radiometer footprint scale (see Section III-B), the mission chose the CVS data as the primary validation reference to establish that the accuracy requirement is met. Specifically, the product accuracy assessment is based on the average of the unbiased root-meansquare difference (ubRMSD) sampled at the CVS [56]. Other metrics used in the validation are the RMSD and the mean difference (MD) (see Appendix B). Owing to errors in the in situ measurements, the ubRMSD, RMSD, and MD are conservative estimates of the true SMAP ubRMSE, RMSE, and bias, respectively (see Section III-A). The validation metrics further include the Pearson correlation $(R)$ (see Appendix B) and the anomaly $R$ computed using the departures from the multiyear, seasonally 
TABLE II

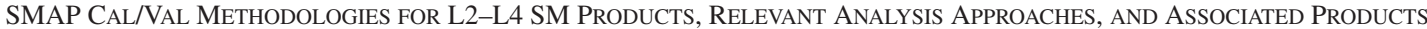

\begin{tabular}{|c|c|c|c|}
\hline Methodology & Key Features & Analysis Approaches & Products \\
\hline \multirow{2}{*}{$\begin{array}{l}\text { Core validation } \\
\text { sites }\end{array}$} & \multirow{2}{*}{$\begin{array}{l}\text { Accurate estimates of products at matching } \\
\text { scales for a limited set of conditions }\end{array}$} & Direct comparisons & P, PE, A, AP, SP, L4 \\
\hline & & Retrieval algorithm testing & $\mathrm{P}, \mathrm{PE}, \mathrm{A}$ \\
\hline \multirow[t]{2}{*}{ Sparse networks } & \multirow{2}{*}{$\begin{array}{l}\text { One point in the grid cell for a wide range of } \\
\text { conditions }\end{array}$} & $\begin{array}{l}\text { Direct comparisons (bias- } \\
\text { insensitive metric only) } \\
\end{array}$ & $\mathrm{P}, \mathrm{PE}, \mathrm{A}, \mathrm{AP}, \mathrm{SP}, \mathrm{L} 4$ \\
\hline & & Triple-collocation & $\mathrm{P}, \mathrm{PE}$ \\
\hline \multirow{3}{*}{ Satellite products } & \multirow{3}{*}{$\begin{array}{l}\text { Estimates over a very wide range of } \\
\text { conditions at matching scales }\end{array}$} & Direct comparisons & $\mathrm{P}, \mathrm{PE}$ \\
\hline & & Triple-collocation & $\mathrm{P}, \mathrm{PE}$ \\
\hline & & Instrumental Variable & L4 \\
\hline Model products & $\begin{array}{l}\text { Estimates over a very wide range of } \\
\text { conditions at matching scales }\end{array}$ & $\begin{array}{l}\text { As part of the triple-collocation } \\
\text { analysis }\end{array}$ & $\mathrm{P}, \mathrm{PE}$ \\
\hline \multirow{2}{*}{ Field campaigns } & \multirow{2}{*}{$\begin{array}{l}\text { Detailed estimates for a very limited set of } \\
\text { conditions }\end{array}$} & Direct comparisons & $\mathrm{P}, \mathrm{PE}$ \\
\hline & & Retrieval algorithm testing & $\mathrm{P}, \mathrm{PE}$ \\
\hline $\begin{array}{l}\text { Assimilation } \\
\text { diagnostics }\end{array}$ & $\begin{array}{l}\text { Assessment of the proper functioning of the } \\
\text { assimilation system }\end{array}$ & $\begin{array}{l}\text { Observation-Forecast (O-F) TB } \\
\text { residuals }\end{array}$ & L4 \\
\hline
\end{tabular}

varying climatology computed for both the reference and SMAP SM [51]. Because the number of available SM CVS across the globe is limited, the validation strategy was complemented with additional data sources. These sources include geographically more extensive SM networks with only one, or very few, measurements within the footprint (i.e., sparse networks; Section III-C), other global satellite-based SM products (Section III-D), global land model-based estimates of SM (Section III-E), and field experiments (Section III-F). Additionally, the validation of the L4 product included data assimilation diagnostics as an important element, reflecting the unique nature of L4 among the products (see Section III-G). Each methodology has key features that are exploited in the continuing validation process to accomplish the most comprehensive validation possible for each product across time and space.

The application of the methodologies and analysis approaches depends on the SMAP products. For example, there are few other high-resolution $(<30 \mathrm{~km}) \mathrm{SM}$ products, especially at the global scale, that can be compared with the SMAP active (A), active-passive (AP), and SP products. Triple collocation (TC) analysis has been used to support the use of the sparse networks and other satellite data products together with land model-based products for complementary assessments of the $\mathrm{P}$ and PE products [57], [58]. However, since the L4 product is based on merging radiometer observations into a land model, traditional TC analysis cannot be used for the L4 SM because there are not enough independent reference datasets. However, other Instrumental Variable approaches can be used to quantify the skill improvement from the assimilation of SMAP observations in L4 (relative to a model-only baseline) [59]. Table II summarizes the different validation methodologies and the analysis approaches applied with them for the different data products.

The SMAP satellite makes measurements in the morning and evening based on its 6 A.M./6 P.M. equator crossing sunsynchronous orbit configuration (see Section II). The accuracy requirement for L2SM products applies to the SM retrieved using the 6 A.M. (descending) SMAP overpasses because of the expected uniformity of the temperature across the soil-vegetation column [49], but the SM retrieved using the 6 P.M. overpasses is also validated (and actually has roughly equivalent accuracy performance to the AM overpasses). L4 SM is available and validated at 3 -h intervals.

Currently, the data record of in situ comparisons with SMAP is over six years long. This allows a very detailed look into the performance of the SMAP products, including seasonal characteristics (e.g., [60]-[62]). Continuing data collection and validation are nevertheless important. CEOS considers the continuous monitoring of data consistency to be a key aspect of any validation program since it allows for the reliable detection of any potential anomalies. For example, SMAP experienced an operational anomaly from June 19 to July 23, 2019; once SMAP science measurements were available again after July 23, 2019, it was extremely important to have immediate access to concurrent validation data to verify that the SM retrieval performance remained unchanged following the operational anomaly.

The metrics computed with respect to in situ data are subject to sampling error and should always be provided together with statistical confidence intervals (CIs). Gruber et al. [34] summarize the appropriate methodology to compute CIs for each metric. While they provide a quantitative way of evaluating the statistical significance of the differences between different products and algorithm versions, it is important to emphasize that they do not provide the confidence with respect to the actual true value, but the confidence in the calculation of the difference between the two datasets (SMAP and the reference). This approach was adopted also by the SMAP validation team. The equations are summarized in Appendix B.

\section{A. Horizontal and Vertical Variability of SM}

SM measurements are scale-dependent and must be interpreted in terms of their spatial support, spacing, and network extent [63]. The validation of SMAP SM with in situ measurements is complicated by the extremely different spatial support of the measurements (point-scale in situ sensor measurements versus km-scale resolution of the SMAP products). Depending on the network, the spacing and extent of the 
in situ measurements may approximate the SMAP footprint, as is the case with the CVS. Perhaps most importantly, the spacing of the station measurements (number and distribution) must allow a reliable estimation of the average SM over the SMAP footprint. The required minimum number of point-scale sensors and their spacing is dictated by the spatial variability of SM within the area of interest and the desired accuracy for the estimate at that spatial scale (e.g., [64]-[68], [9], [10], [69][71]). Upscaling of in situ measurements to a satellite footprint scale can be accomplished by averaging in situ measurements with some weighting scheme and it can also include additional high-resolution information (e.g., [72]-[76]). For the SMAP CVS, the geometric Voronoi diagram ([77]; or see Thiessen Polygons in [78]) approach was chosen as the baseline upscaling approach to avoid geographical overweighting of clustered parts of the pixels - for uniformly distributed networks, the weighting of the stations is also uniform and the upscaling corresponds to a simple arithmetic average [54]. Because of an extremely distinct soil texture gradient at the Carman CVS, an upscaling approach based on the soil texture distribution relative to the SM station locations was applied there [79]. van der Velde et al. [80] presented the upscaling approach applied at the Twente CVS where a smaller number of continuously measuring stations are used to estimate the average SM based on a hydrological model and measurements from additional stations that do not cover the entire time period.

The scale discrepancy presents a particular challenge for determining errors in large-scale SM products because the long-term mean SM at a randomly selected single point may be very different from that of the area-average SM. That is, point-scale SM measurements are typically biased with respect to area-average SM. Conversely, the time-varying component of SM typically has a large autocorrelation over long distances, that is, point measurements can better represent the SM temporal changes over domains of several km [81], [82]. Many studies of temporal stability of SM very effectively illustrate these differences of spatial and temporal evolution of SM (e.g., [83]-[85], [11], [86], [70]). Generally, the sparse networks lack adequate representation for resolving bias and RMSE at the scale of satellite SM retrieval footprints.

While arguably less severe than the challenges facing the sampling of bias [82], there are also challenges in estimating bias-insensitive metrics (e.g., ubRMSE, $R$ ) from sparse ground observations. Most notably, random spatial representativeness errors will spuriously inflate the sampled ubRMSD [87] and degrade the sampled estimates of $R$ [57]. As a result, the recovery of absolute ubRMSE and $R$ metrics acquired from in situ measurements, and especially from sparse networks, requires statistical upscaling techniques capable of estimating, and correcting for, the impact of random spatial representative errors (see Section III-C).

In addition to determining performance metrics, calibration/validation (cal/val) activities are often used to quantify the relative variation of metrics between, for example, two different retrieval techniques. It is worth noting that a robust bulk characterization of relative skill in terms of ubRMSE and $R$ can generally be obtained directly from sparse network data-without the application of upscaling techniques. While point-to-footprint upscaling errors can be large, they can be treated as random in nature and independent of retrieval errors. As a result, random spatial representativeness can be assumed to have an equal impact on ubRMSD and R calculated for multiple products and will not affect the assessment of relative metric differences between two products [88].

A consequential assumption in SMAP validation is that the L2/L3 products provide an estimate of the surface SM in the top $5 \mathrm{~cm}$ (on average) and within the grid cell boundaries. This is especially important in considering the breakdown of uncertainties. The response of a microwave radiometer varies depending on the SM content and its vertical distribution (e.g., [89]-[92]). Accounting for this effect separately in the data product would introduce another set of uncertainties, but because of the assumption, the uncertainty caused by the variable sensing depth is embedded within the product uncertainty (e.g., [93], [80]). Hence, the validation of the surface SM products is done with respect to in situ measurements that correspondingly provide an estimate for the top $5 \mathrm{~cm}$ of the soil column with their own set of uncertainties. Most of the in situ measurements used for SMAP validation measure the SM at $5 \mathrm{~cm}$ depth using a probe that is installed horizontally in the soil that captures the SM over an approximate depth range of 3-7 cm, missing the topmost layer of the soil. Probes that have $\sim 5 \mathrm{~cm}$ prongs and are inserted vertically also capture the topmost layer and provide a truer average of water content in the $0-5 \mathrm{~cm}$ soil column, particularly during rapid dry-down periods after rain events [94]. Vertical installation, however, makes sensors more vulnerable to surface disturbances, and depending on the sensor, may interfere with the water flow, result in inaccurate soil temperature compensation of the probe calibration, or the assumptions of the SM measurement along the sensor prongs may be inaccurate [95]. The study in [96] found that the practical difference of these measurements is dependent on the soil clay content (increasing dependence on sensor orientation with increasing clay content).

\section{B. Core Validation Sites}

The SMAP mission engaged with investigators across the globe to provide data from dense networks. The networks were assessed before the SMAP launch according to the following criteria.

1) Number of sensors: $N>8$ for $36-\mathrm{km}, N>5$ for $9-\mathrm{km}$, and $N>3$ for 3-km pixels (see [54]).

2) Geographical distribution: The sensors are not clustered in only one portion of the pixel but cover (approximately) the entire pixel (although not necessarily evenly, see the next requirement).

3) Spatial upscaling: An average SM can be established based on the measured SM and ancillary information (such as additional short-term observations) (see Section III-A).

4) Calibration: The sensors have undergone a calibration using additional measurements, or the calibration is otherwise verified based on past measurements. 
TABLE III

CORE AND CANDIDATE VALIDATION SITES

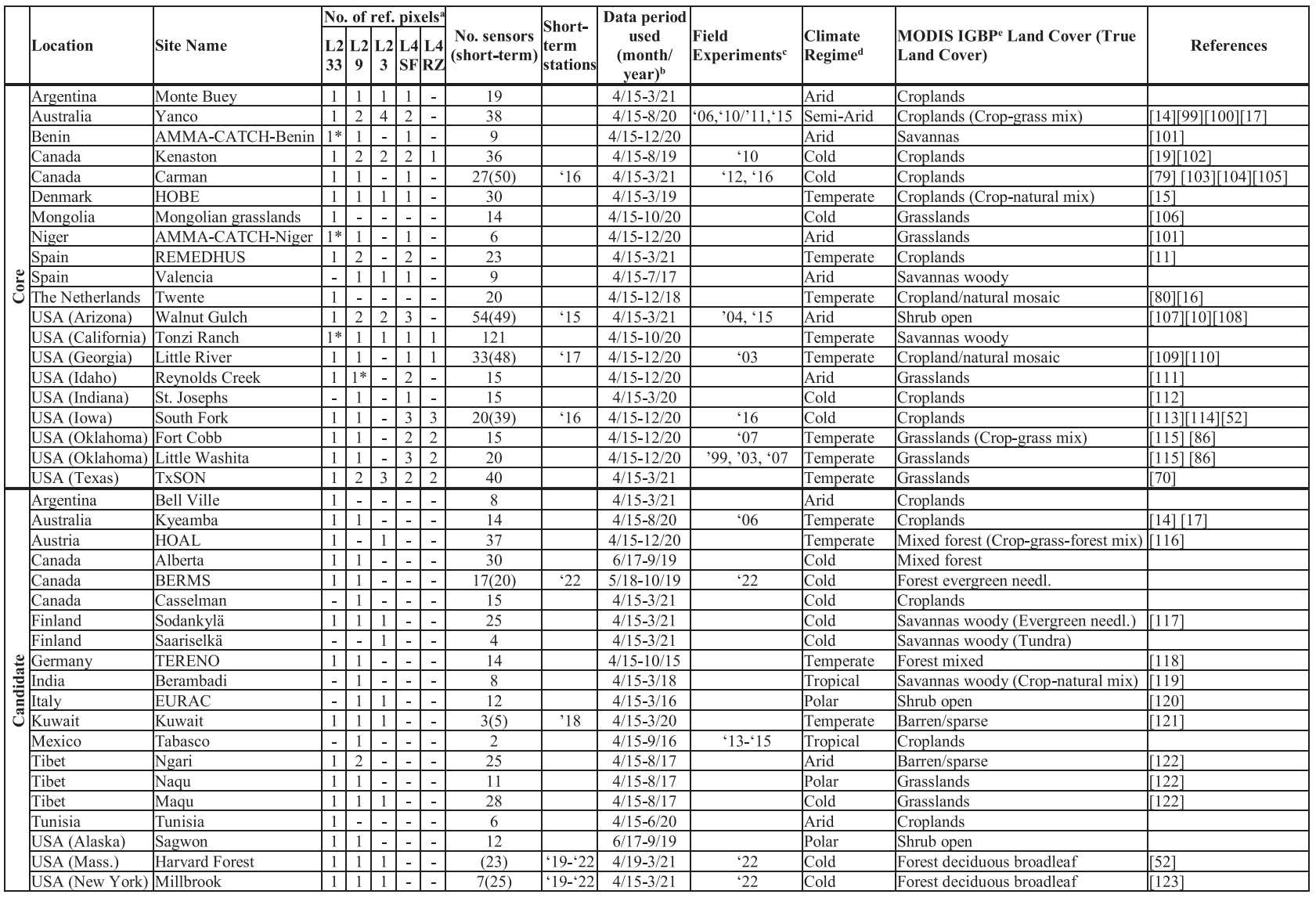

${ }^{*}$ Candidate at this scale

a) A single site can have multiple pixels at various spatial scales (see, e.g., [54]). SF stands for surface and RZ for root-zone.

b) Some but not all sites provide data before $4 / 15$ and/or after $3 / 21$. The range does not account for station outages.

c) Experiments including an $L$-band retrieval aspect and a large-scale sampling.

d) Koeppen-Geiger climate classification scheme [124]

e) MODIS-based International Geosphere-Biosphere Program classification [125].

5) Quality assessment: The time series of each sensor is valid (no dropouts, spikes, drifting, etc.).

6) Maturity: The network has been up and running for a sufficiently long period during which the overall consistency of the measurements was verified.

7) Latency: The data are made available for SMAP validation within 1 week (at most 1 month). This criterion was applied only in the early phase of the mission.

Based on these requirements, currently 15 sites provide reference data at the $33-\mathrm{km}$ scale (or $36 \mathrm{~km}$ for the standard $\mathrm{P}$ product), 17 sites provide reference data at the $9-\mathrm{km}$ scale, and 8 sites provide reference data at the $3-\mathrm{km}$ scale. At the $9-\mathrm{km}$ and 3-km scales, a few sites include more than one independent reference pixel, for a total of 22 (15) pixels at the 9-km (3-km) scale. Two of the original 36-km sites (Kyeamba and Bell Ville) [54] did not continue to provide data from a sufficient number of stations after the initial validation period and were therefore moved to the candidate site category. One site (HOBE) [97] was added only after the initial validation period because it had not met the first-year latency requirement. The 9-km L4 product is validated primarily using $9-\mathrm{km}$ reference pixels that were selected following largely the same principles as for L2 SM validation, resulting in a nearly identical set of $18 \mathrm{CVS}$ with sufficient in situ measurements for surface SM validation. Only seven CVS provide sufficient measurements for root-zone SM validation. Table III lists the CVS and candidate sites and Fig. 1 shows their locations.

Most of the 33-km CVS have more than the minimum required number of measurement locations, which would suggest an uncertainty of less than $0.03 \mathrm{~m}^{3} / \mathrm{m}^{3}$ for the average in situ SM across the 33-km reference pixel [54]. However, Chen et al. [82] found that the variability of the SM caused the CI for the MD to be greater than $0.03 \mathrm{~m}^{3} / \mathrm{m}^{3}$ at seven of the 15 analyzed CVS. The study also accounted for the distribution of the stations (spacing) so that clustered installations had less sampling power; using this adjustment, the MD CI exceeded $0.03 \mathrm{~m}^{3} / \mathrm{m}^{3}$ at nine CVS. The study found that these sites would need to add about eight stations on average to meet the CI goal. At four of the CVS, temporary SM sensors were installed that provided an additional 19-34 measurement stations over one season. These temporary measurements are useful as a reference for the permanent network measurements. As expected, SM measurements from the 


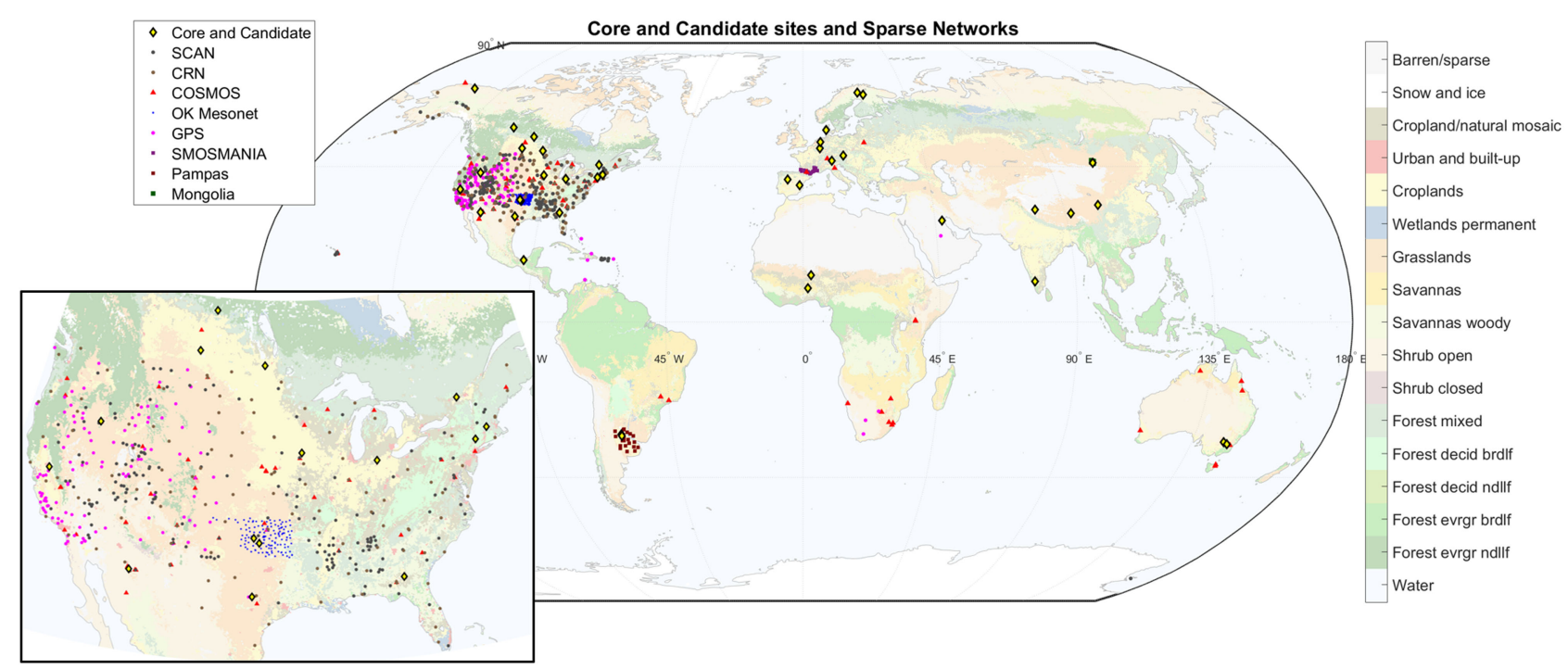

Fig. 1. Map of core and candidate validation sites and sparse networks overlaid on a land cover map (MODIS IGBP).

permanent and temporary networks were very well correlated overall, but the absolute SM difference ranged from 0.009 to $0.034 \mathrm{~m}^{3} / \mathrm{m}^{3}$ [98], which supports the finding by Chen et al. [82] that significant uncertainties in absolute SM remain even with relatively dense spatial sampling.

Even though the candidate validation sites did not satisfy all of the core site requirements, they still offered rich datasets. The 18 candidate sites provided data from six continents and for diverse land cover and climate conditions. The candidate sites could be applied to investigate SM anomalies, the impact of RFI on SM retrievals, and performance outside the validation domain (e.g., forests).

In Section IV, updated performance metrics at the CVS are presented using the six-year data record of the latest SMAP product version for each SM product. The metrics obtained for each CVS are averaged to derive an overall representative value.

\section{Sparse Networks}

During the SMAP period (2015-present), a large number of in situ SM measurements are available from across the world, albeit with larger concentration in North America (see Fig. 1). Most of these measurements are from sparse networks and do not provide SM at the spatial scale of SMAP estimates (see Section III-A). Nevertheless, they still provide useful information and greatly expand the spatial coverage of the in situ validation. The periodically released SMAP assessment reports include performance metrics computed using the sparse network measurements (e.g., [49]). These metrics are not used in an absolute sense, but give a general indication of retrieval performance and to track consistency between algorithm versions (see Section III-A). Table IV summarizes the networks used in the SMAP validation activities. Most of the networks use conventional probe-based measurements, but the $\mathrm{PBO}$ H2O network uses GPS reflectometry to derive SM [126] and the COSMOS network uses neutron measurements to derive SM [127], which have different spatial and vertical support compared to probes.
TABLE IV

SPARSE NETWORKS

\begin{tabular}{|l|l|l|c|c|c|}
\hline Network & Area & Technique & $\begin{array}{c}\text { No. of } \\
\text { stations }\end{array}$ & $\begin{array}{c}\text { Data } \\
\text { period used } \\
\text { (month/ } \\
\text { year) }\end{array}$ & Ref. \\
\hline CRN & USA & $\begin{array}{l}\text { HydraProbe } \\
\text { (triplet) }\end{array}$ & 119 & $4 / 15-3 / 21$ & {$[132]$} \\
\hline SCAN & USA & HydraProbe & 202 & $4 / 15-3 / 21$ & {$[133]$} \\
\hline $\begin{array}{l}\text { Oklahoma } \\
\text { Mesonet }\end{array}$ & $\begin{array}{l}\text { Oklahoma, } \\
\text { USA }\end{array}$ & $\begin{array}{l}\text { Campbell } \\
\text { Scientific } \\
229-L\end{array}$ & 140 & $4 / 15-4 / 18$ & {$[134]$} \\
\hline Pampas & Argentina & HydraProbe & 20 & $4 / 15-3 / 21$ & {$[135]$} \\
\hline SMOSMANIA & France & ThetaProbe & 21 & $4 / 15-12 / 19$ & {$[136]$} \\
\hline $\begin{array}{l}\text { Mongolian } \\
\text { Grasslands }\end{array}$ & Mongolia & Trime IT & 14 & $4 / 15-10 / 20$ & {$[106]$} \\
\hline PBO H2O & Western USA & $\begin{array}{l}\text { GPS } \\
\text { reflectometry }\end{array}$ & 124 & $4 / 15-12 / 17$ & {$[126]$} \\
\hline COSMOS & Mostly USA & $\begin{array}{l}\text { Cosmic ray } \\
\text { probe }\end{array}$ & 79 & $4 / 15-12 / 19$ & {$[127]$} \\
\hline OzNet & Australia & $\begin{array}{l}\text { CS615/ } \\
\text { HydraProbe/ } \\
\text { SDI-12 }\end{array}$ & 50 & $4 / 15-8 / 20$ & {$[14]$} \\
\hline
\end{tabular}

a) Total number of stations in network. Not all stations provide data suitable for SMAP product validation.

b) Some but not all sites provide data before $4 / 15$ and/or after $3 / 21$. The date range does not account for station outages.

The use of sparse networks together with other satellite-based and land model-based SM products in TC approaches has been studied extensively (e.g., [128]-[130]). The basic principle has been to use TC to statistically characterize point-to-footprint upscaling errors and then apply this characterization to correct for the biasing impact of such error on satellite validation metrics [87]. However, despite this potential, work conducted during the SMAP cal/val project revealed significant limitations in the utility of TC for this purpose. First, TC analysis is insensitive to the presence of additive or multiplicative biases in a time series. Such biases can only be detected (and thus eliminated) if TC is given access to a perfectly calibrated dataset (i.e., data 
lacking bias of any kind and degraded only via additive random noise). This assumption, unfortunately, is not satisfied by the sparse network SM observations [57]. As a result, TC cannot contribute directly to the specification of either RMSE (which is sensitive to both additive and multiplicative biases) or even ubRMSE (which is sensitive to multiplicative bias). Even for a bias-tolerant metric like $R$, TC is only truly trustworthy when applied to an SM anomaly time series, that is, after removing the multiyear mean (seasonally varying) SM climatology [57], [131]. Therefore, the utility of TC analysis for the calculation of absolute SMAP cal/val metrics from sparse networks is limited to anomaly $\mathrm{R}$.

We computed bias-insensitive performance metrics with respect to the sparse networks with CIs using the six-year data record for each product. The metrics obtained for each network location were averaged based on land cover to derive representative values for each major land cover class (see Section IV).

\section{Other Global Satellite Products}

Other global satellite-based SM products can be compared directly with SMAP SM estimates by computing the performance metrics between the products at each grid point [137]. Such results do not indicate the correctness of the retrievals-rather the degree of consistency between the products; anomalies in the consistency across the globe can point to potential weak points in the algorithm that are not revealed by geographically limited in situ measurements.

The intercomparison can be developed further by applying TC with additional global information sources. Provided that certain statistical assumptions (e.g., mutual error independence) are met, TC can provide unbiased estimates of anomaly $R$ - even in the absence of ground-based observations. Using a triplet of SMAP (or SMOS) SM retrievals, ASCAT SM retrievals, and surface SM estimates from land surface models, Chen et al. [58] validated the assumptions underlying TC (over limited areas of the globe containing ground-based observations) and, subsequently, applied TC globally to obtain unbiased, 36-km estimates of anomaly $R$ for SMAP, ASCAT, and SMOS SM retrievals. Their results illustrated that SMAP retrievals are significantly outperforming their SMOS or ASCAT equivalents over a large fraction of the globe.

SMOS provides the most relevant satellite products for comparison with the SMAP SM because it uses the same $L$-band frequency as SMAP. Moreover, SMOS retrievals utilize multiangle $\mathrm{TB}$ measurements to compensate for the vegetation effect, but otherwise the retrieval approaches are similar. The comparisons between SMAP and SMOS were updated over the SMAP lifetime (see Section IV). The SMAP PE product on the 9-km grid allows for interpolation of the SM values to the SMOS grid with minimal loss of information because the 9-km SMAP grid spacing is less than a half of the effective resolution of the product (Nyquist Sampling Theorem). Therefore, the metrics (ubRMSD, MD, RMSD, Pearson correlation) were computed over each SMOS grid point with sufficient valid retrievals with the SMAP PE (SCA-V algorithm) and SMOS L3 products after applying the quality flags for both products. The standard bilinear interpolation of the four nearest data points was applied to the SMAP PE product and if any of the values used in the interpolation was flagged, the result was also flagged.

\section{E. Global Model-Based Products}

Like other satellite products, land surface model-based SM products cannot be used as a direct reference for SMAP SM validation [138]. Nevertheless, land models capture the most relevant hydrological processes and SM dynamics based on a large set of input parameters, including precipitation, and therefore offer an additional source of SM information at a global scale and at very high temporal resolution. Various land model products have been used in SMAP validation studies, especially to support TC analyses, including the GMAO Nature Run [57], [58], MERRA-2 [34], ECMWF ERA [139], and ECMWF HTESSEL [58]. These studies exploit the independence of the model products from remote and in situ measurement to compensate remote-sensing error metrics for the impact of random error in model and in situ reference products.

\section{F. Field Experiments}

Before the launch, the SMAP field experiments facilitated retrieval algorithm development and testing (e.g., [99], [103]). After the launch, the field experiments have supported the testing of specific algorithm features under a limited set of conditions. These analyses can be supported by CVS datasets as they offer a longer term reference set, albeit without the supporting measurements provided in a field experiment. For this reason, the SMAP Validation Experiment 2015 (SMAPVEX15) [108] and SMAPVEX16 [104] focused on the locations of the Walnut Gulch, South Fork, and Carman CVS sites. The main objectives of these experiments were, respectively, to support the development and validation of the SM spatial disaggregation algorithm used by SMAP and to provide additional insight into algorithms over agricultural domains, where the analysis of the first-year retrievals revealed specific issues [36]. The SMAP Experiment-4 (SMAPEx-4) and SMAPEx-5 in Australia at the Yanco CVS were also designed to support the development and validation of SM downscaling algorithms [100].

Unfortunately, only SMAPEx-4 was executed before the SMAP radar malfunctioned; when SMAPVEX15 and SMAPEx-5 were conducted later in 2015, only the SMAP radiometer was operational. The Copernicus Sentinel-1 missionnow used for the SP product — did not make measurements over the SMAPVEX15 site at that time, but did cover the SMAPEx-5 site [140]. The topic is particularly important because the validation of the spatial disaggregation techniques is exceptionally difficult. The issue is related to the challenge of reliably characterizing the SM areal mean (discussed in Section III-A), since, in order to show that a disaggregation approach works as intended, absolute SM levels in neighboring grid cells need to be known accurately (see also Section IV-B). Furthermore, the difference between the average SM in the cells needs to be large enough for the disaggregation to have a meaningful impact on the retrieved SM pattern. Such cases are extremely difficult to capture during a short-term field experiment. 
Airborne measurements providing high-resolution SM retrievals are well-suited for evaluating the effectiveness of downscaling approaches because they provide a spatially distributed SM reference (e.g., [141]). The data collected during SMAPVEX15 (despite not being able to test SMAP radar-based disaggregation) were useful for examining: subfootprint spatial heterogeneity; discrepancies in 5-cm in situ sensor readings and SMAP measurements with the help of rain gauge records [108]; the effectiveness of a high-resolution hydrological model for SM validation [142]; and surface roughness effects on SM retrievals [143].

Over agricultural areas, SM retrievals face rapidly changing vegetation and surface roughness conditions that may be large enough to disrupt $L$-band retrieval of SM (e.g., [61], [60], [144]). In SMAPVEX16, the VWC and surface roughness were sampled at multiple fields within the South Fork and Carman CVS. VWC was measured multiple times over the growing season. While the VWC calibrated using the experiment data [114] shows significant differences with respect to the data used by the SMAP algorithm, the differences cannot by themselves explain the retrieval errors of the operational algorithm [104].

\section{G. Assimilation Diagnostics}

In any operational data assimilation system, model estimates are routinely confronted with the assimilated observations. The L4 algorithm computes, in 3-h intervals, the difference between the SMAP TB observations that are available during each 3-h period and the corresponding model forecast TB [145]. These observation-minus-forecast $(\mathrm{O}-\mathrm{F}) \mathrm{TB}$ residuals encapsulate the new information provided by the SMAP observations to the modeling system; they consequently form the basis of the L4 SM analysis, which converts the $\mathrm{O}-\mathrm{F}$ TB residuals into corrections to the modeled SM estimates (a.k.a. SM increments). Because the O-F TB difference involves only TB observations that have not contributed to the corresponding TB forecast, the statistics of the $\mathrm{O}-\mathrm{F}$ TB residuals provide independent verification of the quality of the model's TB estimates and, by extension, the model's SM estimates within the assimilation system. Specifically, in a well-calibrated, unbiased assimilation system, the time series mean of the O-F TB residuals should be close to zero. Moreover, the typical magnitude of the O-F TB residuals (computed as their time series standard deviation) should be consistent with the error assumptions underpinning the assimilation system. Finally, a well-designed land data assimilation-parameterized with accurate measurements of both model and observation errors-will also minimize the temporal standard deviation of $\mathrm{O}-\mathrm{F}$ TB residuals. This principle is particularly useful when evaluating new L4 algorithm versions. For example, the land model revisions in Version 4 of the L4 algorithm resulted in a reduction of the typical magnitude of the O-F TB residuals by $0.13 \mathrm{~K}$ compared to Version 3 [51].

\section{UPDATED VALIDATION RESULTS}

\section{A. Radiometer-Based Product (PE)}

This section presents updated validation results for the PE algorithm only. Results for the $\mathrm{P}$ algorithm are essentially the
TABLE V

L2SMPE ALGORITHM PERFORMANCE OVER CVS DOMINATED BY GRASSLANDS $(N=6)$ AND CROPLANDS $(N=6)$ FOR 6 A.M. OVERPASSES

\begin{tabular}{|l|l|l|c|c|c|c|}
\hline L2SMPE & Land & ubRMSD & MD & RMSD & R & Anom. R \\
\hline \multirow{2}{*}{ SCA-H } & Grass & 0.033 & -0.053 & 0.066 & 0.84 & 0.80 \\
\cline { 2 - 7 } & Crops & 0.055 & -0.038 & 0.070 & 0.73 & 0.74 \\
\hline \multirow{2}{*}{ SCA-V } & Grass & 0.030 & -0.015 & 0.038 & 0.85 & 0.81 \\
\cline { 2 - 7 } & Crops & 0.043 & -0.020 & 0.052 & 0.79 & 0.74 \\
\hline \multirow{2}{*}{ DCA } & Grass & 0.031 & -0.010 & 0.037 & 0.86 & 0.82 \\
\cline { 2 - 7 } & Crops & 0.039 & -0.021 & 0.050 & 0.80 & 0.74 \\
\hline
\end{tabular}

same (not shown) because of the very similar resolution of the products [47]. Fig. 2 shows histograms of the validation metrics for the 6 A.M. overpasses computed over the CVS, with the average metric indicated by the vertical blue line. Metrics include the ubRMSD, MD, RMSD, $R$, and anomaly $R$. The numbers in the plots list the average and median metrics, along with lower and upper bounds of the $95 \%$ CI of the average metric (see Appendix $\mathrm{B}$ ). The performance of the SCA-V (current baseline) and DCA algorithms is essentially the same (well within the CI), while the SCA-H algorithm has a significantly larger MD and ubRMSD.

When categorized based on land cover, the grassland dominant sites have markedly better performance metrics compared to agriculture-dominated sites (see Table V). Across all sites, the DCA performed slightly better than SCA-V (0.036 versus 0.038 $\mathrm{m}^{3} / \mathrm{m}^{3}$ ubRMSD). This difference stems from the agricultural sites, where DCA is better at addressing rapid temporal variability in vegetation attenuation characteristics than SCA-V due to the latter's use of a prescribed NDVI-based VWC climatology.

The metrics were also compared to the soil texture and the mean and variance of the VWC at each site. The soil texture was based on the values obtained from in situ samples where available and from the global dataset used for the SM retrieval otherwise. The only parameter pair that resulted in a meaningful correlation was the MD versus soil clay content. Fig. 3 shows the scatterplot for the MD of each algorithm as a function of the clay content at the CVS. SCA-V exhibits the strongest correlation, while DCA has a somewhat weaker correlation; for SCA-H, the correlation is only marginally meaningful ( $P$-value 0.016$)$. The MD has the most uncertainty of the metrics as discussed in Section III-A, but the level of correlation with clay content is compelling, especially for SCA-V. Although the result seems to indicate a systematic bias in the SMAP SM, the effect may be linked to the vertical distribution of water in the top layers of the soil and the difference between the in situ sensor and the SMAP measurements as the clay content impacts the water retention in the soil. It is also possible that the clay content correlates with the upscaling uncertainty contributing to the observed relationship.

Next, Fig. 4 shows histograms of ubRMSD and correlation versus the sparse network measurements for each algorithm, broken down by grasslands and croplands. The SCA-H has somewhat weaker performance than SCA-V and DCA, particularly for croplands, consistent with the CVS results. All algorithms performed significantly worse for croplands compared to grasslands. As discussed in Section III-C, the representativeness errors over sparse network sites are expected to be large, which is reflected also in the level of the ubRMSD and $R$ values, which are generally worse than for CVS. Furthermore, the sparse 


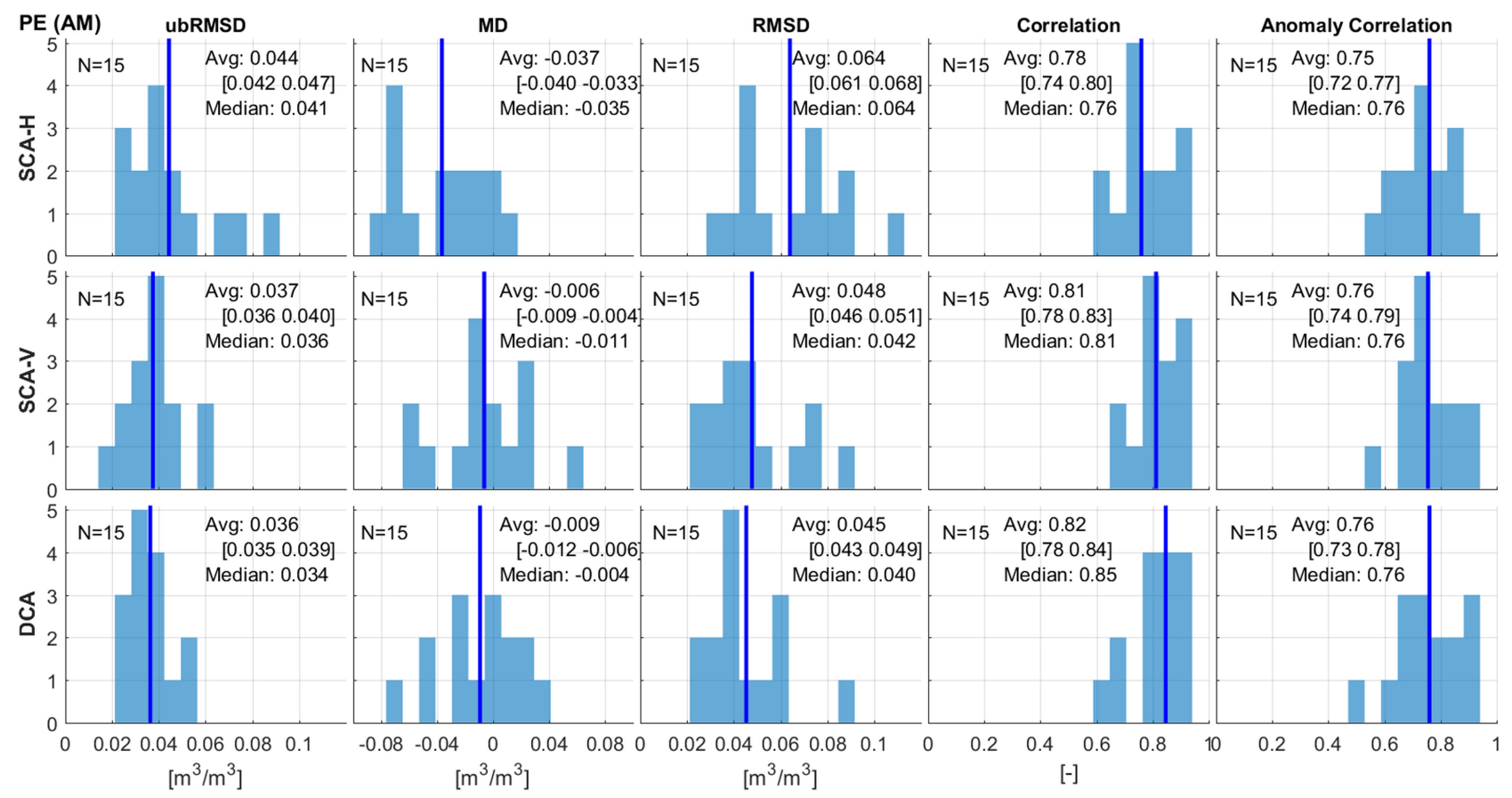

Fig. 2. Histograms of the performance metrics over the CVS (all available data between March 31, 2015 and March 31, 2021) for the L2SMPE SCA-H, SCA-V, and DCA algorithms (version R17000) morning overpasses. The blue line shows average metric values. Text in brackets gives the $95 \%$ CIs of the average metric values. Validation period is from April 2015 to March 2021.

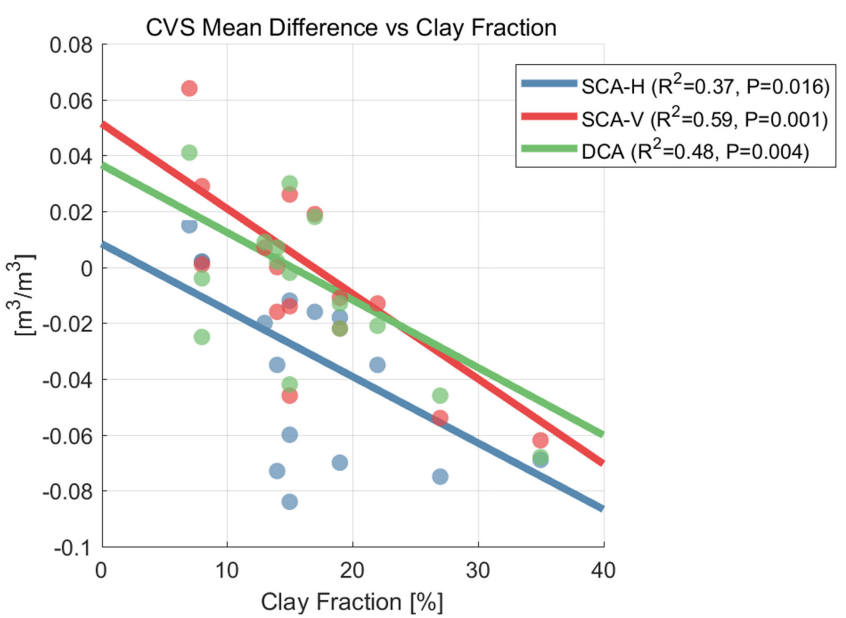

Fig. 3. CVS SM MD versus clay fraction observed at the site for each of the PE algorithms.

networks are particularly susceptible to representativeness errors over croplands, which have relatively higher heterogeneity compared to grasslands. Moreover, the in situ measurements in croplands are typically installed next to the actual fields to avoid interfering with the cultivation activities, which may exacerbate the problem. The metrics of the core site and sparse network comparisons for A.M. and P.M. overpasses are tabulated in Appendix C.

Finally, Fig. 5 shows a comparison of the SMAP L3SMPE SCA-V with the SMOS L3 SM product from their morning overpasses. The quality flags of the products were cross applied before the comparisons. For reference, panels (a) and (b) show

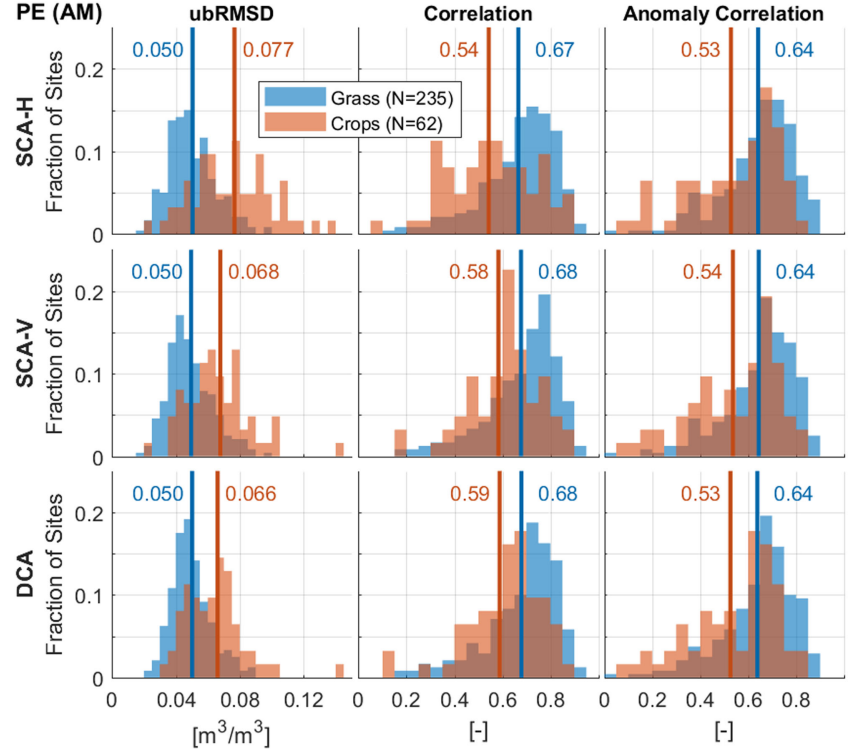

Fig. 4. Histograms of the performance metrics over the sparse network sites for the PE SCA-H, SCA-V, and DCA algorithms. The blue (red) vertical lines indicate average values for grassland (cropland) stations. The numerical values for the average are provided in each panel and the number of stations $(N)$ is provided in the legend. Validation period is from April 2015 to March 2021.

the time series of mean and standard deviation, respectively, for SMAP SM for the nearly six-year period from March 31, 2015 to March 13, 2021. As expected, the mean and variation are small in arid and desert regions, such as the Sahara, the Arabian Peninsula, and Western Australia. Large variations are seen in the Pampas, in the savannas south of the Sahel region, in the 


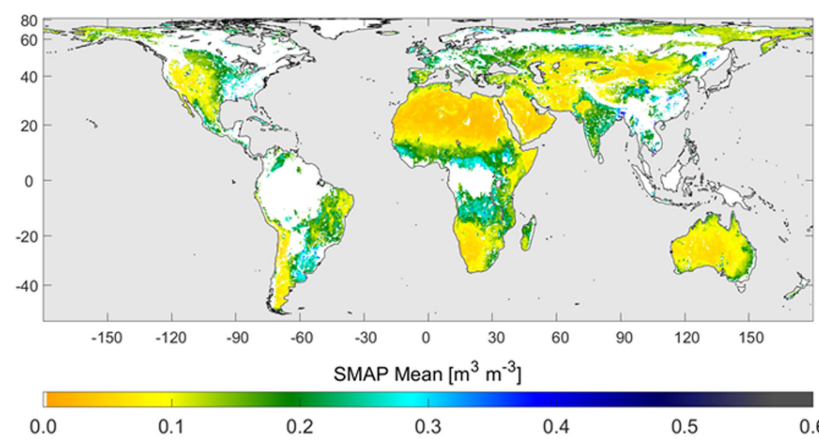

(a)

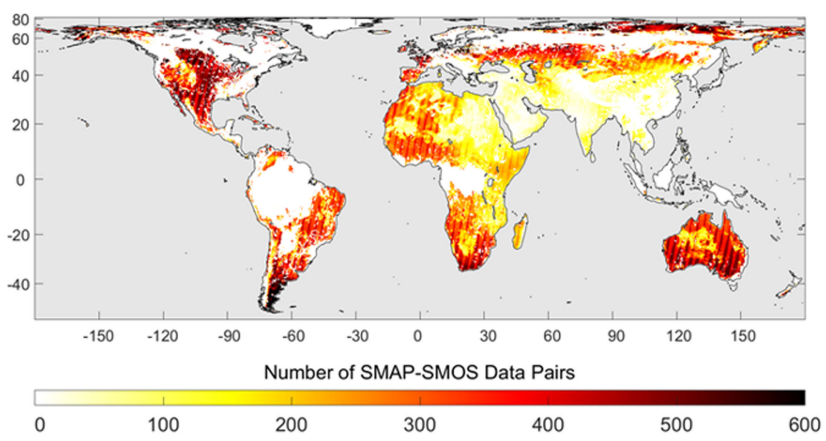

(c)

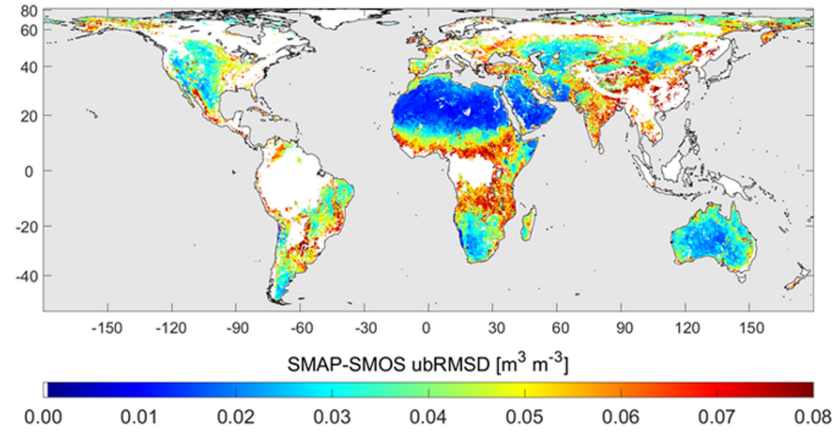

(e)

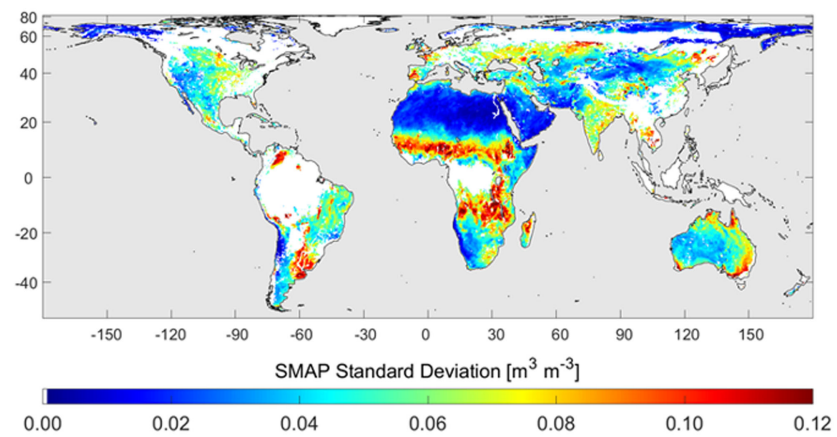

(b)

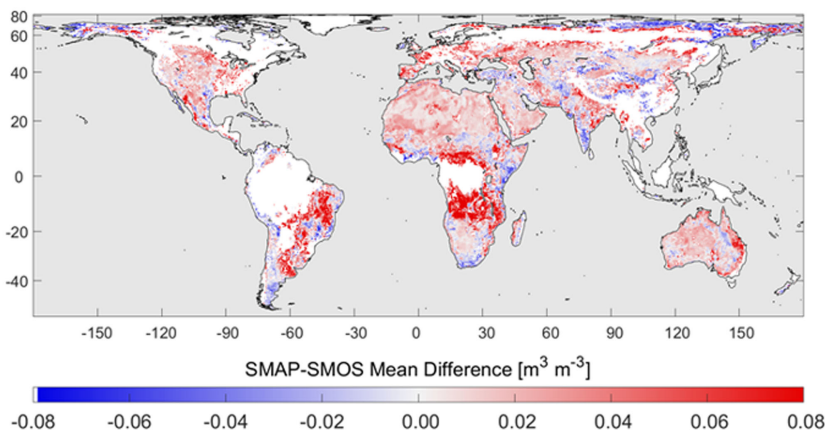

(d)

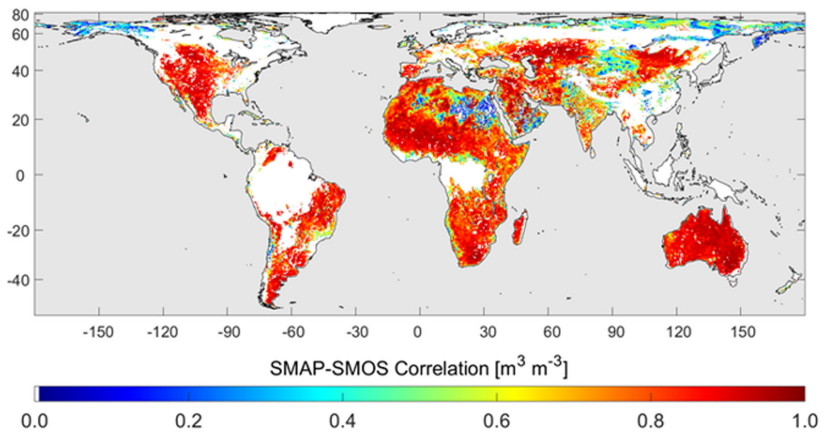

(f)

Fig. 5. Comparison of SMAP SCA-V SM (R17000) and SMOS Level 3 SM (v300) for morning overpasses between March 31, 2015 and March $31,2021$. Time series (a) mean and (b) standard deviation of SMAP SM. (c) Number of SMAP-SMOS data pairs used in the analysis. (d) MD (SMAP minus SMOS) and (e) ubRMSD and (f) Pearson correlation between SMAP and SMOS SM.

savannas south of the Congo rainforest and in eastern Australia. Panel (c) shows the number of valid SMAP-SMOS data pairs used in the comparison, indicating good coverage except in forested regions. Panel (d) shows the MD between the products. SMAP has generally wetter features in the western Sahel, southern Congo rainforest, and eastern India, for example. Panel (e) shows the ubRMSD between SMAP and SMOS. First, regions with low SM variability have naturally low ubRMSD, and regions with high variability are prone to have a high ubRMSD. Therefore, the patterns in SM variability [panel (b)] are, for the most part, repeated in those of the ubRMSD [panel (e)]. However, the savannas south of the Sahel and in eastern Australia exhibit relatively low ubRMSD indicating a particularly good match between the SMAP and SMOS products there. Finally, panel (f) shows the correlation between products. Significant parts of the globe have strong correlations, including regions with relatively low SM variability such as Western Australia.
Owing to the lack of underlying signal, low correlations are expected in areas with extremely low SM variability, such as the Arabian Peninsula and Sahara Desert. There are regions where the differences between the products draw more attention. For example, the Indian subcontinent has relatively large ubRMSD and low correlation, which are not directly explained by high or low variability, respectively, and relatively large and varying MDs. Based on a global TC analysis, Chen et al. [58] suggest that SMAP SM is more reliable than SMOS L3 SM product (v300) in this region.

\section{B. SMAP/Sentinel-1 Combined Product (SP)}

Fig. 6 shows the histograms of the validation metrics over the CVS for the SP product at 9-km and 3-km resolution. Anomaly correlation was not computed because the number of SP retrievals does not allow for a reliable computation of 

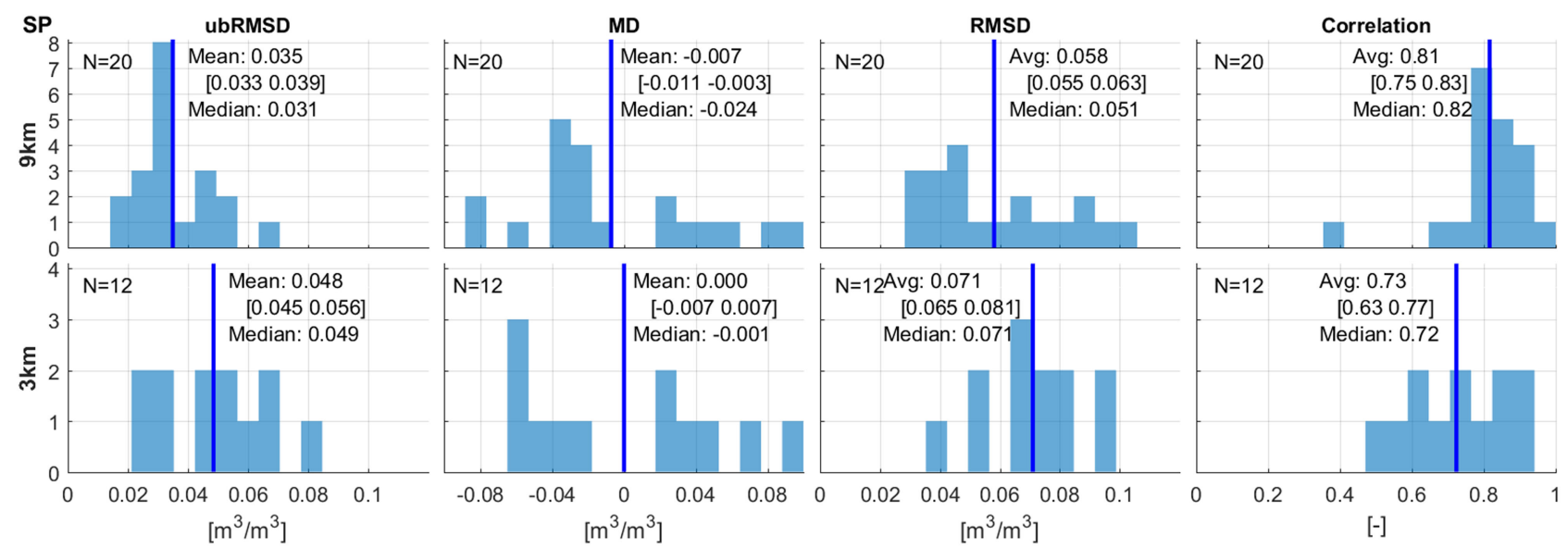

Fig. 6. Histograms of the performance metrics over the CVS (all available data between March 31, 2015 and March 31, 2021) for the L2SMSP at 9-km and 3-km resolution (version R17000). The blue line shows the average of the values. The brackets show the $95 \%$ CIs of the average value. Validation period is from April 2015 to March 2021.

the climatology. The number of sites used is less than shown in Table III. The smaller number of sites reflects the limited coverage by Sentinel-1; SP retrievals are also flagged when the site happens to be systematically on the edge of a Sentinel-1 data granule [48]. The average ubRMSD of $0.035 \mathrm{~m}^{3} / \mathrm{m}^{3}$ at the 9-km scale is below the $0.04 \mathrm{~m}^{3} / \mathrm{m}^{3}$ ubRMSE threshold of the requirement. The difference to the ubRMSD of the PE SCA-V and DCA products is within the statistical CIs. The average MD is reasonable, but with large variation from site to site, which is reflected in the relatively large average RMSD value (compared to that of the SCA-V and DCA algorithms of the PE product). The correlation is in line with the good ubRMSD performance. Considering that the SP algorithm is susceptible to additional uncertainties because of the disaggregation scheme, the performance is overall very satisfactory at $9 \mathrm{~km}$. The narrow distribution of the individual site results around the average value, especially for ubRMSD and correlations, is also a good sign regarding the consistency of the performance.

At the $3-\mathrm{km}$ scale, the overall number of sites is smaller than at the 9-km scale. Additionally, as in the 9-km case, the number of sites used in the comparison is smaller than the values shown in Table III because of the limited Sentinel-1 coverage. However, at $3 \mathrm{~km}$, the site-to-site consistency observed in the 9 -km evaluation breaks down. The reliability of the aggregate results is somewhat questionable, given the large dispersion of the site-specific results around the average values. However, the requirement of only three stations within footprint for the $3-\mathrm{km}$ sites seems particularly small (relative to requirements enforced at 9 and $33 \mathrm{~km}$ ) and may be the primary reason for large spread in the metrics. Naturally, some of the dispersion is due to the retrieval performance; however, the current reliability of 3-km results remains relatively low.

Fig. 7 shows the sparse network metrics for the SP product for grasslands and croplands at the 3-km scale. The number of stations is not the same as in the PE comparison (see Fig. 4) because of the coverage of the SP product, as discussed above. The performance over grasslands is identical to that of the PE product. Over croplands, the correlation is very similar to

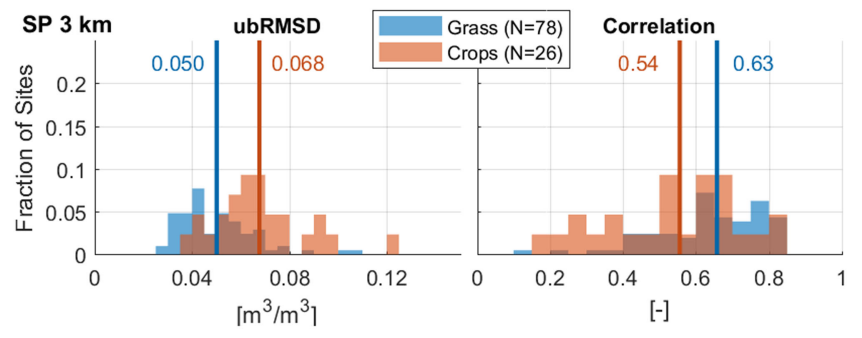

Fig. 7. Histograms of the ubRMSD and correlation over the sparse network sites for the SP product at the 3-km resolution. The blue (red) vertical lines indicate average values for grassland (cropland) stations. The numerical values for the average are provided in each panel and the number of stations $(N)$ is provided in the legend. Validation period is from April 2015 to March 2021.

that of the PE product and the average ubRMSD is somewhat smaller.

Fig. 8 shows the spatial distribution of SM for a $400 \mathrm{~km}$ by 300 $\mathrm{km}$ area in Georgia, USA (a) based on the PE product (b) and the SP product at the 3-km resolution (c) and aggregated up to the 9-km resolution (d). Panel (b) illustrates the true resolution of the PE product $(33 \mathrm{~km})$ as the SM features are spatially smoothed over the 9-km grid. In contrast, the SM features of the 9-km SP product follow distinctly the $9-\mathrm{km}$ grid, and the same is true for the $3-\mathrm{km}$ resolution (d). The observations are consistent with the SP algorithm principle, which relies on the TB observations to provide the information content on the absolute SM level at the coarse scale $(33 \mathrm{~km})$, while the backscatter observations provide the information content on the higher-resolution spatial variations starting from $1 \mathrm{~km}$ (not shown).

In principle, the smaller temporal ubRMSD obtained with the SP product over croplands implies that the $3-\mathrm{km}$ SP product, through its disaggregation technique, compensates for some of the heterogeneity that the PE product cannot resolve. However, in order to evaluate quantitatively this possibility, the skill of the spatial disaggregation would need to be assessed using approaches focused on spatial measures of downscaling performance (as discussed in Section III-F). 

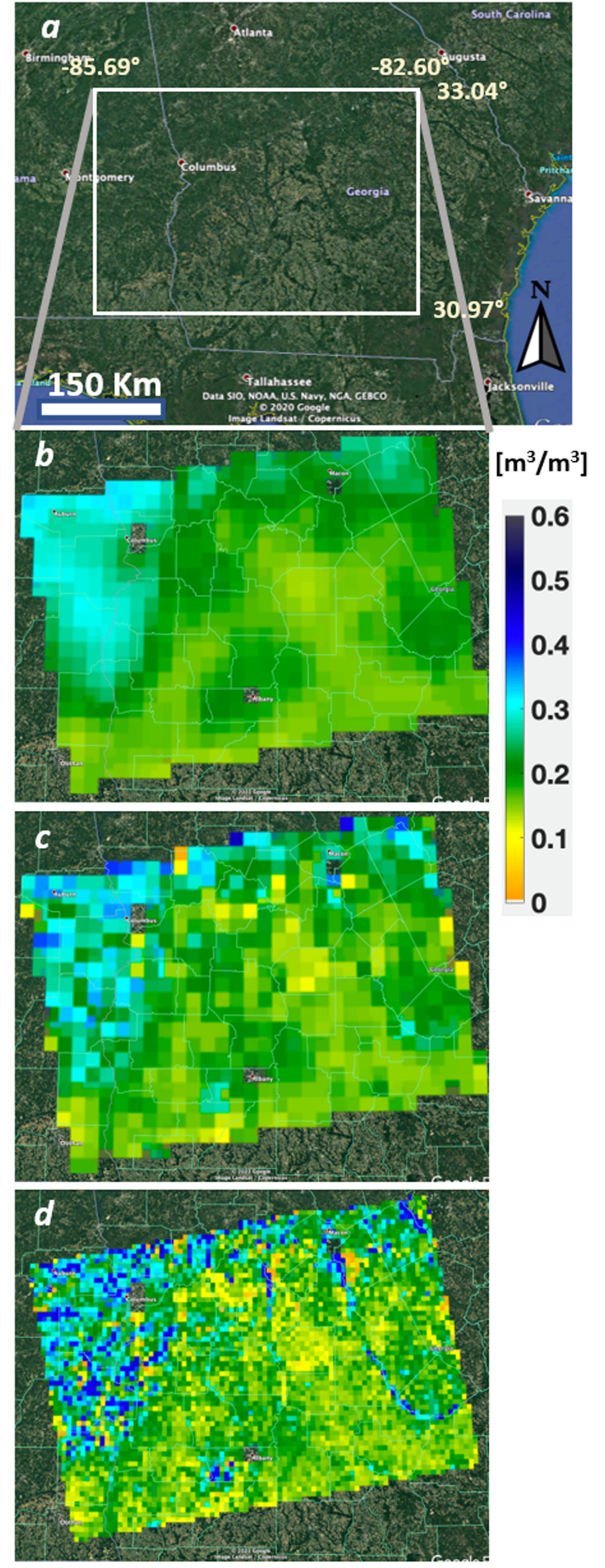

Fig. 8. SMAP SM over a region in Georgia, USA. (a) Map of the area (b) SMAP L2SMPE SM. The grid size is $9 \mathrm{~km}$. (c) SMAP L2SMSP at the 9-km resolution. (d) SMAP L2SMSP at the 3-km resolution.

\section{Assimilation Product (L4)}

Fig. 9 summarizes the performance of L4 surface and rootzone SM product across the CVS for the 9-km reference pixels (see Table III). The ubRMSD values for individual CVS locations are relatively tightly clustered around their average values, which are $0.040 \mathrm{~m}^{3} / \mathrm{m}^{3}$ for surface and $0.027 \mathrm{~m}^{3} / \mathrm{m}^{3}$ for root-zone SM. When factoring in the measurement error of the reference pixel-average in situ observations, where paper [82] conservatively estimates as ubRMSE $\sim 0.01-0.02 \mathrm{~m}^{3} / \mathrm{m}^{3}$, the L4 product clearly meets the accuracy requirement (i.e., average ubRMSE $\leq 0.04 \mathrm{~m}^{3} / \mathrm{m}^{3}$ ) specified prior to the launch of SMAP. The MD values are spread across a much wider range of approximately $\pm 0.1 \mathrm{~m}^{3} / \mathrm{m}^{3}$, with an average MD of $0.023 \mathrm{~m}^{3} / \mathrm{m}^{3}$ for surface and $0.027 \mathrm{~m}^{3} / \mathrm{m}^{3}$ for root-zone SM. The average absolute MD is $0.049 \mathrm{~m}^{3} / \mathrm{m}^{3}$ for surface and $0.047 \mathrm{~m}^{3} / \mathrm{m}^{3}$ for root-zone SM. The relatively large MD values originate in the underlying land surface modeling system that dictates the SM climatology in which the SMAP TB analysis operates. Owing to the large MD values, the RMSDs are noticeably larger than the ubRMSDs and spread across a wider range. The average RMSD is $0.068 \mathrm{~m}^{3} / \mathrm{m}^{3}$ for surface and $0.059 \mathrm{~m}^{3} / \mathrm{m}^{3}$ for root-zone SM. Finally, correlation values exceed 0.6 at most of the sites, with average correlation values of 0.75 for surface and 0.76 for root-zone SM and average anomaly correlation values of 0.71 for surface and 0.80 for root-zone SM. It must be emphasized that the L4 SM validation presented in Fig. 9 is based on 3-h data and $9-\mathrm{km}$ pixels at 18 core sites. When evaluated at the 33-km reference pixels (not shown), the ubRMSD for L4 surface SM drops to $0.037 \mathrm{~m}^{3} / \mathrm{m}^{3}$ and is thus comparable to that of the L2SMPE product (see Fig. 2).

Next, Fig. 10 summarizes the performance of L4 SM across 178 grassland and 94 cropland sparse network stations. Rootzone measurements are not available at all stations, and at one station each for surface and root-zone SM there is no anomaly correlation metric because the number of available measurements was not sufficient to compute the climatology needed for this metric. The average ubRMSD for L4 surface (root-zone) $\mathrm{SM}$ is $\sim 0.056(\sim 0.038) \mathrm{m}^{3} / \mathrm{m}^{3}$, with typical values ranging from 0.03 to $0.09 \mathrm{~m}^{3} / \mathrm{m}^{3}$ for surface SM and from 0.02 to $0.07 \mathrm{~m}^{3} / \mathrm{m}^{3}$ for root-zone SM. The surface SM ubRMSD is slightly higher for cropland than grassland stations, but the difference is much less pronounced than for the L2 product (see Figs. 4 and 7); for L4 root-zone SM, the ubRMSD is nearly identical for grasslands and croplands. As expected, the ubRMSD at the sparse network stations is larger than at the CVS (see Fig. 9) due to enhanced levels of upscaling error associated with characterizing SM at the $9 \mathrm{~km}$ scale using only one or two point-scale sparse network measurements.

Typical values for the L4 correlation and anomaly correlation at the sparse network stations range from 0.5 to 0.9 at a large majority of the stations, with average metrics falling between 0.65 and 0.74 for surface and between 0.59 and 0.70 for root-zone SM (see Fig. 10). Interestingly, the L4 correlation and anomaly correlation skill is better by $\sim 0.04$ on average for cropland than for grassland stations, which is the opposite of the result seen for the L2 product (see Figs. 4 and 7). Most of the sparse network stations are in the continental US, where the L4 algorithm benefits from high-quality land model background estimates owing to the dense network of precipitation gauges available to force the land surface model. Consequently, L4 SM should be less sensitive than the $\mathrm{L} 2$ retrievals to errors incurred in the challenging parameterization of the surface radiative transfer equations over cropland. 


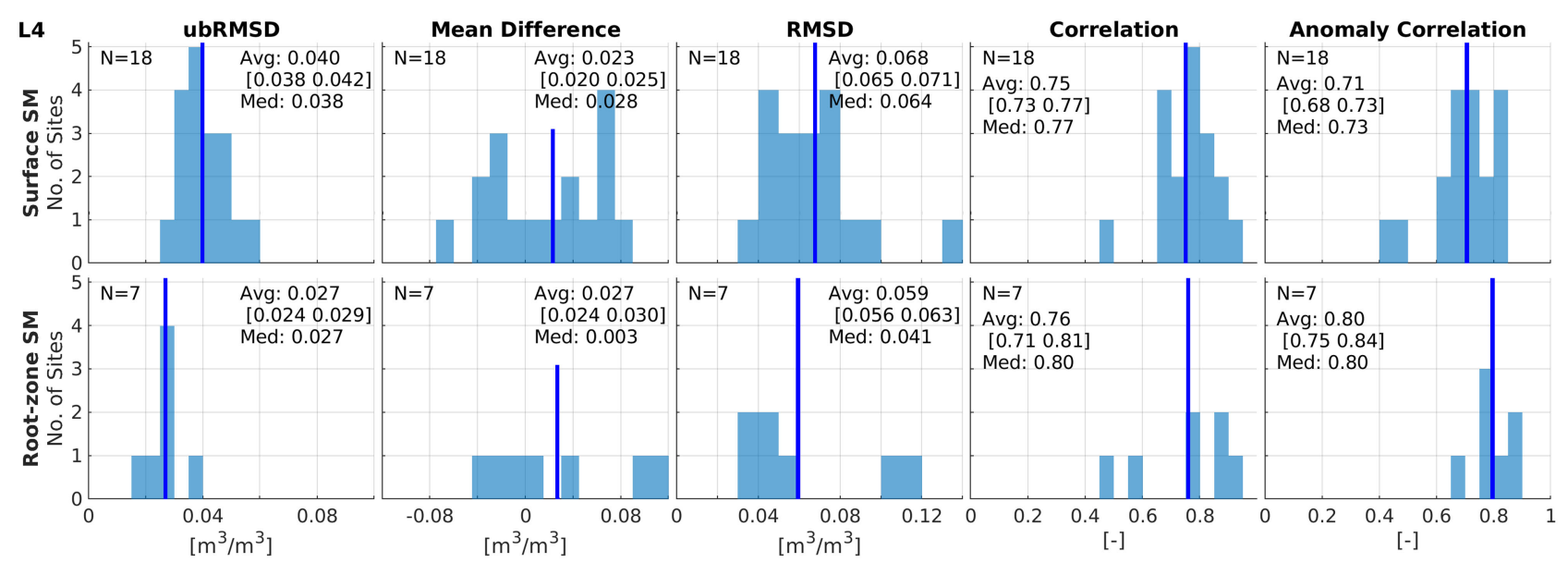

Fig. 9. Histograms of performance metrics over the 9-km reference pixels from $N$ CVS for L4 SM Vv5030 (top) surface and (bottom) root-zone SM. Thin vertical lines indicate average values. Numerical values for average (Avg) and median (Med) are provided in each panel, along with estimates of $95 \%$ statistical CIs for the mean in brackets. Validation period is from April 2015 to March 2021.

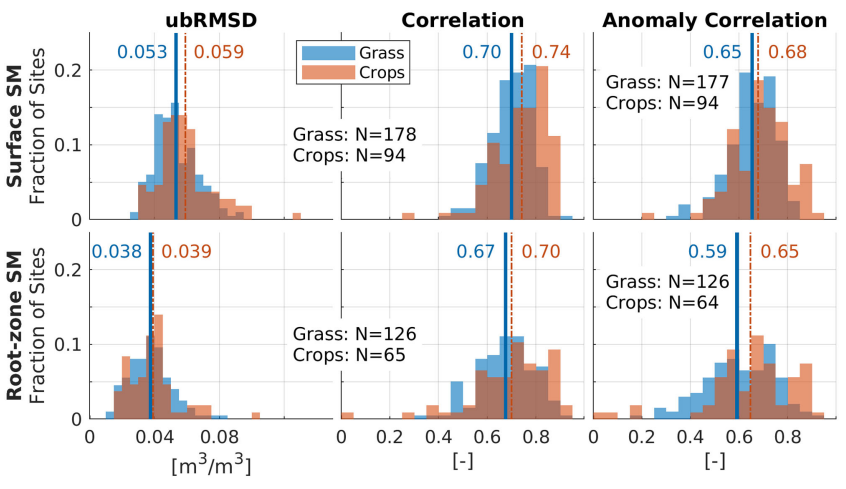

Fig. 10. Histograms of performance metrics over the sparse network sites for L4 SM Vv5030 (top) surface and (bottom) root-zone SM, shown separately for grassland and cropland stations. Thin solid (dashed) vertical lines indicate average values for grassland (cropland) stations. The number of stations $(N)$ and numerical values for the average are provided in each panel. Networks include CRN, SCAN, OK Mesonet, SMOSMANIA, and OzNet (see Table IV). Validation period is from April 2015 to March 2021

Finally, the L4 algorithm's consistency between the assimilated SMAP TB observations and the corresponding TB model forecasts was examined (see Section III-G). Fig. 11(a) shows a global map of the mean O-F TB residuals from the L4 algorithm, with a global average value of only $0.06 \mathrm{~K}$ and an average absolute value of just $0.29 \mathrm{~K}$. The small values primarily reflect the impact of the climatological rescaling of the assimilated SMAP TB observations prior to their assimilation into the land surface model [145]. The L4 algorithm, through this TB rescaling, efficiently assimilates the time series anomaly information contained in the SMAP TB observations while ensuring that the analysis is unbiased. Whereas earlier versions of the L4 algorithm relied on SMOS TB observations to determine the rescaling parameters and resulted in mean absolute $\mathrm{O}-\mathrm{F}$ TB values of $\sim 0.6 \mathrm{~K}$, only SMAP observations are used to compute the rescaling parameters in Version 5. This, together with improvements in the underlying modeling system, considerably improved the algorithm calibration. Fig. 11(b) shows

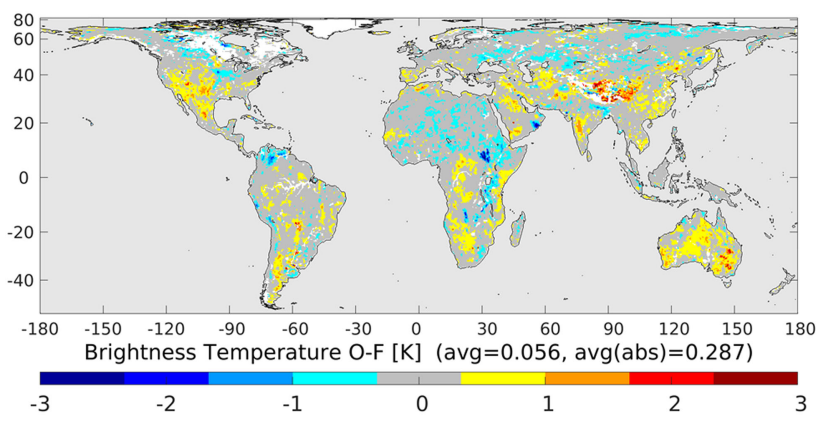

(a)

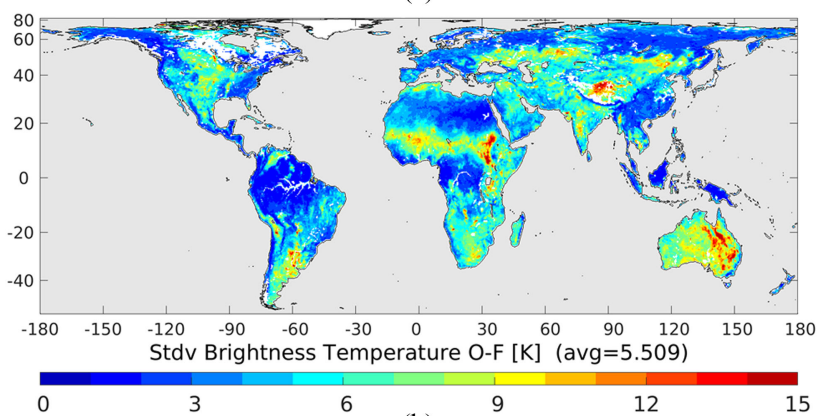

(b)

Fig. 11. (a) Mean and (b) standard deviation of O-F TB residuals from the L4 algorithm (Vv5030) for April 2015 to March 2021. Areas where too few SMAP TB observations are assimilated to compute the O-F TB statistics are shown in white.

the global distribution of the standard deviation of the O-F TB residuals, with values ranging from 2 to $3 \mathrm{~K}$ in very densely and very sparsely vegetated regions up to $10-12 \mathrm{~K}$ in regions with strong SM variability. The typically very large O-F TB residuals in central Australia are a consequence of gross errors in gauge-based precipitation forcing used in the land modeling system. These errors were revealed by the assimilation of SMAP TB observations in the L4 algorithm [145], [59]. The global average O-F TB standard deviation is $5.5 \mathrm{~K}$ in the Version 5 algorithm, which represents a $\sim 0.2 \mathrm{~K}$ reduction from the 
corresponding value in the Version 4 algorithm [51]. This reduction in the typical magnitude of the O-F TB residuals reflects improvements in the underlying land surface modeling system as well as in the calibration stability of the assimilated SMAP TB observations [146].

\section{DISCUSSION}

The CVS analysis illustrates that the performance of the current versions of the SMAP SM products is as expected based on earlier results. The PE product (and, by extension, the $\mathrm{P}$ product) meets the mission requirements by achieving ubRMSD of less than $0.04 \mathrm{~m}^{3} / \mathrm{m}^{3}$ (with both SCA-V and DCA algorithms). The enhancements in the DCA algorithm [50] helped achieve a mean performance of less than $0.04 \mathrm{~m}^{3} / \mathrm{m}^{3}$ ubRMSD also over agricultural areas, although some of the individual sites still exhibit performance not meeting expectations.

The temporal performance of the SP product at $9 \mathrm{~km}$ based on the CVS comparisons is satisfactory. The CVS comparisons at $3 \mathrm{~km}$ suffer from a lack of sites and the low number of sampling points within the $3-\mathrm{km}$ reference pixels (even though meeting the original requirement of three stations). The validation of high-resolution and/or disaggregated SM products will need significantly more resources in the future for completing a full assessment of these products. The availability of sites meeting the original CVS requirements (see Section III-B) at $3 \mathrm{~km}$ (or $1 \mathrm{~km}$ ) is not adequate, and even sites meeting these criteria do not reliably capture the area-average SM. The skill of the spatial downscaling algorithm, as discussed in Section IV-B, is difficult to resolve. Improving the skill requires measurement setups, such as airborne field experiments (e.g., [147], [140]) or particularly dense measurement networks close to each other, which are not commonly available. This is a very significant aspect of the validation of spatially downscaled products that is often overlooked in algorithm assessments.

The performance of L4 surface SM compared well with the PE and SP products over the CVS. Like the SP product, the root-zone product comparisons also suffer from a lack of suitable reference sites, with only seven independent CVS locations currently available.

As discussed in Section III-B, studies have found that to estimate reliably the absolute level of the area-average SM, the number of point measurements required seems to be larger than originally estimated. The SMAP criteria for the number of spatially distributed measurement locations were computed based on the relationship between SM variability in the area and the desired accuracy with a certain level of confidence presented in [67]. The original computation assumed $70 \%$ confidence, and for the $3-\mathrm{km}$ and $9-\mathrm{km}$ scales, a $0.05 \mathrm{~m}^{3} / \mathrm{m}^{3}$ target accuracy with an assumption of a $0.05 \mathrm{~m}^{3} / \mathrm{m}^{3} \mathrm{SM}$ spatial variation within the pixel, which resulted in three and five measurement-location minimums, respectively [54]. With a $90 \%$ confidence, a 0.03 $\mathrm{m}^{3} / \mathrm{m}^{3}$ target accuracy and spatial variation assumptions of 0.06 $\mathrm{m}^{3} / \mathrm{m}^{3}$ and $0.07 \mathrm{~m}^{3} / \mathrm{m}^{3}$ (which are more in line with the literature, e.g., [67]) the corresponding minimum number of locations would be 17 and 23. For the 33-km scale, a $90 \%$ confidence and a $0.08 \mathrm{~m}^{3} / \mathrm{m}^{3} \mathrm{SM}$ variability (instead of the original $0.07 \mathrm{~m}^{3} / \mathrm{m}^{3}$ ) would result in 30 locations (instead of 8 ). These numbers are consistent with the findings of [82] (which also applied $90 \%$ confidence in the computations). This translates into a strong desire to not only see more CVS at different spatial scales but to see them deploy even denser networks at all scales to enable an accurate computation of the bias-sensitive SM metrics. For the bias-insensitive metrics (e.g., $R$ or ubRMSE), the requirements are not as strict; the sampling currently available at the $33-\mathrm{km}$ sites provides a solid reference for computing these metrics [82]. At smaller scales ( $9 \mathrm{~km}, 3 \mathrm{~km}$, and even $1 \mathrm{~km}$ and below), the availability of sites with an adequate sampling, even for resolving the bias-insensitive metrics, is scarcer. Inadequate validation resources will hinder the development of the SM products overall because spatially representative validation references are needed to reveal the true performance of the algorithms; otherwise, the representativeness errors will dominate the comparisons and algorithm improvement will be difficult.

The SMAP SM products have been investigated in several other studies using various dense and sparse networks. Most of the networks are captured in this study, but there are a few additional ones, including the BIEBRZA-S-1 network in Poland [148], the RSMN network in Romania [149], CTP-SMTMN in China [150], and an agricultural area in China [151]. Several studies include complementary analysis approaches and comparisons to other spaceborne SM products over the in situ measurement sites, for example, [36], [152], [25], [148], and [151]. In all these studies, the SMAP performance over the study sites was rated very favorably with respect to the other products. Most of these studies did not include CIs and the differences were small in some cases. In [151], SMAP was the only product to produce reasonable performance over a corn field in China. The study also highlighted the importance of the varying surface roughness in agricultural areas.

Several of these studies also assess the surface temperature used in the SM retrieval algorithm. These comparisons shed light on potential systematic errors arising from the estimation of the effective soil temperature needed for the inversion of the radiative transfer model [153], even though the effective soil temperature (based on GEOS model analysis soil temperature for the SMAP algorithms [49]) generally differs from the physical soil temperature. This aspect is also particularly important for the consistency of the retrievals between the 6 A.M. and 6 P.M. overpasses. Different soil temperatures and the different vertical distribution of temperature in the soil-vegetation continuum can cause systematic differences in the retrievals even though their overall performance metrics are similar.

Capturing SM during or right after precipitation is important for many hydrological applications. Colliander et al. [154] quantified the retrieval degradation over CVS during and right after (high vertical gradient in SM) rain events and showed that the SMAP PE product maintains sensitivity to SM even during rain events and suggests that flagging of rain events may be unnecessary to ensure SM retrieval quality.

The utility of the SMAP SM products has been also revealed through other means than comparisons to reference measurements. For example, Colliander et al. [155] showed 
that the L4 product is consistent with SM condition surveys conducted by USDA National Agriculture Statistics Service volunteers indicating the value of the SMAP observations in the prediction of crop yield by geographical area. Jones et al. [156] showed the value of SMAP SM in clarifying water supply controls affecting ecosystem productivity and land-atmosphere $\mathrm{CO}_{2}$ exchange. Purdy et al. [157] showed that the SMAP SM improves evapotranspiration retrievals for water limited regions. Akbar et al. [158] and Gianotti et al. [159] used an analysis of SMAP SM dynamics to investigate the coupling between SM and energy fluxes. Crow et al. [160] showed the value of the SMAP SM data in improving hydrologic forecasts and Dong et al. [88] showed the SMAP products can achieve a meaningful correlation between SM and near-surface air temperature.

During the first three years of the SMAP mission, the objective was to provide SM products that meet the requirements across the validation domain. Thereafter, the objective was broadened to include areas outside of the original validation domain, including forests. The mission is currently engaged in exploring the improvement and validation of SMAP SM products over forested areas through field experiments [52], [161], an added focus on forested candidate CVS (see Table III) and other networks, such as the National Ecological Observatory Network [53]. Furthermore, the effort to expand the validation domain includes accounting for the complex soil composition of the boreal and arctic regions. One obstacle in addressing the retrieval issues in these areas has been the distortion of the global projection of the EASE v2 grid at high latitudes [162]. One solution is the use of the north polar grid projection, which is currently being implemented by the SMAP mission.

\section{CONCLUSION}

The validation of six years of SMAP SM products demonstrates that they meet the accuracy requirements set for the mission. The DCA algorithm of the radiometer-based enhanced product (PE) exhibits the best performance-although the differences between the DCA and SCA-V are small. All of the algorithms show a relative degradation of the performance over croplands where the retrievals are challenged by rapidly changing vegetation and landscape heterogeneity. DCA is the only algorithm maintaining less than $0.04 \mathrm{~m}^{3} / \mathrm{m}^{3}$ mean ubRMSD for the agriculturally dominated CVS. The PE product is also consistent with the SMOS L3 product across most parts of the globe. The validation of the $3-\mathrm{km} \mathrm{SM}$ product is hindered by the small number of high-quality validation pixels and the limited temporal and spatial coverage of Copernicus Sentinel-1 data. When aggregating the $3-\mathrm{km} \mathrm{SM}$ up to $9-\mathrm{km}$, the evaluation is more robust and the performance is satisfactory. The 9-km L4 product provides surface and root-zone SM, and the performance of both meets the mission accuracy requirement. Notably, L4 SM does not exhibit similar degradation of performance over croplands as the L2 products.

The SMAP validation program has fostered an increased use of in situ resources for SM validation. At the same time, studies have found that the spatial sampling requirements for the CVS may need to be even higher than originally planned for SMAP to accurately measure the area-average absolute SM [82]. Going forward, it would be important for the community to support efforts that aim at providing more accurate reference data at all spatial scales. Counterintuitively, the availability of reference data is more restrictive at smaller scales (1 and $3 \mathrm{~km})$ than at coarser scales. Accurate reference data-designed to capture true SM conditions at a variety of spatial scales - are the only way to ensure continued improvement in the quality of satellitebased SM products.

\section{APPENDIX A}

CEOS has put forward a four-stage validation hierarchy that has been adopted by many data providers (https://lpvs.gsfc.nasa. gov). The validation stage increases with increasing product maturity and extensiveness of the validation effort. It is a useful guide to assess the progress of a validation program.

1) Stage 1 Validation: Product accuracy is assessed from a small (typically < 30) set of locations and time periods by comparison with in situ or other suitable reference data.

2) Stage 2 Validation: Product accuracy is estimated over a significant (typically $>30$ ) set of locations and time periods by comparison with reference in situ or other suitable reference data. Spatial and temporal consistency of the product, and its consistency with similar products, has been evaluated over globally representative locations and time periods. Results are published in the peer-reviewed literature.

3) Stage 3 Validation: Uncertainties in the product and its associated structure are well quantified over a significant (typically $>30$ ) set of locations and time periods representing global conditions by comparison with reference in situ or other suitable reference data. Validation procedures follow community-agreed-upon good practices. Spatial and temporal consistency of the product, and its consistency with similar products, has been evaluated over globally representative locations and time periods. Results are published in the peer-reviewed literature.

4) Stage 4 Validation: Validation results for stage 3 are systematically updated when new product versions are released and as the interannual time series expands. When appropriate for the product, uncertainties in the product are quantified using fiducial reference measurements over a global network of sites and time periods (if available).

\section{APPENDIX B}

This Appendix describes the computation of the performance metrics and the statistical CIs. The performance metrics are computed following [55]. The root-mean-square difference (RMSD) is defined as

$$
\operatorname{RMSD}=\sqrt{\frac{1}{N} \sum_{i=1}^{N}\left(x_{i}-y_{i}\right)^{2}}
$$

where $x_{i}$ is the SMAP SM sample; $y_{i}$ is the in situ SM sample (either CVS or sparse network), and $N$ is the number of samples. 
TABLE VI

CVS Metrics FOR THE L2SMPE PRODUCt CATEGORIZED BASED ON THE LAND COVER FOR THE 6 P.M. OVERPASSES

\begin{tabular}{|c|c|c|c|c|c|c|c|c|c|c|c|c|c|c|c|c|c|c|c|}
\hline \multicolumn{2}{|c|}{ L2SMPE (6 PM) } & \multicolumn{3}{|c|}{ ubRMSD $\left(\mathbf{m}^{3} / \mathbf{m}^{3}\right)$} & \multicolumn{3}{|c|}{$\operatorname{MD}\left(\mathrm{m}^{3} / \mathrm{m}^{3}\right)$} & \multicolumn{3}{|c|}{ RMSD $\left(\mathrm{m}^{3} / \mathrm{m}^{3}\right)$} & \multicolumn{3}{|c|}{$\mathbf{R}(-)$} & \multicolumn{3}{|c|}{ Anom R (-) } & \multicolumn{3}{|c|}{$\mathbf{N}$} \\
\hline Land Cover & Site Name & $\begin{array}{c}\text { SCA- } \\
\mathrm{H}\end{array}$ & $\begin{array}{c}\text { SCA- } \\
\text { V }\end{array}$ & DCA & \begin{tabular}{|c|} 
SCA- \\
$\mathrm{H}$
\end{tabular} & \begin{tabular}{|c|} 
SCA- \\
V
\end{tabular} & DCA & $\begin{array}{c}\text { SCA- } \\
\text { H }\end{array}$ & $\begin{array}{c}\text { SCA- } \\
\text { V- }\end{array}$ & DCA & $\begin{array}{c}\mathrm{SCA}- \\
\mathrm{H}\end{array}$ & $\begin{array}{c}\text { SCA- } \\
\text { V }\end{array}$ & DCA & \begin{tabular}{|c|} 
SCA- \\
H
\end{tabular} & $\begin{array}{c}\text { SCA- } \\
\text { V }\end{array}$ & DCA & $\begin{array}{c}\mathrm{SCA}- \\
\mathrm{H}\end{array}$ & $\begin{array}{c}\text { SCA- } \\
\text { V }\end{array}$ & DCA \\
\hline \multirow{7}{*}{ Grasslands } & Reynolds Creek & 0.047 & 0.044 & 0.046 & -0.074 & -0.027 & $-0.01^{7}$ & 0.087 & 0.051 & 0.049 & 0.55 & 0.63 & 0.6 & 0.57 & 0.61 & 0.55 & 207 & 246 & 240 \\
\hline & TxSON & 0.02 & 0.019 & 0.022 & -0.068 & -0.016 & -0.001 & 0.071 & 0.025 & 0.022 & 0.93 & 0.93 & 0.93 & 0.9 & 0.91 & 0.89 & 900 & 900 & 900 \\
\hline & Fort Cobb & 0.038 & 0.03 & 0.03 & -0.081 & -0.05 & -0.051 & 0.089 & 0.058 & 0.059 & 0.87 & 0.89 & 0.87 & 0.85 & 0.87 & 0.85 & 847 & 856 & 798 \\
\hline & Little Washita & 0.025 & 0.021 & 0.026 & -0.048 & -0.009 & -0.002 & 0.054 & 0.023 & 0.026 & 0.9 & 0.91 & 0.90 & 0.87 & 0.9 & 0.89 & 642 & 642 & 639 \\
\hline & MAHASRI & 0.034 & 0.031 & 0.031 & -0.026 & -0.018 & -0.019 & 0.043 & 0.035 & 0.037 & 0.76 & 0.77 & 0.70 & 0.72 & 0.73 & 0.64 & 353 & 448 & 213 \\
\hline & Yanco & 0.048 & 0.041 & 0.033 & -0.012 & 0.016 & 0.011 & 0.05 & 0.044 & 0.035 & 0.90 & 0.91 & 0.92 & 0.84 & 0.85 & 0.84 & 573 & 575 & 521 \\
\hline & Average & 0.035 & 0.031 & 0.031 & -0.052 & -0.017 & -0.013 & 0.066 & 0.040 & 0.038 & 0.82 & 0.84 & 0.82 & 0.79 & 0.81 & 0.78 & & & \\
\hline \multirow{7}{*}{ Croplands } & South Fork & 0.052 & 0.045 & 0.038 & -0.068 & -0.057 & -0.054 & 0.086 & 0.073 & 0.066 & 0.73 & 0.76 & 0.77 & 0.78 & 0.78 & 0.77 & 357 & 367 & 297 \\
\hline & Kenaston & 0.036 & 0.025 & 0.03 & -0.031 & -0.001 & 0.006 & 0.047 & 0.025 & 0.031 & 0.83 & 0.89 & 0.85 & 0.85 & 0.86 & 0.83 & 366 & 367 & 365 \\
\hline & Carman & 0.085 & 0.066 & 0.052 & -0.072 & -0.065 & -0.072 & 0.111 & 0.093 & 0.089 & 0.50 & 0.53 & 0.57 & 0.57 & 0.58 & 0.62 & 494 & 495 & 488 \\
\hline & Monte Buey & 0.062 & 0.04 & 0.033 & -0.005 & 0.001 & -0.022 & 0.062 & \begin{tabular}{|l|}
0.04 \\
\end{tabular} & 0.04 & 0.83 & 0.88 & 0.8 & 0.8 & 0.86 & 0.83 & 315 & 336 & 338 \\
\hline & REMEDHUS & 0.04 & 0.037 & 0.035 & -0.029 & -0.007 & -0.007 & 0.049 & \begin{tabular}{|l|}
0.038 \\
\end{tabular} & 0.036 & 0.82 & 0.85 & 0.86 & 0.71 & 0.7 & 0.67 & 704 & 860 & 805 \\
\hline & HOBE & 0.043 & 0.035 & 0.042 & 0.01 & 0.008 & 0.000 & 0.044 & 0.036 & 0.042 & 0.72 & 0.85 & 0.84 & 0.74 & 0.66 & 0.62 & 123 & 123 & 123 \\
\hline & $\overline{\text { Average }}$ & 0.053 & 0.042 & 0.038 & -0.032 & -0.02 & -0.025 & 0.067 & 0.051 & 0.050 & 0.74 & 0.79 & 0.78 & 0.74 & 0.74 & 0.72 & & & \\
\hline \multirow{3}{*}{$\begin{array}{l}\text { Crops/ } \\
\text { natural }\end{array}$} & Little River & 0.044 & 0.036 & 0.038 & 0.023 & 0.067 & 0.043 & 0.05 & 0.076 & 0.057 & 0.76 & 0.76 & 0.78 & 0.71 & 0.71 & 0.72 & 642 & 637 & 641 \\
\hline & Twente & 0.072 & 0.059 & 0.054 & 0.019 & \begin{tabular}{|l|}
0.03 \\
\end{tabular} & -0.026 & 0.074 & 0.067 & 0.059 & 0.83 & 0.82 & 0.82 & 0.64 & 0.64 & 0.63 & 562 & 562 & 562 \\
\hline & Average & 0.058 & 0.048 & 0.046 & 0.021 & 0.049 & 0.009 & 0.062 & 0.071 & 0.058 & 0.80 & 0.79 & 0.8 & 0.68 & 0.68 & 0.68 & & & \\
\hline
\end{tabular}

$N$ refers to the number of data points.

TABLE VII

CVS METRICS For THE L2SMPE PRODUCT CATEGORIZED BASED ON THE LAND COVER FOR THE 6 A.M. OVERPASSES

\begin{tabular}{|c|c|c|c|c|c|c|c|c|c|c|c|c|c|c|c|c|c|c|c|}
\hline \multicolumn{2}{|c|}{ L2SMPE (6 AM) } & \multicolumn{3}{|c|}{ ubRMSD $\left(\mathbf{m}^{3} / \mathbf{m}^{3}\right)$} & \multicolumn{3}{|c|}{$\mathrm{MD}\left(\mathrm{m}^{3} / \mathrm{m}^{3}\right)$} & \multicolumn{3}{|c|}{$\operatorname{RMSD}\left(\mathrm{m}^{3} / \mathrm{m}^{3}\right)$} & \multicolumn{3}{|c|}{$\mathbf{R}(-)$} & \multicolumn{3}{|c|}{ Anom R (-) } & \multicolumn{3}{|c|}{$\mathbf{N}$} \\
\hline Land Cover & Site Name & $\begin{array}{c}\text { SCA- } \\
\text { H }\end{array}$ & \begin{tabular}{|c|} 
SCA- \\
V
\end{tabular} & DCA & \begin{tabular}{|c|} 
SCA- \\
H
\end{tabular} & \begin{tabular}{|c|} 
SCA- \\
V
\end{tabular} & DCA & \begin{tabular}{|c|} 
SCA- \\
H
\end{tabular} & $\begin{array}{c}\text { SCA- } \\
\text { V }\end{array}$ & DCA & $\begin{array}{c}\text { SCA- } \\
\text { H }\end{array}$ & \begin{tabular}{|c|} 
SCA- \\
V
\end{tabular} & DCA & \begin{tabular}{|c|} 
SCA- \\
H
\end{tabular} & \begin{tabular}{|c|} 
SCA- \\
V
\end{tabular} & DCA & \begin{tabular}{|c|} 
SCA- \\
H
\end{tabular} & $\begin{array}{c}\text { SCA- } \\
\text { V }\end{array}$ & DCA \\
\hline \multirow{7}{*}{ Grasslands } & Reynolds Creek & 0.041 & 0.041 & 0.044 & -0.07 & \begin{tabular}{|c|}
-0.022 \\
\end{tabular} & -0.013 & 0.081 & 0.046 & 0.046 & 0.64 & 0.67 & 0.63 & 0.58 & 0.58 & 0.51 & 150 & 174 & 171 \\
\hline & TxSON & 0.022 & 0.022 & 0.025 & -0.074 & -0.017 & 0.001 & 0.077 & 0.028 & 0.025 & 0.92 & 0.93 & 0.92 & 0.91 & 0.91 & 0.90 & 828 & 828 & 828 \\
\hline & Fort Cobb & 0.033 & 0.029 & 0.032 & -0.084 & -0.046 & -0.042 & \begin{tabular}{|l|}
0.09 \\
\end{tabular} & 0.054 & 0.053 & 0.88 & 0.89 & 0.89 & 0.86 & 0.87 & 0.88 & 767 & 769 & 753 \\
\hline & Little Washita & 0.022 & 0.021 & 0.027 & -0.060 & -0.014 & -0.002 & 0.064 & 0.025 & 0.027 & 0.90 & 0.92 & 0.91 & 0.87 & 0.90 & 0.91 & 613 & 613 & 613 \\
\hline & MAHASRI & 0.035 & 0.033 & 0.025 & -0.018 & -0.011 & -0.022 & 0.039 & 0.035 & 0.034 & 0.78 & 0.80 & 0.88 & 0.72 & 0.76 & 0.85 & 295 & 287 & 117 \\
\hline & Yanco & 0.042 & 0.038 & 0.034 & -0.016 & 0.019 & 0.018 & 0.045 & 0.042 & 0.039 & 0.90 & 0.90 & 0.92 & 0.85 & 0.86 & 0.89 & 543 & 542 & 532 \\
\hline & Average & 0.033 & 0.030 & 0.031 & -0.053 & -0.015 & -0.010 & 0.066 & 0.038 & 0.037 & 0.84 & 0.85 & 0.86 & 0.80 & 0.81 & 0.82 & & & \\
\hline \multirow{7}{*}{ Croplands } & South Fork & 0.052 & 0.046 & 0.040 & -0.075 & -0.054 & -0.046 & 0.091 & 0.071 & 0.062 & 0.70 & 0.74 & 0.77 & 0.76 & 0.76 & 0.76 & 351 & 358 & 324 \\
\hline & Kenaston & 0.041 & 0.030 & 0.031 & -0.035 & 0.00 & 0.007 & 0.053 & 0.030 & 0.031 & 0.72 & 0.78 & 0.79 & 0.79 & 0.8 & 0.78 & 265 & 266 & 266 \\
\hline & Carman & 0.085 & 0.062 & 0.051 & -0.069 & -0.062 & -0.069 & 0.109 & 0.088 & 0.085 & \begin{tabular}{|l|}
0.61 \\
\end{tabular} & 0.67 & 0.70 & 0.64 & 0.67 & 0.72 & 421 & 427 & 429 \\
\hline & Monte Buey & 0.067 & 0.045 & 0.033 & -0.035 & -0.013 & -0.021 & 0.075 & 0.047 & 0.040 & 0.76 & 0.85 & 0.85 & 0.76 & 0.82 & 0.82 & 332 & 350 & 359 \\
\hline & REMEDHUS & 0.039 & 0.038 & 0.038 & -0.020 & 0.007 & 0.010 & 0.044 & 0.039 & 0.039 & 0.83 & 0.85 & 0.85 & 0.69 & 0.69 & 0.68 & 678 & 730 & 690 \\
\hline & HOBE & 0.045 & \begin{tabular}{|l|}
0.036 \\
\end{tabular} & 0.042 & 0.002 & 0.001 & -0.004 & 0.045 & 0.036 & 0.042 & 0.75 & 0.86 & 0.85 & 0.77 & 0.74 & 0.69 & 124 & 124 & 124 \\
\hline & Average & 0.055 & 0.043 & 0.039 & -0.038 & -0.020 & 0.021 & 0.070 & 0.052 & 0.050 & 0.73 & 0.79 & 0.80 & 0.74 & 0.74 & 0.74 & & & \\
\hline \multirow{3}{*}{$\begin{array}{l}\text { Crops/ } \\
\text { natural }\end{array}$} & Little River & 0.045 & 0.036 & 0.040 & 0.014 & 0.064 & 0.040 & 0.047 & 0.074 & 0.057 & 0.73 & 0.77 & 0.78 & 0.68 & 0.71 & 0.74 & 721 & 718 & 722 \\
\hline & $\begin{array}{l}\text { Twente } \\
\end{array}$ & 0.071 & 0.060 & 0.054 & 0.002 & 0.029 & -0.025 & 0.071 & 0.066 & 0.060 & 0.81 & 0.81 & 0.82 & 0.64 & 0.66 & 0.67 & 449 & 449 & 448 \\
\hline & Average & 0.058 & 0.048 & 0.047 & 0.008 & 0.046 & 0.008 & 0.059 & 0.070 & 0.058 & 0.77 & 0.79 & 0.80 & 0.66 & 0.68 & 0.71 & & & \\
\hline
\end{tabular}

\begin{tabular}{|l|l|l|l|l|l|l|l|l|l|l|l|l|l|l|l|l|l|l|l|}
\hline Shrub open & Walnut Gulch & 0.025 & 0.026 & 0.028 & -0.014 & 0.024 & 0.029 & 0.029 & 0.036 & 0.040 & 0.76 & 0.77 & 0.69 & 0.74 & 0.75 & 0.64 & 315 & 335 & 301 \\
\hline
\end{tabular}

$N$ refers to the number of data points.

The mean difference (MD) is defined as

$$
\mathrm{MD}=\frac{1}{N} \sum_{i=1}^{N} x_{i}-y_{i} .
$$

The unbiased RMSD is defined as

$$
\operatorname{ubRMSD}=\sqrt{\mathrm{RMSD}^{2}-\mathrm{MD}^{2}}
$$

The Pearson correlation $(R)$ is defined as

$$
R=\frac{\sum_{i=1}^{N}\left(x_{i}-\bar{x}\right)\left(y_{i}-\bar{y}\right)}{\sqrt{\sum_{i=1}^{N}\left(x_{i}-\bar{x}\right)^{2} \sum_{i=1}^{N}\left(y_{i}-\bar{y}\right)^{2}}}
$$

where the overbar denotes average. Anomaly $R$ is computed using the same equation, but the climatology of $x$ and $y$ is removed from them before applying the equation.
The confidence intervals (CIs) of the aforementioned metrics are calculated following [34]. The CI of the MD for one measurement location is defined as

$$
\mathrm{CI}_{\mathrm{MD}}=\left[\mathrm{MD}+t_{N-1}^{\alpha / 2} \frac{\mathrm{ubRMSD}}{\sqrt{N}}, \mathrm{MD}+t_{N-1}^{1-\alpha / 2} \frac{\mathrm{ubRMSD}}{\sqrt{N}}\right]
$$

where $t_{N-1}^{\alpha / 2}$ is the value at $\alpha / 2$ for the $t$-distribution with $N-1$ degrees of freedom. The CI of the ubRMSD for one measurement location is defined as

$$
\mathrm{CI}_{\mathrm{ubRMSD}}=\left[\mathrm{ubRMSD} \frac{\sqrt{N-1}}{\chi_{N-1}^{1-\alpha / 2}}, \operatorname{ubRMSD} \frac{\sqrt{N-1}}{\chi_{N-1}^{\alpha / 2}}\right]
$$

where $\chi_{N-1}^{1-\alpha / 2}$ is the value at $1-\alpha / 2$ for the $\chi$-distribution with $\mathrm{N}-1$ degrees of freedom. The CI of RMSD for one measurement location is defined as

$$
\mathrm{CI}_{\mathrm{RMSD}}=\left[\sqrt{\mathrm{CI}_{\mathrm{MD}}^{2}(1)+\mathrm{CI}_{\mathrm{ubRMSD}}^{2}(1)},\right.
$$


TABLE VIII

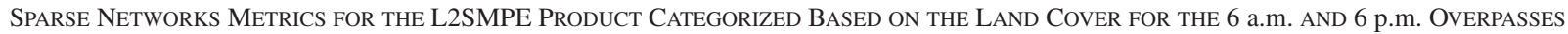

\begin{tabular}{|c|c|c|c|c|c|c|c|c|c|c|c|}
\hline \multirow{2}{*}{ Land Cover } & \multirow{2}{*}{$\begin{array}{c}\text { Over- } \\
\text { pass }\end{array}$} & \multicolumn{3}{|c|}{$\operatorname{ubRMSD}\left(\mathrm{m}^{3} / \mathbf{m}^{3}\right)$} & \multicolumn{3}{|c|}{$\mathbf{R}(-)$} & \multicolumn{3}{|c|}{ Anom R (-) } & \multirow{2}{*}{$\mathbf{N}$} \\
\hline & & SCA-H & SCA-V & DCA & SCA-H & SCA-V & DCA & $\overline{\text { SCA-H }}$ & SCA-V & DCA & \\
\hline \multirow{2}{*}{ Grasslands } & $\mathbf{A M}$ & 0.051 & 0.050 & 0.051 & 0.65 & 0.66 & 0.67 & 0.63 & 0.63 & 0.62 & 255 \\
\hline & PM & 0.050 & 0.049 & 0.050 & 0.65 & 0.65 & 0.65 & 0.61 & 0.60 & 0.59 & 256 \\
\hline \multirow{2}{*}{ Croplands } & $\mathbf{A M}$ & 0.077 & 0.068 & 0.067 & 0.53 & 0.58 & 0.58 & 0.52 & 0.53 & 0.52 & 74 \\
\hline & PM & 0.076 & 0.066 & 0.064 & 0.55 & 0.59 & 0.60 & 0.52 & 0.53 & 0.52 & 73 \\
\hline \multirow{2}{*}{$\begin{array}{l}\text { Crop/Natural } \\
\text { vegetation mosaic }\end{array}$} & $\mathbf{A M}$ & 0.071 & 0.063 & 0.063 & 0.61 & 0.67 & 0.68 & 0.53 & 0.62 & 0.63 & 25 \\
\hline & PM & 0.070 & 0.062 & 0.061 & 0.62 & 0.67 & 0.68 & 0.53 & 0.60 & 0.61 & 25 \\
\hline \multirow{2}{*}{ Open shrublands } & $\mathbf{A M}$ & 0.042 & 0.041 & 0.042 & 0.52 & 0.54 & 0.54 & 0.51 & 0.52 & 0.52 & 44 \\
\hline & PM & 0.042 & 0.042 & 0.043 & 0.47 & 0.47 & 0.47 & 0.45 & 0.44 & 0.44 & 44 \\
\hline \multirow{2}{*}{ Savannas } & $\mathbf{A M}$ & 0.038 & 0.037 & 0.038 & 0.83 & 0.82 & 0.83 & 0.71 & 0.73 & 0.74 & 3 \\
\hline & PM & 0.040 & 0.038 & 0.039 & 0.83 & 0.82 & 0.82 & 0.71 & 0.72 & 0.73 & 3 \\
\hline \multirow{2}{*}{ Woody savannas } & $\mathbf{A M}$ & 0.060 & 0.057 & 0.057 & 0.70 & 0.72 & 0.73 & 0.62 & 0.66 & 0.67 & 27 \\
\hline & PM & 0.059 & 0.056 & 0.055 & 0.70 & 0.71 & 0.72 & 0.62 & 0.64 & 0.64 & 27 \\
\hline \multirow[b]{2}{*}{ Barren/Sparse } & $\mathbf{A M}$ & 0.022 & 0.022 & 0.023 & 0.54 & 0.53 & 0.54 & 0.54 & 0.52 & 0.53 & 8 \\
\hline & PM & 0.022 & 0.023 & 0.024 & 0.47 & 0.45 & 0.45 & 0.48 & 0.45 & 0.46 & 8 \\
\hline \multirow{2}{*}{$\begin{array}{l}\text { Evergreen } \\
\text { needleleaf forest }\end{array}$} & $\mathbf{A M}$ & 0.042 & 0.040 & 0.039 & 0.70 & 0.71 & 0.71 & 0.64 & 0.65 & 0.66 & 4 \\
\hline & $\mathbf{P M}$ & 0.039 & 0.038 & 0.039 & 0.72 & 0.71 & 0.72 & 0.63 & 0.62 & 0.63 & 4 \\
\hline \multirow{2}{*}{ Mixed forest } & $\mathbf{A M}$ & 0.071 & 0.049 & 0.044 & 0.33 & 0.57 & 0.67 & 0.15 & 0.47 & 0.61 & 1 \\
\hline & PM & 0.073 & 0.047 & 0.041 & 0.33 & 0.58 & 0.67 & 0.25 & 0.56 & 0.67 & 1 \\
\hline
\end{tabular}

$N$ refers to the number of stations.

TABLE IX

CVS METRICS FOR THE L2SMSP PRODUCT AT THE 9-KM SCALE CATEGORIZED BASED ON THE LAND COVER

\begin{tabular}{|c|c|c|c|c|c|c|c|}
\hline \begin{tabular}{|l|} 
Land \\
Cover
\end{tabular} & Site Name & Pix & $\begin{array}{c}\text { ub } \\
\text { RMSD } \\
\left(\mathbf{m}^{3} / \mathbf{m}^{3}\right)\end{array}$ & $\underset{\left(\mathbf{m}^{3} / \mathbf{m}^{3}\right)}{\text { MD }}$ & $\begin{array}{l}\text { RMSD } \\
\left(\mathbf{m}^{3} / \mathbf{m}^{3}\right)\end{array}$ & $\begin{array}{l}\mathbf{R} \\
(-)\end{array}$ & $\mathbf{N}$ \\
\hline \multirow{9}{*}{ Grasslands } & Walnut Gulch & 6 & 0.023 & 0.028 & 0.037 & 0.88 & 42 \\
\hline & TxSON & 2 & 0.017 & -0.031 & 0.036 & 0.9 & 14 \\
\hline & TxSON & 11 & 0.02 & -0.024 & 0.031 & 0.91 & 64 \\
\hline & Fort Cobb & 11 & 0.03 & -0.019 & 0.035 & 0.85 & 66 \\
\hline & Little Washita & 25 & 0.033 & -0.028 & 0.043 & 0.84 & 155 \\
\hline & Niger & 2 & 0.031 & 0.026 & 0.041 & 0.87 & 63 \\
\hline & Yanco & 2 & 0.055 & -0.011 & 0.056 & 0.88 & 58 \\
\hline & Yanco & 16 & 0.05 & 0.041 & 0.065 & 0.8 & 83 \\
\hline & Average & & 0.032 & -0.002 & 0.043 & 0.87 & \\
\hline \multirow{10}{*}{ Croplands } & South Fork & 10 & 0.045 & -0.06 & 0.075 & 0.79 & 57 \\
\hline & St Josephs & 7 & 0.03 & -0.034 & 0.046 & 0.68 & 31 \\
\hline & Kenaston & 10 & 0.032 & -0.082 & 0.088 & 0.79 & 44 \\
\hline & Kenaston & 11 & 0.036 & -0.08 & 0.087 & 0.76 & 35 \\
\hline & \begin{tabular}{|l|} 
Carman \\
\end{tabular} & 6 & 0.07 & -0.037 & 0.079 & 0.4 & 46 \\
\hline & Monte Buey & 11 & 0.023 & -0.039 & 0.045 & 0.93 & 19 \\
\hline & REMEDHUS & 3 & 0.047 & 0.087 & 0.099 & 0.79 & 118 \\
\hline & REMEDHUS & 8 & 0.043 & -0.039 & 0.059 & 0.77 & 329 \\
\hline & Valencia & 6 & 0.023 & -0.023 & 0.033 & 0.77 & 15 \\
\hline & Average & & 0.039 & -0.034 & 0.068 & 0.74 & \\
\hline $\begin{array}{l}\text { Crops/ } \\
\text { natural }\end{array}$ & Little River & 21 & 0.03 & 0.09 & 0.095 & 0.84 & 32 \\
\hline \begin{tabular}{|l|} 
Shrub \\
open
\end{tabular} & Walnut Gulch & 7 & 0.031 & 0.06 & 0.068 & 0.79 & 109 \\
\hline
\end{tabular}

Pix refers to the pixel ID within the site. $N$ refers to the number of data points.

$$
\left.\sqrt{\mathrm{CI}_{\mathrm{MD}}^{2}(2)+\mathrm{CI}_{\mathrm{ubRMSD}}^{2}(2)}\right]
$$

The CI of $R$ for one measurement location is defined as

$$
\mathrm{CI}_{R}=\left[\frac{e^{2 z_{L}}-1}{e^{2 z_{L}}+1}, \frac{e^{2 z_{U}}-1}{e^{2 z_{U}}+1}\right]
$$

where

$$
z_{L / U}=z_{r}-/+\frac{F^{-1}(\alpha / 2)}{\sqrt{N_{e f f}-3}}
$$

TABLE X

\begin{tabular}{|c|c|c|c|c|c|c|c|}
\hline $\begin{array}{l}\text { Land } \\
\text { Cover }\end{array}$ & Site Name & Pix & \begin{tabular}{|c|} 
ub \\
RMSD \\
$\left(\mathbf{m}^{3} / \mathbf{m}^{3}\right)$ \\
\end{tabular} & $\begin{array}{c}\text { MD } \\
\left(\mathrm{m}^{3} / \mathbf{m}^{3}\right)\end{array}$ & $\begin{array}{l}\text { RMSD } \\
\left(\mathrm{m}^{3} / \mathrm{m}^{3}\right)\end{array}$ & $\begin{array}{l}\mathbf{R} \\
(-)\end{array}$ & $\mathbf{N}$ \\
\hline \multirow{6}{*}{ Grasslands } & TxSON & 1 & 0.031 & 0.060 & 0.068 & 0.79 & 109 \\
\hline & TxSON & 2 & 0.017 & -0.031 & 0.036 & 0.90 & 14 \\
\hline & Yanco & 2 & 0.030 & 0.090 & 0.095 & 0.84 & 32 \\
\hline & Yanco & 3 & 0.032 & -0.082 & 0.088 & 0.79 & 44 \\
\hline & Yanco & 4 & 0.036 & -0.080 & 0.087 & 0.76 & 35 \\
\hline & \begin{tabular}{|l|} 
Average \\
\end{tabular} & & 0.039 & -0.034 & 0.068 & 0.74 & \\
\hline \multirow{6}{*}{ Croplands } & Kenaston & 1 & 0.020 & -0.024 & 0.031 & 0.91 & 64 \\
\hline & Kenaston & 2 & 0.03 & -0.019 & 0.035 & 0.85 & 66 \\
\hline & Monte Buey & 1 & 0.033 & -0.028 & 0.043 & 0.84 & 155 \\
\hline & Valencia & 1 & 0.045 & -0.06 & 0.075 & 0.79 & 57 \\
\hline & Yanco & 1 & 0.030 & -0.034 & 0.046 & 0.68 & 31 \\
\hline & Average & & 0.030 & 0.090 & 0.095 & 0.84 & \\
\hline $\begin{array}{l}\text { Shrub } \\
\text { open }\end{array}$ & Walnut Gulch & 5 & 0.023 & 0.028 & 0.037 & 0.88 & 42 \\
\hline
\end{tabular}

CVS METRICS FOR THE L2SMSP PRODUCT AT THE 3-KM SCALE CATEGORIZED BASED ON THE LAND COVER

Pix refers to the pixel ID within the site. $N$ refers to the number of data points.

TABLE XI

SPARSE NETWORK COMPARISON RESULTS FOR THE L2SMSP PRODUCT AT THE 3-KM SCALE CATEGORIZED BASED ON THE LAND COVER

\begin{tabular}{|l|c|c|c|}
\hline Land Cover & $\begin{array}{c}\text { ubRMSD } \\
\left(\mathbf{m}^{\mathbf{3}} / \mathbf{m}^{\mathbf{3}}\right)\end{array}$ & $\begin{array}{c}\mathbf{R} \\
\mathbf{( - )}\end{array}$ & $\mathbf{N}$ \\
\hline Grasslands & 0.050 & 0.63 & 78 \\
\hline Croplands & 0.068 & 0.54 & 26 \\
\hline Crops/natural & 0.077 & 0.25 & 3 \\
\hline Shrubs open & 0.042 & 0.57 & 32 \\
\hline Savannas & 0.036 & 0.47 & 2 \\
\hline Woody Savanna & 0.069 & 0.38 & 1 \\
\hline Barren/Sparse & 0.017 & 0.72 & 2 \\
\hline
\end{tabular}

$N$ refers to the number of stations.

in which $F^{-1}$ is the normal inverse function with mean 0 and standard deviation 1 , and

$$
z_{r}=\frac{1}{2} \ln \left(\frac{1+R}{1-R}\right) .
$$


TABLE XII

CVS Metrics For L4 Surface (SF) AND Root-Zone (RZ) SM AT THE 9-KM SCALE CATEGoRized BASEd on LAND Cover

\begin{tabular}{|c|c|c|c|c|c|c|c|c|c|c|c|c|c|c|c|}
\hline \multicolumn{2}{|c|}{ L4 (9-km, 3-hourly) } & \multicolumn{2}{|c|}{$\begin{array}{c}\text { ubRMSD } \\
\text { (m3/m3) }\end{array}$} & \multicolumn{2}{|c|}{$\begin{array}{c}\text { MD } \\
(\mathrm{m} 3 / \mathrm{m} 3)\end{array}$} & \multicolumn{2}{|c|}{$\begin{array}{c}\text { RMSD } \\
(\mathrm{m} 3 / \mathrm{m} 3)\end{array}$} & \multicolumn{2}{|c|}{$\begin{array}{l}R \\
(-)\end{array}$} & \multicolumn{2}{|c|}{$\begin{array}{c}\text { Anomaly R } \\
(-)\end{array}$} & \multicolumn{2}{|c|}{$\begin{array}{l}\text { No. of 9-km } \\
\text { ref. pixels }\end{array}$} & \multicolumn{2}{|c|}{$\begin{array}{l}\text { Avg. no. of 3-hr } \\
\text { data per ref. pix. }\end{array}$} \\
\hline Land Cover & Site Name & SF & $\mathbf{R Z}$ & SF & $\mathbf{R Z}$ & SF & $\mathbf{R Z}$ & SF & $\mathbf{R Z}$ & SF & $\mathbf{R Z}$ & SF & $\mathbf{R Z}$ & SF & $\mathbf{R Z}$ \\
\hline \multirow[t]{7}{*}{ Grasslands } & Reynolds Creek & 0.044 & $\mathrm{n} / \mathrm{a}$ & -0.022 & $\mathrm{n} / \mathrm{a}$ & 0.049 & $\mathrm{n} / \mathrm{a}$ & 0.70 & $\mathrm{n} / \mathrm{a}$ & 0.69 & $\mathrm{n} / \mathrm{a}$ & 2 & $\mathrm{n} / \mathrm{a}$ & 3,222 & $\mathrm{n} / \mathrm{a}$ \\
\hline & TxSON & 0.034 & 0.020 & 0.071 & 0.111 & 0.079 & 0.112 & 0.85 & 0.89 & 0.81 & 0.87 & 2 & 2 & 17,302 & 15,349 \\
\hline & Fort Cobb & 0.037 & 0.026 & -0.042 & 0.000 & 0.056 & 0.041 & 0.82 & 0.80 & 0.83 & 0.78 & 2 & 2 & 12,240 & 8,682 \\
\hline & Little Washita & 0.037 & 0.029 & -0.021 & -0.021 & 0.047 & 0.037 & 0.78 & 0.76 & 0.77 & 0.75 & 3 & 2 & 9,183 & 3,855 \\
\hline & Niger & 0.039 & $\mathrm{n} / \mathrm{a}$ & 0.067 & $\mathrm{n} / \mathrm{a}$ & 0.078 & $\mathrm{n} / \mathrm{a}$ & 0.48 & $\mathrm{n} / \mathrm{a}$ & 0.44 & $\mathrm{n} / \mathrm{a}$ & 1 & $\mathrm{n} / \mathrm{a}$ & 1,053 & $\mathrm{n} / \mathrm{a}$ \\
\hline & Yanco & 0.053 & $\mathrm{n} / \mathrm{a}$ & -0.038 & $\mathrm{n} / \mathrm{a}$ & 0.065 & $\mathrm{n} / \mathrm{a}$ & 0.87 & $\mathrm{n} / \mathrm{a}$ & 0.85 & $\mathrm{n} / \mathrm{a}$ & 2 & $\mathrm{n} / \mathrm{a}$ & 10,207 & $\mathrm{n} / \mathrm{a}$ \\
\hline & Average & 0.040 & 0.025 & 0.003 & 0.030 & 0.062 & 0.063 & 0.75 & 0.82 & 0.73 & 0.80 & & & & \\
\hline \multirow[t]{8}{*}{ Croplands } & South Fork & 0.055 & 0.037 & 0.021 & 0.003 & 0.063 & 0.050 & 0.66 & 0.49 & 0.74 & 0.82 & 3 & 3 & 9,319 & 4,918 \\
\hline & Kenaston & 0.032 & 0.022 & -0.021 & -0.034 & 0.041 & 0.041 & 0.75 & 0.88 & 0.74 & 0.89 & 2 & 1 & 5,200 & 2,921 \\
\hline & Carman & 0.048 & $\mathrm{n} / \mathrm{a}$ & 0.034 & $\mathrm{n} / \mathrm{a}$ & 0.059 & $\mathrm{n} / \mathrm{a}$ & 0.68 & $\mathrm{n} / \mathrm{a}$ & 0.70 & $\mathrm{n} / \mathrm{a}$ & 1 & $\mathrm{n} / \mathrm{a}$ & 8,274 & $\mathrm{n} / \mathrm{a}$ \\
\hline & Monte Buey & 0.036 & $\mathrm{n} / \mathrm{a}$ & -0.071 & $\mathrm{n} / \mathrm{a}$ & 0.079 & $\mathrm{n} / \mathrm{a}$ & 0.79 & $\mathrm{n} / \mathrm{a}$ & 0.81 & $\mathrm{n} / \mathrm{a}$ & 1 & $\mathrm{n} / \mathrm{a}$ & 3,738 & $\mathrm{n} / \mathrm{a}$ \\
\hline & REMEDHUS & 0.042 & $\mathrm{n} / \mathrm{a}$ & 0.065 & $\mathrm{n} / \mathrm{a}$ & 0.098 & $\mathrm{n} / \mathrm{a}$ & 0.67 & $\mathrm{n} / \mathrm{a}$ & 0.63 & $\mathrm{n} / \mathrm{a}$ & 2 & $\mathrm{n} / \mathrm{a}$ & 9,689 & $\mathrm{n} / \mathrm{a}$ \\
\hline & HOBE & 0.045 & $\mathrm{n} / \mathrm{a}$ & -0.013 & $\mathrm{n} / \mathrm{a}$ & 0.047 & $\mathrm{n} / \mathrm{a}$ & 0.83 & $\mathrm{n} / \mathrm{a}$ & 0.63 & $\mathrm{n} / \mathrm{a}$ & 1 & $\mathrm{n} / \mathrm{a}$ & 1,067 & $\mathrm{n} / \mathrm{a}$ \\
\hline & St Josephs & 0.041 & $\mathrm{n} / \mathrm{a}$ & 0.056 & $\mathrm{n} / \mathrm{a}$ & 0.070 & $\mathrm{n} / \mathrm{a}$ & 0.72 & $\mathrm{n} / \mathrm{a}$ & 0.66 & $\mathrm{n} / \mathrm{a}$ & 1 & $\mathrm{n} / \mathrm{a}$ & 2,413 & $\mathrm{n} / \mathrm{a}$ \\
\hline & Average & 0.043 & 0.029 & 0.010 & -0.015 & 0.065 & 0.045 & 0.73 & 0.68 & 0.70 & 0.86 & & & & \\
\hline Crops/natural & Little River & 0.031 & 0.027 & 0.081 & 0.097 & 0.087 & 0.100 & 0.80 & 0.60 & 0.79 & 0.65 & 1 & 1 & 4,290 & 3,471 \\
\hline Open shrubs & Walnut Gulch & 0.032 & $\mathrm{n} / \mathrm{a}$ & 0.043 & $\mathrm{n} / \mathrm{a}$ & 0.058 & $\mathrm{n} / \mathrm{a}$ & 0.75 & $\mathrm{n} / \mathrm{a}$ & 0.74 & $\mathrm{n} / \mathrm{a}$ & 3 & $\mathrm{n} / \mathrm{a}$ & 12,363 & $\mathrm{n} / \mathrm{a}$ \\
\hline \multirow{2}{*}{$\begin{array}{l}\text { Woody } \\
\text { savannas }\end{array}$} & Tonzi Ranch & 0.037 & 0.029 & 0.007 & 0.033 & 0.038 & 0.035 & 0.92 & 0.90 & 0.70 & 0.80 & 1 & 1 & 10,344 & 3,667 \\
\hline & Valencia & 0.027 & $\mathrm{n} / \mathrm{a}$ & 0.066 & $\mathrm{n} / \mathrm{a}$ & 0.072 & $\mathrm{n} / \mathrm{a}$ & 0.65 & $\mathrm{n} / \mathrm{a}$ & 0.73 & $\mathrm{n} / \mathrm{a}$ & 1 & $\mathrm{n} / \mathrm{a}$ & 1,766 & $\mathrm{n} / \mathrm{a}$ \\
\hline Savannas & Benin & 0.047 & $\mathrm{n} / \mathrm{a}$ & 0.127 & $\mathrm{n} / \mathrm{a}$ & 0.135 & $\mathrm{n} / \mathrm{a}$ & 0.78 & $\mathrm{n} / \mathrm{a}$ & 0.47 & $\mathrm{n} / \mathrm{a}$ & 1 & $\mathrm{n} / \mathrm{a}$ & 6,637 & $\mathrm{n} / \mathrm{a}$ \\
\hline
\end{tabular}

TABLE XIII

Sparse Networks Metrics for L4 Surface (SF) AND Root-Zone (RZ) SM Categorized BaSed on Land Cover

\begin{tabular}{|c|c|c|c|c|c|c|c|c|c|c|}
\hline \multirow{3}{*}{$\begin{array}{l}\text { L4 } \\
\text { (9-km, 3-hr) } \\
\text { Land Cover } \\
\end{array}$} & \multirow{2}{*}{\multicolumn{2}{|c|}{$\begin{array}{l}\text { ubRMSD } \\
(\mathrm{m} 3 / \mathrm{m} 3) \\
\end{array}$}} & \multirow{2}{*}{\multicolumn{2}{|c|}{$\begin{array}{l}\mathbf{R} \\
(-)\end{array}$}} & \multirow{2}{*}{\multicolumn{2}{|c|}{$\begin{array}{c}\text { Anomaly R } \\
(-)\end{array}$}} & \multicolumn{4}{|c|}{ No. of stations } \\
\hline & & & & & & & \multicolumn{2}{|c|}{$\begin{array}{c}\text { ubRMSD, } \\
\mathbf{R}\end{array}$} & \multicolumn{2}{|c|}{$\begin{array}{c}\text { Anomaly } \\
\mathbf{R}\end{array}$} \\
\hline & SF & $\mathbf{R Z}$ & SF & $\mathbf{R Z}$ & SF & $\mathbf{R Z}$ & SF & $\mathbf{R Z}$ & SF & $\mathbf{R Z}$ \\
\hline Grasslands & 0.053 & 0.038 & 0.70 & 0.67 & 0.65 & 0.59 & 178 & 126 & 177 & 126 \\
\hline Croplands & 0.059 & 0.039 & 0.74 & 0.70 & 0.68 & 0.65 & 94 & 65 & 94 & 64 \\
\hline Crop/Natural vegetation mosaic & 0.059 & 0.043 & 0.72 & 0.67 & 0.66 & 0.64 & 41 & 37 & 41 & 37 \\
\hline Open shrublands & 0.037 & 0.026 & 0.70 & 0.67 & 0.64 & 0.62 & 27 & 12 & 27 & 12 \\
\hline Woody savannas & 0.063 & 0.044 & 0.69 & 0.67 & 0.59 & 0.58 & 31 & 24 & 31 & 24 \\
\hline Barren/Sparse & 0.024 & $\mathrm{n} / \mathrm{a}$ & 0.72 & $\mathrm{n} / \mathrm{a}$ & 0.65 & $\mathrm{n} / \mathrm{a}$ & 2 & $\mathrm{n} / \mathrm{a}$ & 2 & $\mathrm{n} / \mathrm{a}$ \\
\hline Evergreen needleleaf forest & 0.058 & 0.044 & 0.71 & 0.64 & 0.58 & 0.55 & 7 & 4 & 7 & 4 \\
\hline Mixed forest & 0.058 & 0.040 & 0.70 & 0.68 & 0.61 & 0.65 & 23 & 17 & 23 & 16 \\
\hline Evergreen broadleaf forest & 0.036 & 0.028 & 0.51 & 0.25 & 0.47 & 0.23 & 1 & 1 & 1 & 1 \\
\hline Deciduous broadleaf forest & 0.049 & 0.034 & 0.73 & 0.70 & 0.67 & 0.67 & 15 & 11 & 14 & 9 \\
\hline Urban and built-up & 0.071 & 0.038 & 0.58 & 0.67 & 0.62 & 0.70 & 4 & 3 & 3 & 2 \\
\hline
\end{tabular}

In the calculation of the $\mathrm{CI}_{R}$, the effective number of samples is computed as

$$
N_{\mathrm{eff}}=N\left(\frac{1-\rho}{1+\rho}\right)
$$

where

$$
\rho=\sqrt{\rho_{x} \rho_{y}}
$$

in which $\rho_{x}$ and $\rho_{y}$ are the 1-lag autocorrelation of the SMAP and in situ SM samples, respectively. The CI for the anomaly $R$ is computed similarly as for $R$. For the $95 \%$ CIs, $\alpha=0.05$.

For the average metrics, the CIs of the separate locations are combined as follows:

$$
\overline{\mathrm{CI}_{P}}=\frac{1}{M} \sum_{j=1}^{M} P_{j}-\frac{P_{j}-\mathrm{CI}_{P, j}}{\sqrt{M}}
$$

where $P_{j}$ denotes the metric (MD, ubRMSD, RMSD, $R$, or anomaly $R$ ) whose CIs are computed for site $j$, and $M$ denotes the number of sites.

\section{APPENDIX C}

\section{A. Result Tables for Radiometer-Based Product (PE)}

Tables VI and VII summarize the PE product CVS metrics for the 6 P.M. and 6 A.M. overpasses, respectively. Table VIII summarizes the sparse network comparison results for the PE product.

\section{B. Result Tables for SMAP/Sentinel-1 Combined Product (SP)}

Tables IX and X summarize the SP product CVS metrics for the $9-\mathrm{km}$ and $3-\mathrm{km}$ scales, respectively. Table XI summarizes 
the sparse network comparison results for the SP product at the 3-km scale.

\section{Result Tables for Assimilation Product (L4)}

Table XII summarizes the L4 product CVS metrics. Table XIII summarizes the sparse network comparison results for the L4 product.

\section{ACKNOWLEDGMENT}

Computational resources for $\mathrm{L} 4$ production were provided by the NASA High-End Computing program through the NASA Center for Climate Simulation. SMAP radiometer and SM data products and SMAP core site validation data are available from the National Snow and Ice and Data Center. ${ }^{1}$ SMAP radar products are available from the Alaska Satellite Facility. ${ }^{2}$ USDA is an equal opportunity provider and employer. This research was a contribution from the Long-Term Agroecosystem Research network.

\section{Authors' Affiliations}

Andreas Colliander, Steven Chan, Julian Chaubell, Seungbum Kim, R. Scott Dunbar, Land B. Dang, and Simon H. Yueh are with the Jet Propulsion Laboratory, California Institute of Technology, Pasadena, CA 91109 USA (e-mail: andreas.colliander@jpl.nasa.gov; steven.k.chan @jpl.nasa.gov; mario.j. chaubell@jpl.nasa.gov; seungbum.kim@jpl.nasa.gov; roy.s.dunbar@jpl.nasa. gov; lan.b.dang@jpl.nasa.gov; simon.h.yueh@jpl.nasa.gov).

Rolf H. Reichle, Rajat Bindlish, Qing Liu, and Peggy E. O'Neill are with the NASA Goddard Space Flight Center, Greenbelt, MD 20771-0003 USA (e-mail: rolf.reichle@nasa.gov; rajat.bindlish@nasa.gov; qing.liu-1@nasa.gov; peggy.e.oneill@nasa.gov).

Wade T. Crow and Michael H. Cosh are with the Hydrology and Remote Sensing Laboratory, United States Department of Agriculture, Agricultural Research Service, Beltsville, MD 20705 USA (e-mail: wade.crow@ars.usda.gov; michael.cosh@ars.usda.gov).

Fan Chen is with the Hydrology and Remote Sensing Laboratory, United States Department of Agriculture, Agricultural Research Service, Beltsville, MD 20705 USA, and also with the Science Systems and Applications, Inc., Lanham, MD 20706 USA (e-mail: fan.chen@ars.usda.gov).

Narendra Narayan Das is with the Department of Civil and Agricultural Engineering, Michigan State University, East Lansing, MI 48824 USA (e-mail: dasnaren@msu.edu).

John S. Kimball is with the Numerical Terradynamic Simulation Group, University of Montana, Missoula, MT 59812 USA (e-mail: john.kimball@mso.umt.edu).

Thomas J. Jackson, retired, was with the Hydrology and Remote Sensing Laboratory, United States Department of Agriculture, Agricultural Research Service, Beltsville, MD 20705 USA (e-mail: tom.jackson@ars.usda.gov).

Hala Khalid Al-Jassar is with the Physics Department, Kuwait University, Kuwait City 13060, Kuwait (e-mail: hala.aljassar@ku.edu.kw).

Jun Asanuma is with the Center for Research in Isotopes and Environmental Dynamics, University of Tsukuba, Tsukuba 305-8577, Japan (e-mail: asanuma@ied.tsukuba.ac.jp).

Bimal K. Bhattacharya is with the Space Applications Centre, Indian Space Research Organization, Ahmedabad 380015, India (e-mail: bkbhattacharya@sac.isro.gov.in).

Aaron A. Berg is with the Department of Geography, Environment and Geomatics, University of Guelph, Guelph, ON N1G 2W1, Canada (e-mail: aberg@uoguelph.ca).

David D. Bosch is with the Southeast Watershed Research Laboratory, United States Department of Agriculture, Agricultural Research Service, Tifton, GA 31794 USA (e-mail: david.bosch@usda.gov).

Laura Bourgeau-Chavez is with the Michigan Technical Research Institute, Ann Arbor, MI 48105 USA (e-mail: lchavez@mtu.edu).

\footnotetext{
${ }^{1}$ [Online]. Available: https://nsidc.org/data/smap

${ }^{2}$ [Online]. Available: https://asf.alaska.edu/data-sets/sar-data-sets/smap/ smap-data-and-imagery/
}

Todd Caldwell is with the Jackson School of Geosciences, the University of Texas at Austin, Austin TX 78758 USA (e-mail: tcaldwell@usgs.gov).

Jean-Christophe Calvet is with the CNRM, Université de Toulouse, Météo-France, CNRS, 31057 Toulouse, France (e-mail: jean-christophe.calvet@meteo.fr).

Chandra Holifield Collins is with the Southwest Watershed Research Center, United States Department of Agriculture, Agricultural Research Service, Tucson, AZ 85719 USA (e-mail: chandra.holifield@usda.gov).

Karsten H. Jensen is with the University of Copenhagen, 1165 Copenhagen, Denmark (e-mail:khj@ign.ku.dk).

Stan Livingston is with the National Soil Erosion Research Laboratory, United States Department of Agriculture, Agricultural Research Service, West Lafayette, IN 47907 USA (e-mail: stan.livingston@usda.gov).

Ernesto Lopez-Baeza is with the University of Valencia, 46100 Valencia, Spain (e-mail: ernesto.lopez@uv.es).

José Martínez-Fernández is with the Instituto de Investigación en Agrobiotecnología, Universidad de Salamanca, 37185 Salamanca, Spain (e-mail: jmf@usal.es).

Heather McNairn is with the Agriculture and Agri-Food Canada, Ottawa, ON K1A 0C6, Canada (e-mail: heather.mcnairn@agr.gc.ca).

Mahta Moghaddam is with the University of Southern California, Los Angeles, CA 90089 USA (e-mail: mahta@usc.edu).

Carsten Montzka is with the Research Center Juelich, Institute of Bio- and Geosciences: Agrosphere, 52425 Juelich, Germany (e-mail: c.montzka@fzjuelich.de).

Claudia Notarnicola is with the EURAC-Institute for Earth Observation, 39100 Bolzano, Italy (e-mail: claudia.notarnicola@eurac.edu).

Thierry Pellarin is with the University of Grenoble Alpes, CNRS, IRD, Grenoble INP, IGE, 38000 Grenoble, France (e-mail: thierry.pellarin@univgrenoble-alpes.fr)

Isabella Greimeister-Pfeil and Mariette Vreugdenhil are with the Vienna University of Technology, 1040 Vienna, Austria (e-mail: isabella.pfeil@geo.tuwien.ac.at; mariette.vreugdenhil@geo.tuwien.ac.at).

Jouni Pulliainen is with the Finnish Meteorological Institute, 00560 Helsinki, Finland (e-mail: jouni.pulliainen@fmi.fi).

Judith Gpe. Ramos Hernández is with the Universidad Nacional Autónoma de México, Mexico City 04510, Mexico (e-mail: jramosh@iingen.unam.mx).

Mark Seyfried is with the Northwest Watershed Research Center, United States Department of Agriculture, Agricultural Research Service, Boise, ID 83712 USA (e-mail: mark.seyfried@usda.gov).

Patrick J. Starks is with the Grazinglands Research Laboratory, United States Department of Agriculture, Agricultural Research Service, El Reno, OK 73036 USA (e-mail: patrick.starks@usda.gov).

Zhongbo Su, R. van der Velde, and Yijian Zeng are with the University of Twente, 7500 AE Enschede, The Netherlands (e-mail: z.su@utwente.nl; r.vandervelde@utwente.nl; y.zeng@utwente.nl).

Marc Thibeault is with the Comisión Nacional de Actividades Espaciales, Buenos Aires C1063ACH, Argentina (e-mail: mthibeault@conae.gov.ar).

Jeffrey P. Walker is with the Monash University, Clayton, VIC 3800, Australia (e-mail: jeff.walker@monash.edu).

Mehrez Zribi is with the CESBIO, Université de Toulouse, CNRS/UPS/IRD/CNES/INRAE, 31401 Toulouse, France (e-mail mehrez.zribi@ird.fr).

Dara Entekhabi is with the Massachusetts Institute of Technology, Cambridge, MA 02139 USA (e-mail: darae@ @mit.edu).

\section{REFERENCES}

[1] D. Entekhabi, S. Yueh, P. O'Neill, and K. Kellogg, SMAP HandbookSoil Moisture Active Passive: Mapping Soil Moisture and Freeze/Thaw From Space. Pasadena, CA, USA: SMAP Project, Jet Propulsion Lab., 2014.

[2] T. J. Schmugge, P. E. O'Neill, and J. R. Wang, "Passive microwave soil moisture research," IEEE Trans. Geosci. Remote Sens., vol. GRS-24, no. 1, pp. 12-22, Jan. 1986.

[3] A. Colliander, Calibration and Validation: Encyclopedia of Remote Sensing, E. G. Njoku, Ed. Berlin, Germany: Springer, 2014.

[4] A. Loew et al., "Validation practices for satellite-based earth observation data across communities," Rev. Geophys., vol. 55, no. 3, pp. 779-817, 2017, doi: 10.1002/2017RG000562.

[5] T. J. Jackson et al., "SMAP science data calibration and validation plan,” SMAP Mission, Jet Propulsion Lab., Mar. 14, 2014. [Online]. Available: http://smap.jpl.nasa.gov/science/validation/ 
[6] T. Kawanishi et al., "The Advanced Microwave Scanning Radiometer for the Earth Observing System (AMSR-E), NASDA's contribution to the EOS for global energy and water cycle studies," IEEE Trans. Geosci. Remote Sens., vol. 41, no. 2, pp. 184-194, Feb. 2003.

[7] S. Mecklenburg et al., "ESA's Soil Moisture and Ocean Salinity mission: From science to operational applications," Remote Sens. Environ., vol. 180, pp. 3-18, 2016, doi: 10.1016/j.rse.2015.12.025.

[8] D. D. Bosch, V. Lakshmi, T. J. Jackson, M. Choi, and J. M. Jacobs, "Large scale measurements of soil moisture for validation of remotely sensed data: Georgia soil moisture experiment 2003,' J. Hydrol., vol. 323, pp. 120-137, 2006, doi: 10.1016/j.jhydrol.2005.08.024.

[9] M. H. Cosh, T. J. Jackson, P. J. Starks, and G. C. Heathman, "Temporal stability of surface soil moisture in the Little Washita River watershed and its applications in satellite soil moisture product validation," J. Hydrol., vol. 323, pp. 168-177, 2006, doi: 10.1016/j.jhydrol.2005.08.020.

[10] M. H. Cosh, T. J. Jackson, S. Moran, and R. Bindlish, "Temporal persistence and stability of surface soil moisture in a semi-arid watershed," Remote Sens. Environ., vol. 112, no. 2, pp. 304-313, 2008, doi: 10.1016/j.rse.2007.07.001.

[11] J. Martinez-Fernandez and A. Ceballos, "Mean soil moisture estimation using temporal stability analysis," J. Hydrol., vol. 312, pp. 28-38, 2005, doi: 10.1016/j.jhydrol.2005.02.007.

[12] C. Rudiger et al., "Goulburn river experimental catchment data set," Water Resour. Res., vol. 43, 2007, Art. no. W10403, doi: 10.1029/2006WR005837.

[13] T. J. Jackson et al., "Validation of advanced microwave scanning radiometer soil moisture products," IEEE Trans. Geosci. Remote Sens., vol. 48, no. 12, pp. 4256-4272, Dec. 2010.

[14] A. B. Smith et al., "The Murrumbidgee soil moisture monitoring network data set," Water Resour. Res., vol. 48, 2012, Art. no. W07701, doi: 10.1029/2012WR011976.

[15] S. Bircher, N. Skou, K. H. Jensen, J. P. Walker, and L. Rasmussen, "A soil moisture and temperature network for SMOS validation in Western Denmark," Hydrol. Earth Syst. Sci., vol. 16, pp. 1445-1463, 2012, doi: 10.5194/hess-16-1445-2012.

[16] L. Dente, Z. Su, and J. Wen, "Validation of SMOS soil moisture products over the Maqu and Twente regions," Sensors, vol. 12, pp. 9965-9986, 2012, doi: 10.3390/s120809965.

[17] O. Merlin et al., "The NAFE'06 data set: Towards soil moisture retrieval at intermediate resolution," Adv. Water Resour., vol. 31, no. 11, pp. 1444-1455, 2008, doi: 10.1016/j.advwatres.2008.01.018.

[18] T. J. Jackson et al., "Validation of Soil Moisture and Ocean Salinity (SMOS) soil moisture over watershed networks in the U.S.," IEEE Trans. Geosci. Remote Sens., vol. 50, no. 5, pp. 1530-1543, May 2012.

[19] E. Tetlock, B. Toth, A. Berg, T. Rowlandson, and J. T. Ambadan, "An 11-year (2007-2017) soil moisture and precipitation dataset from the Kenaston Network in the Brightwater Creek Basin, Saskatchewan, Canada," Earth Syst. Sci. Data, vol. 11, no. 2, pp.787-796, 2019, doi: 10.5194/essd-11-787-2019.

[20] R. Bindlish, T. J. Jackson, A. J. Gasiewski, M. Klein, and E. G. Njoku, "Soil moisture mapping and AMSR-E validation using the PSR in SMEX02," Remote Sens. Environ., vol. 103, no. 2, pp. 127-139, 2006, doi: 10.1016/j.rse.2005.02.003.

[21] R. Bindlish et al., "Aircraft based soil moisture retrievals under mixed vegetation and topographic conditions," Remote Sens. Environ., vol. 112, no. 2, pp. 375-390, 2008, doi: 10.1016/j.rse.2007.01.024.

[22] T. J. Jackson et al., "Polarimetric scanning radiometer C- and X-band microwave observations during SMEX03," IEEE Trans. Geosci. Remote Sens., vol. 43, no. 11, pp. 2418-2430, Nov. 2005.

[23] S. Delwart et al., "SMOS validation and the COSMOS campaigns," IEEE Trans. Geosci. Remote Sens., vol. 46, no. 3, pp. 695-704, Mar. 2008.

[24] J. T. dall'Amico, F. Schlenz, A. Loew, and W. Mauser, "First results of SMOS soil moisture validation in the upper Danube catchment," IEEE Trans. Geosci. Remote Sens., vol. 50, no. 5, pp. 1507-1516, May 2012.

[25] A. Al-Yaari et al., "Assessment and inter-comparison of recently developed/reprocessed microwave satellite soil moisture products using ISMN ground-based measurements," Remote Sens. Environ., vol. 224, pp. 289-303, 2019, doi: 10.1016/j.rse.2019.02.008.

[26] K. Rotzer et al., "Catchment scale validation of SMOS and ASCAT soil moisture products using hydrological modeling and temporal stability analysis," J. Hydrol., vol. 519, no. Part A, pp. 934-946, 2014, doi: 10.1016/j.jhydrol.2014.07.065.

[27] S. Bircher, N. Skou, and Y. H. Kerr, "Validation of SMOS L1C and L2 products and important parameters of the retrieval algorithm in the Skjern
River Catchment, Western Denmark," IEEE Trans. Geosci. Remote Sens., vol. 51, no. 5, pp. 2969-2985, May 2013.

[28] I. Gherboudj, R. Magagi, K. Goita, A. A. Berg, B. Toth, and A Walker, "Validation of SMOS data over agricultural and boreal forest areas in Canada," IEEE Trans. Geosci. Remote Sens., vol. 50, no. 5, pp. 1623-1635, May 2012.

[29] N. Sanchez, J. Martinez-Fernandez, A. Scaini, and C. Perez-Gutierrez, "Validation of the SMOS L2 soil moisture data in the REMEDHUS network (Spain)," IEEE Trans. Geosci. Remote Sens., vol. 50, no. 5, pp. 1602-1611, May 2012.

[30] A. Robock et al., "The Global Soil Moisture Data Bank," Bull. Amer. Meteorol. Soc., vol. 81, no. 6, pp. 1281-1299, 2000.

[31] W. A. Dorigo et al., "The International Soil Moisture Network: A data hosting facility for global in situ soil moisture measurements," Hydrol. Earth Syst. Sci., vol. 15, no. 5, pp. 1675-1698, 2011, doi: 10.5194/hess-15-1675-2011.

[32] N. N. Das et al., Assessment Report for the L2_SM_SP Version-3 Release Data Products, SMAP Project, JPL D-56549, Jet Propulsion Lab., Pasadena, CA, USA, Aug. 21, 2020.

[33] P. O'Neill et al., Calibration and Validation for the L2/3_SM_P Version 7 and L2/3_SM_P_E Version 4 Data Products SMAP Project, JPL D56297, Jet Propulsion Lab., Pasadena, CA, USA, Aug. 31, 2020.

[34] A. Gruber et al., "Validation practices for satellite soil moisture retrievals: What are (the) errors?," Remote Sens. Environ., vol. 244, 2020, Art. no. 111806, doi: 10.1016/j.rse.2020.111806.

[35] C. Montzka et al., "Soil moisture product validation good practices protocol version 1.0," in Good Practices for Satellite Derived Land Product Validation, C. Montzka, M. Cosh, J. Nickeson, and F. Camacho, Eds., Washington, DC, USA: Land Product Validation Subgroup (WGCV/CEOS), 2020, p. 123, doi: 10.5067/doc/ceoswgcv/lpv/sm.001.

[36] S. K. Chan et al., "Assessment of the SMAP passive soil moisture product," IEEE Trans. Geosci. Remote Sens., vol. 54, no. 8, pp. 4994-5007, Aug. 2016.

[37] S. B. Kim et al., "Surface soil moisture retrieval using the L-band synthetic aperture radar onboard the Soil Moisture Active Passive (SMAP) satellite and evaluation at core validation sites," IEEE Trans. Geosci. Remote Sens., vol. 55, no. 4, pp. 1897-1914, Apr. 2017.

[38] N. N. Das et al., "The SMAP mission combined active-passive soil moisture product at $9 \mathrm{~km}$ and $3 \mathrm{~km}$ spatial resolutions," Remote Sens. Environ., vol. 211, pp. 204-217, 2018, doi: 10.1016/j.rse.2018.04.011.

[39] R. H. Reichle et al., "Assessment of the SMAP Level-4 surface and root-zone soil moisture product using in situ measurements," J. Hydrometeorol., vol. 18, pp. 2621-2645, 2017, doi: 10.1175/JHM-D-17-0063.1.

[40] M. J. Brodzik, B. Billingsley, T. Haran, B. Raup, and M. H. Savoie, "EASE-Grid 2.0: Incremental but significant improvements for earthgridded data sets," ISPRS Int. J. Geo-Inf., vol. 1, no. 1, pp. 32-45, 2012, doi: 10.3390/ijgi1010032.

[41] M. J. Brodzik et al., "EASE-Grid 2.0: Incremental but significant improvements for earth-gridded data sets. ISPRS International Journal of Geo-Information 2012, 1, 32-45," ISPRS Int. J. Geo-Inf., vol. 3, no. 3, pp. 1154-1156, 2014, doi: 10.3390/ijgi3031154.

[42] J. R. Piepmeier et al., "Radio-Frequency interference mitigation for the soil moisture active passive microwave radiometer," IEEE Trans. Geosci. Remote Sens., vol. 52, no. 1, pp. 761-775, Jan. 2014.

[43] J. R. Piepmeier et al., "SMAP L-band microwave radiometer: Instrument design and first year on orbit," IEEE Trans. Geosci. Remote Sens., vol. 55, no. 4, pp. 1954-1966, Apr. 2017.

[44] P. N. Mohammed, M. Aksoy, J. R. Piepmeier, J. T. Johnson, and A. Bringer, "SMAP L-band microwave radiometer: RFI mitigation prelaunch analysis and first year on-orbit observations," IEEE Trans. Geosci. Remote Sens., vol. 54, no. 10, pp. 6035-6047, Oct. 2016.

[45] S. Chan, E. G. Njoku, and A. Colliander, "Algorithm theoretical basis document (ATBD): Level 1C radiometer data product," SMAP Project, Rev. A, Dec. 9, 2014.

[46] M. J. Chaubell et al., "Algorithm theoretical basis document (ATBD): SMAP level 1(B/C) enhanced radiometer brightness temperature data product," SMAP Project, Rev. B, May 31, 2018.

[47] S. K. Chan et al., "Development and assessment of the SMAP enhanced passive soil moisture product," Remote Sens. Environ., vol. 204, pp. 931-941, 2018, doi: 10.1016/j.rse.2017.08.025.

[48] N. N. Das et al., "The SMAP and Copernicus Sentinel 1A/B microwave active-passive high resolution surface soil moisture product," Remote Sens. Environ., vol. 233, 2019, Art. no. 111380, doi: 10.1016/j.rse.2019.111380.

[49] P. O’Neill, S. Chan, E. G. Njoku, T. Jackson, and R. Bindlish, "Algorithm theoretical basis document (ATBD): L2 \& L3 radiometer soil moisture (Passive) data products,' SMAP Project, Rev. F, Aug. 31, 2020. 
[50] M. J. Chaubell et al., "Improved SMAP dual-channel algorithm for the retrieval of soil moisture," IEEE Trans. Geosci. Remote Sens., vol. 58, no. 6, pp. 3894-3905, Jun. 2020.

[51] R. Reichle et al., "Version 4 of the SMAP Level-4 soil moisture algorithm and data product," J. Adv. Model. Earth Syst., vol. 11, no. 10, pp. 3106-3130, 2019, doi: 10.1029/2019MS001729.

[52] A. Colliander et al., "SMAP detects soil moisture under temperate forest canopies," Geophys. Res. Lett., vol. 47, 2020, Art. no. e2020GL089697, doi: 10.1029/2020GL089697.

[53] E. Ayres, A. Colliander, M. Cosh, R. Joshua, S. Simkin, and M. Genazzio, "Validation of SMAP soil moisture at terrestrial National Ecological Observatory Network (NEON) sites show potential for soil moisture retrieval in forested areas," IEEE J. Sel. Topics Appl. Earth Observ. Remote Sens., vol. 14, pp. 10903-10918, 2021, doi: 10.1109/JSTARS.2021.3121206.

[54] A. Colliander et al., "Validation of SMAP surface soil moisture products with core validation sites," Rem. Sens. Environ., vol. 191, pp. 215-231, 2017, doi: 10.1016/j.rse.2017.01.021.

[55] D. Entekhabi, R. H. Reichle, R. D. Koster, and W. T. Crow, "Performance metrics for soil moisture retrievals and application requirements," J. Hydrometeorol., vol. 11, pp. 832-840, 2010, doi: 10.1175/ 2010JHM1223.1.

[56] SMAP Science Definition Team, SMAP Algorithm Development Team, Skill Metrics for Validation of SMAP Data Products, D. Entekhabi, E.G. Njoku, Ed. SMAP Project, Oct. 31, 2012.

[57] F. Chen et al., "Application of triple collocation in ground-based validation of soil moisture active/passive (SMAP) level 2 data products," IEEE J. Sel. Topics Appl. Earth Observ. Remote Sens., vol. 10, no. 2, pp. 489-502, Feb. 2017.

[58] F. Chen et al., "Global-Scale evaluation of SMAP, SMOS and ASCAT soil moisture products using triple collocation," Remote Sens. Environ., vol. 214, pp. 1-13, 2018, doi: 10.1016/j.rse.2018.05.008.

[59] R. H. Reichle et al., "The contributions of gauge-based precipitation and SMAP brightness temperature observations to the skill of the SMAP level-4 soil moisture product," J. Hydrometeorol., vol. 22, pp. 405-424, 2021, doi: 10.1175/JHM-D-20-0217.1.

[60] S. Zwieback et al., "Estimating time-dependent vegetation biases in the SMAP soil moisture product," Hydrol. Earth Syst. Sci., vol. 22, pp. 4473-4489, Feb. 2018.

[61] V. A. Walker, B. K. Hornbuckle, M. H. Cosh, and J. H. Prueger, "Seasonal evaluation of SMAP soil moisture in the U.S. Corn belt," Remote Sens., vol. 11 , no. 21,2019 , Art. no. 2488 , doi: 10.3390/rs11212488.

[62] A. Colliander et al., "Seasonal dependence of SMAP radiometer-based soil moisture performance as observed over core validation sites," in Proc. IEEE Int. Geosci. Remote Sens. Symp., Yokohama, Japan, 2019, pp. 5320-5323.

[63] A. W. Western, R. B. Grayson, and G. Bloschl, "Scaling of soil moisture: A hydrologic perspective," Апnи. Rev. Earth Planet. Sci., vol. 30, pp. 149-180, 2002, doi: 10.1146/annurev.earth.30.091201.140434.

[64] I. Rodriguez-Iturbe, G. K. Vogel, R. Rigon, D. Entekhabi, F. Castelli, and A. Rinaldo, "On the spatial organization of soil moisture fields," Geophys. Res. Lett., vol. 22, no. 22, pp. 2757-2760, 1995, doi: 10.1029/95GL02779.

[65] J. S. Famiglietti., J. W. Rudnicki, and M. Rodell, "Variability in surface moisture content along a hillslope transect: Rattlesnake Hill, Texas," J. Hydrol., vol. 210, pp. 259-281, 1998, doi: 10.1016/S0022-1694(98)00187-5.

[66] J. S. Famiglietti et al., "Ground-based investigation of soil moisture variability within remote sensing footprints during the southern great plains 1997 (SGP97) hydrology experiment," Water Resour. Res., vol. 35, no. 6, pp. 1839-1851, 1999, doi: 10.1029/1999WR900047.

[67] J. S. Famiglietti, D. Ryu, A. A. Berg, M. Rodell, and T. J. Jackson, "Field observations of soil moisture variability across scales," Water Resour. Res., vol. 44, 2008, Art. no. W01423, doi: 10.1029/2006WR00580.

[68] W. T. Crow and E. F. Wood, "Multi-scale dynamics of soil moisture variability observed during SGP'97," Geophys. Res. Lett., vol. 26, no. 23, pp. 3485-3488, 1999, doi: 10.1029/1999GL010880.

[69] M. S. Yee, J. P. Walker, A. Monerris, C. Rüdiger, and T. J. Jackson, "On the identification of representative in situ soil moisture monitoring stations for the validation of SMAP soil moisture products in Australia," J. Hydrol., vol. 537, pp. 367-381, 2016, doi: 10.1016/j.jhydrol.2016.03.060.

[70] T. G. Caldwell et al., "The Texas soil observation network: A comprehensive soil moisture dataset for remote sensing and land surface model validation," Vadose Zone J., vol. 18, pp. 1-20, 2019, doi: 10.2136/vzj2019.04.0034.
[71] C. Montzka, H. R. Bogena, M. Herbst, M. H. Cosh, T. Jagdhuber, and H. Vereecken, "Estimating the number of reference sites necessary for the validation of global soil moisture products," IEEE Geosci. Remote Sens. Lett., vol. 18, no. 9, pp. 1530-1534, Sep. 2021.

[72] J. Qin et al., "Spatial upscaling of in-situ soil moisture measurements based on MODIS-derived apparent thermal inertia," Remote Sens. Environ., vol. 138, pp. 1-9, 2013.

[73] J. Kang, R. Jin, and X. Li, "Regression kriging-based upscaling of soi moisture measurements from a wireless sensor network and multiresource remote sensing information over heterogeneous cropland," IEEE Geosci. Remote Sens. Lett., vol. 12, no. 1, pp. 92-96, Jan. 2015.

[74] J. Kang et al., "High spatio-temporal resolution mapping of soil moisture by integrating wireless sensor network observations and MODIS apparent thermal inertia in the Babao River Basin, China," Remote Sens. Environ., vol. 191, no. Suppl. C, pp. 232-245, 2017.

[75] J. Wang et al., "Upscaling in situ soil moisture observations to pixel averages with spatio-temporal geostatistics," Remote Sens., vol. 7, no. 9, pp. 11372-11388, 2015.

[76] C. F. Ma et al., "Multi-scale validation of SMAP soil moisture products over cold and arid regions in northwestern China using distributed ground observation data," Remote Sens., vol. 9, no. 4, 2017, Art. no. 327, doi: $10.3390 / \mathrm{rs} 9040327$

[77] G. Voronoi, "Nouvelles applications des paramètres continus à la théorie des formes quadratiques," J. für die Reine und Angewandte Mathematik, vol. 134, no. 4, pp. 198-287, 1908.

[78] S. L. Dingman, Physical Hydrology. Long Grove, IL, USA: Waveland Press, 2015.

[79] H. A. Bhuiyan et al., "Assessing SMAP soil moisture scaling and retrieval in the Carman (Canada) study site," Vadose Zone J., vol. 17, no. 1-14, 2018, Art. no. 180132, doi: 10.2136/vzj2018.07.0132.

[80] R. van der Velde et al., "Validation of SMAP L2 passive-only soil moisture products using upscaled in situ measurements collected in Twente, The Netherlands," Hydrol. Earth Syst. Sci., vol. 25, pp. 473-495, 2021, doi: 10.5194/hess-25-473-2021.

[81] W. T. Crow et al., "Upscaling sparse ground-based soil moisture observations for the validation of coarse-resolution satellite soil moisture products," Rev. Geophys., vol. 50, 2012, Art. no. RG2002, doi: 10.1029/2011RG000372.

[82] F. Chen et al., "Uncertainty of reference pixel soil moisture averages sampled at SMAP core validation sites," J. Hydrometeorol., vol. 20, pp. 1553-1568, 2019, doi: 10.1175/JHM-D-19-0049.1.

[83] G. Vachaud, A. Passerat De Silans, P. Balabanis, and M. Vauclin, "Temporal stability of spatially measured soil water probability density function," Soil Sci. Soc. Amer. J., vol. 49, pp. 822-828, 1985, doi: 10.2136/sssaj1985.03615995004900040006x.

[84] A. Gómez-Plaza, J. Alvarez-Rogel, J. Albaladejo, and V. M. Castillo, "Spatial patterns and temporal stability of soil moisture across a range of scales in a semi-arid environment," Hydrol. Process., vol. 14, pp. 1261-1277, 2000.

[85] M. H. Cosh, T. J. Jackson, R. Bindlish, and J. H. Prueger, "Watershed scale temporal and spatial stability of soil moisture and its role in validating satellite estimates," Remote Sens. Environ., vol. 92, no. 4, pp. 427-435, 2004, doi: 10.1016/j.rse.2004.02.016.

[86] M. H. Cosh, P. J. Starks, J. A. Guzman, and D. N. Moriasi, "Upper Washita river experimental watersheds: Multiyear stability of soil water content profiles," J. Environ. Qual., vol. 43, pp. 1328-1333, 2014, doi: 10.2134/jeq2013.08.0318.

[87] D. G. Miralles, W. T. Crow, and M. H. Cosh, "Estimating spatial sampling errors in coarse-scale soil moisture estimates derived from point-scale observations," J. Hydrometeorol., vol. 11, no. 6, pp. 1423-1429, 2010, doi: 10.1175/2010JHM1285.1.

[88] J. Dong et al., "Comparison of microwave remote sensing and land surface modeling for surface soil moisture climatology estimation," Remote Sens. Environ., vol. 242, 2020, Art. no. 111756 , doi: 10.1016/j.rse.2020.111756. 2020.

[89] E. G. Njoku and J.-A. Kong, "Theory for passive microwave remote sensing of near-surface soil moisture," J. Geophys. Res., vol. 82, no. 20, pp. 3108-3118, 1977.

[90] M. J. Escorihuela, A. Chanzy, J. P. Wigneron, and Y. H. Kerr, "Effective soil moisture sampling depth of L-band radiometry: A case study," Remote Sens. Environ., vol. 114, no. 5, pp. 995-1001, 2010 doi: 10.1016/j.rse.2009.12.011. 
[91] S. Lv, Y. Zeng, J. Wen, H. Zhao, and Z. Su, "Estimation of penetration depth from soil effective temperature in microwave radiometry," Remote Sens., vol. 10, no. 4, 2018, Art. no. 519.

[92] X. Shen et al., "Soil moisture retrieval depth of P- and L-band radiometry: Predictions and observations," IEEE Trans. Geosci. Remote Sens., vol. 59, no. 8, pp. 6814-6822, Aug. 2021.

[93] P. J. Shellito et al., "SMAP soil moisture drying more rapid than observed in situ following rainfall events," Geophys. Res. Lett., vol. 43, pp. 8068-8075, early access, 2016, doi: 10.1002/2016GL069946.

[94] A. Berg, J. Thomas-Ambadan, A. Colliander, H. McNcairn, J. Powers, and E. Tetlock, "The impact of in-situ probe orientation on SMAP validation statistics," IEEE Geosci. Remote Sens. Lett., to be published, doi: 10.1109/LGRS.2020.3018077.

[95] T. G. Caldwell, T. Bongiovanni, M. H. Cosh, C. Halley, and M. H. Young, "Field and laboratory evaluation of the CS655 soil water content sensor," Vadose Zone J., vol. 17, 2018, Art. no. 170214. doi: 10.2136/vzj2017.12.0214.

[96] J. R. Adams, H. McNairn, A. A. Berg, and C. Champagne, "Evaluation of near-surface soil moisture data from an AAFC monitoring network in Manitoba, Canada: Implications for L-band satellite validation," J. Hydrol., vol. 521, pp. 582-592, 2015, doi: 10.1016/j.jhydrol.2014.10.024.

[97] K. H. Jensen and J. C. Refsgaard, "HOBE: The Danish hydrological observatory," Vadose Zone J., vol. 17, pp. 1-24, 2018, doi: 10.2136/vzj2018.03.0059.

[98] J. Whitcomb et al., "Evaluation of SMAP core validation site representativeness errors using dense networks of in situ sensors and random forests," IEEE J. Sel. Topics Appl. Earth Observ. Remote Sens., vol. 13, pp. 6457-6472, Oct. 2020, doi: 10.1109/jstars.2020.3033591.

[99] R. Panciera et al., "The soil moisture active passive experiments (SMAPEx): Toward soil moisture retrieval from the SMAP mission," IEEE Trans. Geosci. Remote Sens., vol. 52, no. 1, pp. 490-507, Jan. 2014.

[100] N. Ye et al., "Evaluation of SMAP downscaled brightness temperature using SMAPEx-4/5 airborne observations," Remote Sens. Environ., vol. 221, pp. 363-372, 2019, doi: 10.1016/j.rse.2018.11.033.

[101] S. Galle et al., "AMMA-CATCH, a critical zone observatory in West Africa, monitoring a region in transition," Vadose Zone J., vol. 17, pp. 1-24, 2018, doi: 10.2136/vzj2018.03.0062.

[102] R. Magagi et al., "CanEX-SM 10 (Canadian experiment for soil moisture in 2010): Overview and preliminary results," IEEE Trans. Geosci. Remote Sens., vol. 51, no. 1, pp. 347-363, Jan. 2013.

[103] H. McNairn et al., "The soil moisture active passive validation experiment 2012 (SMAPVEX12): Pre-launch calibration and validation of the SMAP satellite," IEEE Trans. Geosci. Remote Sens., vol. 53, no. 5, pp. 2784-2801, May 2015.

[104] A. Colliander et al., "Comparison of high-resolution airborne soil moisture retrievals to SMAP soil moisture during the SMAP Validation Experiment 2016 (SMAPVEX16)," Remote Sens. Environ., vol. 227, pp. 137-150, 2019, doi: 10.1016/j.rse.2019.04.004.

[105] T. L. Rowlandson et al., "Capturing agricultural soil freeze/thaw state through remote sensing and ground observations: A soil freeze/thaw validation campaign," Remote Sens. Environ., vol. 211, pp. 59-70, 2018, doi: 10.1016/j.rse.2018.04.003.

[106] X. Wen, H. Lu, C. Li, T. Koike, and I. Kaihotsu, "Inter-Comparison of soil moisture products from SMOS, AMSR-E, ECMWF and GLDAS over the Mongolia Plateau," Proc. SPIE, vol. 9260, 2014, Art. no. 926000.

[107] T. O. Keefer, M. S. Moran, and G. B. Paige, "Long-term meteorological and soil hydrology database walnut gulch experimental watershed, Arizona, United States," Water Resour. Res., vol. 44, 2008, Art. no. W05S07, doi: 10.1029/2006WR005702.

[108] A. Colliander et al., "Validation and scaling of soil moisture in a semi-arid environment: SMAP Validation Experiment 2015 (SMAPVEX15)," Remote Sens. Environ., vol. 196, pp. 101-112, 2017, doi: 10.1016/j.rse.2017.04.022.

[109] D. D. Bosch et al., "Little river experimental watershed database," Water Resour. Res., vol. 43, 2007, Art. no. W09472, doi: 10.1029/2006WR005844.

[110] M. Choi, J. M. Jacobs, and D. D. Bosch, "Remote sensing observatory validation of surface soil moisture using Advanced Microwave Scanning Radiometer E, Common Land Model, and ground based data: Case study in SMEX03 Little River Region, Georgia, U.S.,"Water Resour. Res., vol. 44, 2008, Art. no. W08421, doi: 10.1029/2006WR005578.

[111] M. S. Seyfried, K. A. Lohse, D. Marks, G. N. Flerchinger, F. Pierson, and S. Holbrook, "Reynolds creek experimental watershed and critical zone observatory," Vadoze Zone J., vol. 17, 2018, Art. no. 180129, doi: 10.2136/vzj2018.07.0129.
[112] E. Han, G. C. Heathman, V. Merwade, and M. H. Cosh, "Application of observation operators for field scale soil moisture averages and variances in agricultural landscapes," J. Hydrol., vol. 444/445, pp. 34-50, 2012.

[113] E. Coopersmith, M. H. Cosh, W. A. Petersen, J. H. Prueger, and J. J. Niemeier, "Soil moisture model calibration and validation: An ARS watershed on the South Fork Iowa river," J. Hydrometeorol., vol. 16, pp. 1087-1101, 2015.

[114] M. H. Cosh et al., "Estimating vegetation water content during the soil moisture active passive validation experiment 2016," J. Appl. Remote Sens., vol. 13, no. 1, 2019, Art. no. 014516, doi: $10.1117 / 1 . J R S .13 .014516$.

[115] P. J. Starks, J. L. Steiner, and A. J. Stern, "Upper Washita river experimental watersheds: Land cover data sets (1974-2007) for two southwestern Oklahoma agricultural watersheds," J. Environ. Qual., vol. 43, pp. 1310-1318, 2014, doi: 10.2134/jeq2013.07.0292.

[116] G. Blöschl et al., "The hydrological open air laboratory (HOAL) in Petzenkirchen: A hypothesis-driven observatory," Hydrol. Earth Syst. Sci., vol. 20, no. 1, pp. 227-255, 2016.

[117] J. Ikonen et al., "The Sodankyla in-situ soil moisture observation network: An example application to earth observation data product evaluation," Geosci. Instrum. Methods Data Syst. Discuss., vol. 5, pp. 599-629, 2015.

[118] S. Zacharias et al., "A network of terrestrial environmental observatories in Germany," Vadose Zone J., vol. 10, pp. 955-973, 2011.

[119] G. Singh et al., "Validation of SMAP soil moisture products using ground-based observations for the paddy dominated tropical region of India," IEEE Trans. Geosci. Remote Sens., vol. 57, no. 11, pp. 8479-8491, Nov. 2019.

[120] L. Pasolli et al., "Estimation of soil moisture in mountain areas using SVR technique applied to multiscale active radar images at C band," IEEE J. Sel. Topics Appl. Earth Observ. Remote Sens., vol. 8, no. 1, pp. 262-283, Jan. 2015.

[121] H. K. AlJassar et al., "Forward simulation of multi-frequency microwave brightness temperature over desert soils in Kuwait and comparison with satellite observations," Remote Sens., vol. 11, no. 14, 2019, Art. no. 1647, doi: 10.3390/rs11141647.

[122] Z. Su et al., "The Tibetan Plateau observatory of plateau scale soil moisture and soil temperature (Tibet-Obs) for quantifying uncertainties in coarse resolution satellite and model products," Hydrol. Earth Syst. Sci., vol. 15, no. 7, pp. 2303-2316, 2011, doi: 10.5194/hess-15-2303-2011.

[123] E. J. Coopersmith et al., "Deploying temporary networks for upscaling of sparse network stations," Int. J. Appl. Earth Observ. Geoinf., vol. 52, pp. 433-444, 2016, doi: 10.1016/j.jag.2016.07.013.

[124] M. C. Peel, B. L. Finlayson, and T. A. McMahon, "Updated world map of the Koeppen-Geiger climate classification," Hydrol. Earth Syst. Sci., vol. 11, pp. 1633-1644, 2007, doi: 10.5194/hess-11-1633-2007.

[125] S. B. Kim, "Ancillary data report: Landcover classification," SMAP Project, Jan. 11, 2013. [Online]. Available: smap.jpl.nasa.gov/documents

[126] K. M. Larson, E. E. Small, E. D. Gutmann, A. L. Bilich, J. J. Braun, and V. U. Zavorotny, "Use of GPS receivers as a soil moisture network for water cycle studies," Geophys. Res. Lett., vol. 35, 2008, Art. no. L24405, doi: 10.1029/2008GL036013.

[127] M. Zreda et al., "COSMOS: The COsmic-ray soil moisture observing system," Hydrol. Earth Syst. Sci., vol. 16, pp. 4079-4099, 2012, doi: 10.5194/hess-16-4079-2012.

[128] K. Scipal, T. Holmes, R. de Jeu, V. Naeimi, and W. Wagner, "A possible solution for the problem of estimating the error structure of global soil moisture data sets," Geophys. Res. Lett., vol. 35, 2008, Art. no. L24403, doi: 10.1029/2008GL035599.

[129] A. Gruber, W. Dorigo, S. Zwieback, A. Xaver, and W. Wagner, "Characterizing coarse-scale representativeness of in situ soil moisture measurements from the International Soil Moisture Network," Vadose Zone J., vol. 12, pp. 1-16, 2013, doi: 10.2136/vzj2012.0170.

[130] A. Gruber, C.-H. Su, S. Zwieback, W. Crow, W. Dorigo, and W. Wagner, "Recent advances in (soil moisture) triple collocation analysis," Int. J. Appl. Earth Observ. Geoinf., vol. 45, no. Part B, pp. 200-211, 2016, doi: 10.1016/j.jag.2015.09.002.

[131] C. Draper, R. de Jeu Reichle, V. Naeimi, R. Parinussa, and W. Wagner, "Estimating root mean square errors in remotely sensed soil moisture over continental scale domains," Remote Sens. Environ., vol. 137, pp. 288-298, 2013, doi: 10.1016/j.rse.2013.06.013.

[132] H. J. Diamond et al., "U.S. Climate reference network, after one decade of operations: Status and assessment," Bull. Amer. Meteorol. Soc., vol. 94, pp. 485-498, 2013, doi: 10.1175/BAMS-D-12-00170.1. 
[133] G. L. Schaefer, M. H. Cosh, and T. J. Jackson, "The USDA natural resources conservation service soil climate analysis network (SCAN)," J. Ocean. Atmos. Technol., vol. 24, pp. 2073-2077, 2007.

[134] B. G. Illston et al., "Mesoscale monitoring of soil moisture across a statewide network," J. Atmos. Ocean. Technol., vol. 25, pp. 167-182, 2008.

[135] J.-C. Calvet, N. Fritz, F. Froissard, D. Suquia, A. Petitpa, and B. Piguet, "In situ soil moisture observations for the CAL/VAL of SMOS: The SMOSMANIA network," in Proc. IEEE Int. Geosci. Remote Sens. Symp., 2007, pp. 1196-1199.

[136] C. Albergel et al., "A first assessment of the SMOS data in southwestern France using in situ and airborne soil moisture estimates: The CAROLS airborne campaign," Remote Sens. Environ., vol. 115, no. 10, pp. 2718-2728, 2011, doi: 10.1016/j.rse.2011.06.012.

[137] M. S. Burgin et al., "A comparative study of the SMAP passive soil moisture product with existing satellite-based soil moisture products," IEEE Trans. Geosci. Remote Sens., vol. 55, no. 5, pp. 2959-2971, May 2017.

[138] R. D. Koster, Z. Guo, R. Yang, P. A. Dirmeyer, K. Mitchell, and M. J. Puma, "On the nature of soil moisture in land surface models," J. Climate, vol. 22, no. 16, pp. 4322-4335, 2009, doi: 10.1175/2009JCLI2832.1.

[139] F. Fascetti, N. Pierdicca, L. Pulvirenti, and R. Crapolicchio, "SMOS, ASCAT, SMAP and ERA soil moisture comparison through the triple and quadruple collocation technique," Proc. SPIE, vol. 10003, Oct. 2016, Art. no. $100030 \mathrm{H}$, doi: $10.1117 / 12.2244615$.

[140] E. Ghafari et al., "On the impact of C-band in place of L-band radar for SMAP downscaling," Remote Sens. Environ., vol. 251, 2020, Art. no. 112111, doi: 10.1016/j.rse.2020.112111.

[141] S. Sabaghy et al., "Comprehensive analysis of alternative downscaled soil moisture products," Remote Sens. Environ., vol. 239, 2020, Art. no. 111586, doi: 10.1016/j.rse.2019.111586.

[142] X. Cai et al., "Validation of SMAP soil moisture for the SMAPVEX15 field campaign using a hyper-resolution model," Water Resour. Res., vol. 53, pp. 3013-3028, 2017.

[143] M. Neelam, A. Colliander, B. Mohanty, M. H. Cosh, S. Misra, and T. J. Jackson, "Multiscale surface roughness for improved soil moisture estimation," IEEE Trans. Geosci. Remote Sens., vol. 58, no. 8, pp. 5264-5276, Aug. 2020.

[144] H. Zhao et al. "An air-to-soil transition model for discrete scatteringemission modelling at L-band," J. Remote Sens., vol. 2021, 2021, Art. no. 3962350, doi: 10.34133/2021/3962350

[145] R. H. Reichle et al., "Global assessment of the SMAP Level-4 surface and root-zone soil moisture product using assimilation diagnostics," J. Hydrometeorol., vol. 18, pp. 3217-3237, 2017, doi: 10.1175/JHM-D-17-0130.1.

[146] J. Peng et al., "SMAP radiometer brightness temperature calibration for the L1B_TB, L1C_TB (Version 5), and L1C_TB_E (Version 3) data products," SMAP Project, Jet Propulsion Lab., Pasadena, CA, USA, Aug. 8, 2020. [Online]. Available: https://nsidc.org/data/smap/data_versions

[147] X. Wu, J. P. Walker, C. Rudiger, R. Panciera, and Y. Gao, "Intercomparison of alternate soil moisture downscaling algorithms using active-passive microwave observations," IEEE Geosci. Remote Sens. Lett., vol. 14, no. 2, pp. 179-183, Feb. 2017.

[148] H. Ma, J. Zeng, N. Chen, X. Zhang, M. H. Cosh, and W. Wang, "Satellite surface soil moisture from SMAP, SMOS, AMSR2 and ESA CCI: A comprehensive assessment using global ground-based observations," Remote Sens. Environ., vol. 231, 2019, Art. no. 111215, doi: 10.1016/j.rse.2019.111215.

[149] J. Zeng, K. S. Chen, H. Bi, and Q. Chen, "A preliminary evaluation of the SMAP radiometer soil moisture product over United States and Europe using ground-based measurements," IEEE Trans. Geosci. Remote Sens., vol. 54, no. 8, pp. 4929-4940, Aug. 2016.

[150] R. Zhang, S. Kim, and A. Sharma, "A comprehensive validation of the SMAP Enhanced Level-3 Soil Moisture product using ground measurements over varied climates and landscapes," Remote Sens. Environ., vol. 223, pp. 82-94, 2019, doi: 10.1016/j.rse.2019.01.015.

[151] X. Zheng et al., "Performance of four passive microwave soil moisture products in maize cultivation areas of Northeast China," IEEE J. Sel. Topics Appl. Earth Observ. Remote Sens., vol. 13, pp. 2451-2460, May 2020, doi: 10.1109/JSTARS.2020.2995623.

[152] C. Cui et al., "Soil moisture mapping from satellites: An intercomparison of SMAP, SMOS, FY3B, AMSR2, and ESA CCI over two dense network regions at different spatial scales," Remote Sens., vol. 10, 2018, Art. no. 33, doi: 10.3390/rs10010033.

[153] S. Lv, Y. Zeng, J. Wen, and Z. Su, "A reappraisal of global soil effective temperature schemes," Remote Sens. Environ. vol. 183, pp. 144-153, 2016, doi: 10.1016/j.rse.2016.05.012.
[154] A. Colliander et al., "Effect of rainfall events on SMAP radiometer-based soil moisture accuracy using core validation sites," J. Hydrometeorol., vol. 21, no. 2, pp. 255-264, 2020, doi: 10.1175/JHM-D-19-0122.1.

[155] A. Colliander et al., "Consistency between NASS surveyed soil moisture conditions and SMAP soil moisture observations," Water Resour. Res., vol. 55, no. 9, pp. 7682-7693, 2019c, doi: 10.1029/2018WR024475.

[156] L. A. Jones et al., "The SMAP Level 4 carbon product for monitoring ecosystem land-atmosphere CO2 exchange," IEEE Trans. Geosci. Remote Sens., vol. 55, no. 11, pp. 6517-6532, Nov. 2017

[157] A. J. Purdy et al., "Soil moisture improves global evapotranspiration," Remote Sens. Environ., vol. 219, pp. 1-14, 2018, doi: 10.1016/j.rse.2018.09.023

[158] R. Akbar, D. J. Short Gianotti, K. A. McColl, E. Haghighi, G. D Salvucci, and D. Entekhabi, "Estimation of landscape soil water losses from satellite observations of soil moisture," J. Hydrometeorol., vol. 19, no. 5, pp. 871-889, 2018, doi: 10.1175/JHM-D-17-0200.1

[159] D. J. Gianotti, A. J. Rigden, G. D. Salvucci, and D. Entekhabi, "Satellite and station observations demonstrate water availability's effect on continental-scale evaporative and photosynthetic land surface dynamics," Water Resour. Res., vol. 55, pp. 540-554, 2019, doi: 10.1029/2018WR023726.

[160] W. T. Crow, F. Chen, R. H. Reichle, Y. Xia, and Q. Liu, "Exploiting soil moisture, precipitation, and streamflow observations to evaluate soil moisture/runoff coupling in land surface models," Geophys. Res. Lett., vol. 45, pp. 4869-4878, 2018, doi: 10.1029/2018GL077193.

[161] N. Holtzman et al., "L-band vegetation optical depth as an indicator of plant water potential in a temperate deciduous forest stand," Biogeosciences, vol. 18, pp. 739-753, 2021, doi: 10.5194/bg-2020-373.

[162] E. Wrona, T. L. Rowlandson, M. Nambiar, A. A. Berg, A. Colliander, and P. Marsh, "Validation of the Soil Moisture Active Passive (SMAP) satellite soil moisture retrieval in an arctic tundra environment," Geophys. Res. Lett., vol. 44, pp. 4152-4158, 2017, doi: 10.1002/2017GL072946.

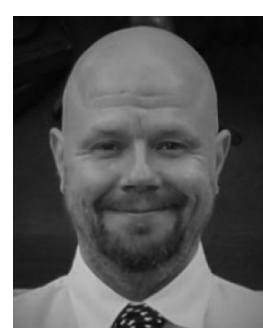

Andreas Colliander (Senior Member, IEEE) received the M.Sc. (Tech.), Lic.Sc. (Tech.), and D.Sc. (Tech.) degrees in electrical engineering from Aalto University, Espoo, Finland, in 2002, 2005, and 2007, respectively.

He is currently a Research Scientist with the Jet Propulsion Laboratory, California Institute of Technology, Pasadena, CA, USA. He is currently leading the calibration and validation of the geophysical retrievals of NASA's SMAP mission and developing multifrequency retrievals for ice sheets and polar atmosphere. His research is focused on the development of microwave remote sensing techniques.

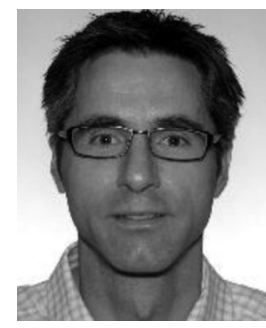

Rolf H. Reichle received the M.S. degree ("Diplom") in physics from the University of Heidelberg, Heidelberg, Germany, in 1996, and the Ph.D. degree in environmental engineering from the Massachusetts Institute of Technology, Cambridge, MA, USA, in 2000

He is currently a Research Physical Scientist with the Global Modeling and Assimilation Office, NASA Goddard Space Flight Center, Greenbelt, MD, USA. His research interests include land data assimilation, satellite-based remote sensing, and applications related to land-atmosphere interactions, weather prediction, and seasonal climate forecasting.

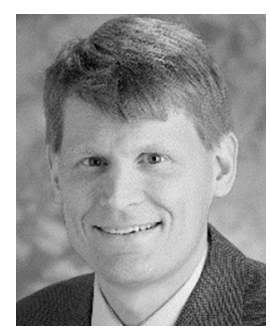

Wade T. Crow received the Ph.D. degree in civil and environmental engineering from Princeton University, Princeton, NJ, USA, in 2001.

$\mathrm{He}$ is currently a Research Physical Scientis with the Hydrology and Remote Sensing Laboratory, United States Department of Agriculture, Agricultural Research Service, Beltsville, MD, USA. His research focuses on the development of hydrologic and agricultural applications for remote sensing data and the implementation of appropriate data assimilation approaches to facilitate this goal with a special emphasis on techniques that fuse information from various disparate remote sensing sources. 


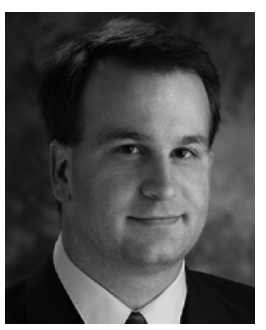

Michael H. Cosh (Senior Member, IEEE) received the Ph.D. degree in civil and environmental engineering from Cornell University, Ithaca, NY, USA, in 2002.

He is currently a Research Hydrologist with the Hydrology and Remote Sensing Laboratory, United States Department of Agriculture, Agricultural Research Service, Beltsville, MD, USA. His current research interests include the monitoring of soil moisture from both in situ resources and satellite products, and he conducts research on satellite calibration and validation for such missions as the Soil Moisture Active Passive and Soil Moisture Ocean Salinity Missions.

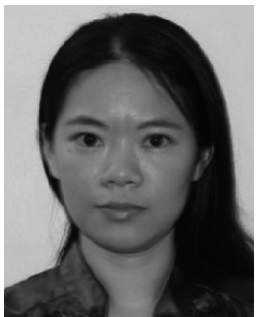

Fan Chen received the Ph.D. degree in climatology from the University of North Carolina, Chapel Hill, NC, USA, in 2006.

She is currently a Visiting Scientist with the Hydrology and Remote Sensing Laboratory, United States Department of Agriculture, Agricultural Research Service, Beltsville, MD, USA. Her research involves validation methodology for satellite retrievals of geophysical variables and application of data assimilation techniques to leverage satellite surface soil moisture products in hydrologic modeling.

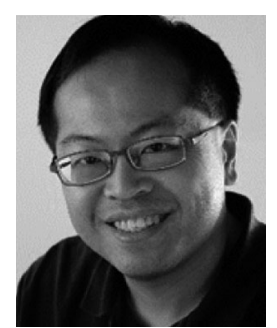

Steven Chan (Senior Member, IEEE) received the $\mathrm{Ph} . \mathrm{D}$. degree in electrical engineering from the University of Washington, Seattle, WA, USA, in 1996.

$\mathrm{He}$ is currently a Research Scientist with the Jet Propulsion Laboratory, California Institute of Technology, Pasadena, CA, USA. His work in remote sensing of soil moisture encompasses the NASA Aqua/AMSR-E instrument, the JAXA GCOMW/AMSR2 instrument, the ESA SMOS mission, the NASA SMAP mission, and more recently the NISAR mission.

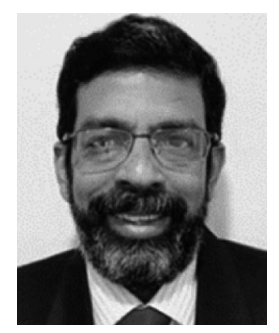

Narendra Narayan Das received the Bachelor of Engineering degree from the National Institute of Technology, Raipur, India, and the master's and Ph.D. degrees from Texas A\&M University, College Station, TX, USA, in 2005 and 2008, respectively.

$\mathrm{He}$ is currently an Associate Professor with the Department of Biosystems \& Agricultural Engineering and Civil \& Environmental Engineering, Michigan State University, East Lansing, MI, USA.

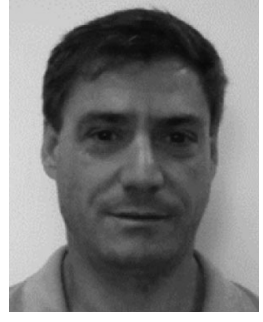

Julian Chaubell received the Bachelor of Science degree in mathematics from the University of Mar del Plata, Buenos Aires, Argentina, in 1997, and the Ph.D. degree in applied and computational mathematics from the California Institute of Technology, Pasadena, CA, USA, in 2004

He is currently with the Jet Propulsion Laboratory, California Institute of Technology, Pasadena, CA His research interests include the forward modeling of radar and radiometer measurements as well measurements.

Seungbum Kim received the B.Sc. degree from the Korea Advanced Institute of Science and Technology, Daejeon, South Korea, in 1992, and the M.S. and Ph.D. degrees from the University College London, London, U.K., in 1993 and 1998 , respectively.

He is currently a Research Scientist with the Jet Propulsion Laboratory, California Institute of Technology, Pasadena, CA, USA. His research interests include microwave modeling, and soil moisture retrieval with the radar.

Qing Liu received the Ph.D. degree in atmospheric science from the Georgia Institute of Technology, Atlanta, GA, USA, in 2004.

She is currently with the Global Modeling and Assimilation Office, NASA Goddard Space Flight Center, Greenbelt, MD, USA, working on the development of land modeling and data assimilation systems.

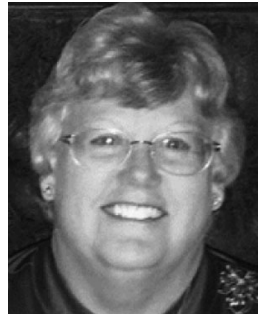

Peggy E. O'Neill (Fellow, IEEE) received the B.S degree (summa cum laude) with University Honors in geography from Northern Illinois University, DeKalb, IL, USA, in 1976, and the M.A. degree in geography from the University of California at Santa Barbara, Santa Barbara, CA, USA, in 1979.

She is currently a Research Physical Scientist and SMAP Deputy Project Scientist with the Hydrological Sciences Laboratory, NASA/Goddard Space Flight Center, Greenbelt, MD, USA, where she conducts research in soil moisture retrieval and land surface hydrology, primarily through microwave remote sensing techniques.

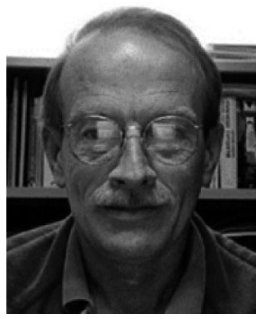

R. Scott Dunbar received the B.S. degree in physics and astronomy from the University of Albany, Albany, NY, USA, in 1976, and the Ph.D. degree in physics from Princeton University, Princeton, NJ, USA, in 1980.

$\mathrm{He}$ is currently with the Jet Propulsion Laboratory, California Institute of Technology, Pasadena CA, USA. He has contributed to the development of science algorithms for the NSCAT and SeaWinds ocean vector wind scatterometer projects, and since 2009 , he has been working on SMAP soil moisture and freeze-thaw algorithm development.

Land B. Dang photograph and biography not available at the time of publication.

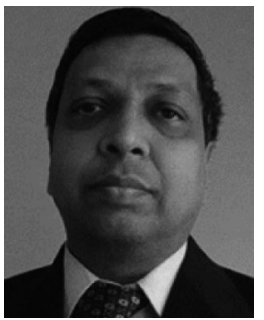

Rajat Bindlish (Senior Member, IEEE) received the B.S. degree in civil engineering from the Indian Institute of Technology Bombay, Mumbai, India, in 1993, and the M.S. and Ph.D. degrees in civil engineering from The Pennsylvania State University, State College, PA, USA, in 1996 and 2000, respectively.

$\mathrm{He}$ is currently with the NASA Goddard Space Flight Center, Greenbelt, MD, USA. His research interest involves the application of microwave remote sensing in hydrology.

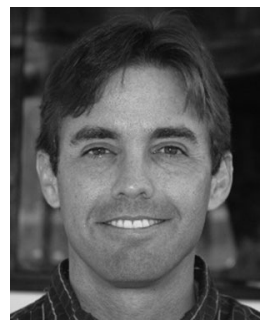

John S. Kimball (Senior Member, IEEE) received the B.A. and M.A. degrees in physical geography from San Diego State University, San Diego, CA, USA, in 1987 and 1990, respectively, and the Ph.D. degree in bioresource engineering from Oregon State University, Corvallis, OR, USA, in 1995.

He is currently a Professor of Systems Ecology and Director of the Numerical Terradynamic Simulation Group, University of Montana, Missoula, MT, USA. 
Thomas J. Jackson (Fellow, IEEE) received the Ph.D. degree in civil engineering from the University of Maryland, College Park, MD, USA, in 1976.

$\mathrm{He}$ is a Hydrologist and retired from the Hydrology and Remote Sensing Laboratory, United States Department of Agriculture, Agricultural Research Service, Beltsville, MD, USA, in 2018

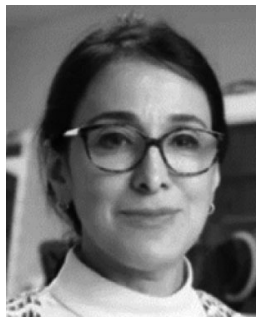

Hala Khalid Al-Jassar received the Ph.D. degree in space and climate physics from the Mullard Space Science Laboratory, University of London, London, U.K., in 1995.

She is currently an Associate Professor with the Physics Department, Kuwait University, Kuwait City, Kuwait, and is the Leader of the Space and Climate Physics Research Group. During the last 26 years, she established the remote sensing laboratories in the physics department and developed remote sensing ment, Kuwait University. program in engineering physics at Physics Depart-

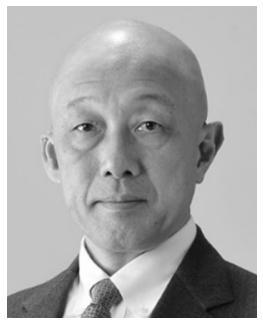

Jun Asanuma, received the B.Eng., and M.Eng. degrees in civil engineering from University of Tokyo, Tokyo, Japan, in 1989 and 1991, respectively, and the Ph.D. degree in civil \& environmental engineering from Cornell University, Ithaca, NY, USA, in 1996.

After having worked at the research center of Nippon Koei Co. Ltd, Japan, as a research engineer in hydrology, he joined Department of Civil and Environmental Engineering at Nagaoka University of Technology, Japan, then moved to Terrestrial Environmental Research Center at University of Tsukuba as a lecturer in 2000. His research interests include land surface hydrology, with emphases on the exchange of mass and energy between the land and the atmosphere through turbulence theories, modeling techniques, field measurement techniques, and satellite remote sensing.

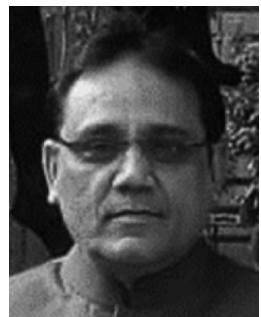

Bimal K. Bhattacharya received the M.Sc. and Ph.D. degrees from Indian Agricultural Research Institute, New Delhi, India, in 1991 and 1995, respectively.

Since 2000, he has been a Scientist with the Space Applications Centre, Indian Space Research Organization (ISRO), Ahmedabad, India. He is involved in developing satellite-based agro-met products and their utilization in National Agro-met Advisory Services in India. He is the Science Leader of AVIRISNG airborne hyperspectral mission in India and also the Science Co-Chair of ISRO-CNES (Indo-French) thermal infrared mission.

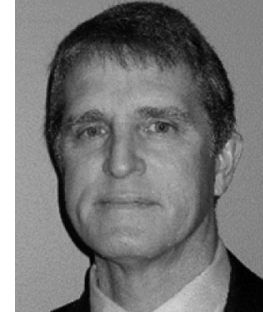

David D. Bosch received the Ph.D. degree in hydrology from The University of Arizona, Tucson, AZ, USA, in 1990.

In 1986, he joined the Agricultural Research Service. He is currently a Research Hydrologist with the Southeast Watershed Research Laboratory, Agricultural Research Service, Tifton, GA, USA, and he leads a Watershed Research Program. His primary research interests include watershed and landscape scale hydrology, agricultural impacts on water quality, and hydrologic and solute transport modeling of

watershed processes.

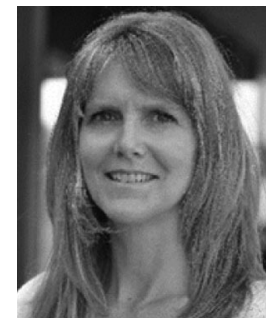

Laura Bourgeau-Chavez received the B.S. and M.S. degrees from the School of Natural Resources and Environment, University of Michigan, Ann Arbor MI, USA, and the Ph.D. degree from the School of Forestry and Environmental Management, University of New Brunswick, Fredericton, NB, Canada.

She is currently a Senior Research Scientist with the Michigan Tech Research Institute and an Adjunct Assistant Professor with the College of Forest Resources and Environmental Science, Michigan Technological University, Houghton, MI, USA. Her main interests are in using passive and active microwave radar imaging for extracting moisture, inundation and biophysical information from wetland and upland landscapes.

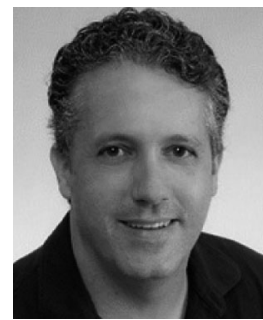

Todd Caldwell received the $\mathrm{Ph} . \mathrm{D}$. degrees in hydrogeology from the University of Nevada, Reno, NV USA, in 2011.

He is currently a Research Hydrologist with the Nevada Water Science Center, U.S. Geological Survey, Carson City, NV, USA. Prior to 2019, he was a researcher in the Jackson School of Geosciences at the University of Texas at Austin where he coordinated the Texas Soil Observation Network or TxSON, a core validation site for the Soil Moisture Active Passive Mission.

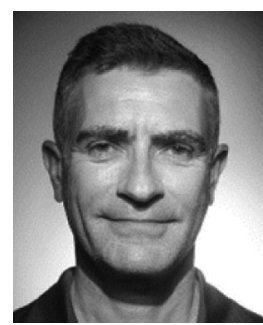

Jean-Christophe Calvet received the M.Eng. degree in agronomy from AgroParisTech, Paris, France, in 1990, the M.Sc./Eng. degree in meteorology from the Ecole Nationale de la Météorologie, Toulouse, France, in 1990, the Ph.D. degree from the University of Toulouse, Toulouse, France, in 1996, and the Habilitation degree in 2002.

He is currently with Météo-France, Toulouse, the French meteorological service, where he has been the Head of a land modeling and remote sensing team since 2003. His research interests include landatmosphere exchange modeling and the use of remote sensing over land surfaces for meteorology.

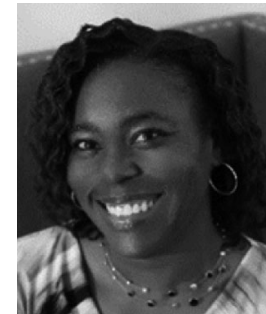

Chandra Holifield Collins received the Ph.D. degree in soil water and environmental science with a minor in remote sensing from the University of Arizona, Tucson, AZ, USA, in 2006

She is currently a Soil Scientist with the USDAAgricultural Research Service's Southwest Watershed Research Center, Tucson, AZ. Her research interests include image analysis and the use of remote sensing data for agricultural applications, with current focus on operational tools for rangeland management. ON, Canada. His research interest includes remote sensing to support hydrological modeling.

Aaron A. Berg received the Ph.D. degree in earth Irvine, Irvine, CA, USA, in 2003.

$\mathrm{He}$ is currently a Professor and Canada Research Chair with the Department of Geography, Environ- 


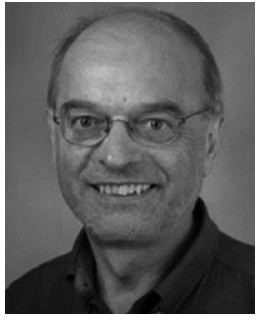

Karsten H. Jensen received the M.Sc. and Ph.D. degrees in hydrology from the Technical University of Denmark, Kongens Lyngby, Denmark, in 1977 and in 1983, respectively.

He is currently a Professor in hydrology with the University of Copenhagen, Copenhagen, Denmark. $\mathrm{He}$ has been PI for a number of major research programs and is currently director of HOBE- the Danish Hydrological Observatory and Project Leader of two Danida Fellowship Centre research projects in South Africa and India. His current research interest is integrated hydrological modeling at catchment scale under current and future climate conditions.

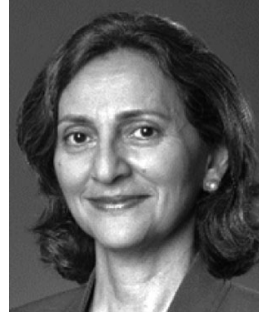

Mahta Moghaddam (Fellow, IEEE) received the B.S. degree from the University of Kansas (highest distinction), Lawrence, KS, USA, in 1986, and the M.S. and Ph.D. degrees from the University of Illinois at Urbana-Champaign, Champaign, IL, USA, in 1989 and 1991, respectively, all in electrical and computer engineering.

She is a Distinguished Professor and the Ming Hsieh Chair in electrical and computer engineering with the University of Southern California, Los Angeles, CA, USA, and the Co-Director of the USC Center for Sustainability Solutions. Her research interest is in the area of radar remote sensing, including software-defined radar, for characterization of root-zone soil moisture, ground water, and permafrost active layer, geophysical retrievals using signal-of-opportunity reflectometry, and autonomous observing systems integrating in situ and remote sensing assets.
Stan Livingston photograph and biography not available at the time of publication.

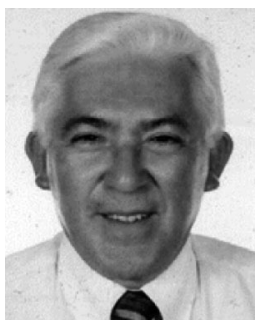

Ernesto Lopez-Baeza received the Doctorate degree in physics from the University of Valencia, Valencia, Spain, in 1986.

$\mathrm{He}$ is currently an Associate Professor in applied physics with the Department of Earth Physics and Thermodynamics, University of Valencia, and has been the Director of the Climatology from Satellites Group since 2000. He is responsible for the Valencia Anchor Station surface validation site in the framework of the current EO missions CERES, GERB, Sentinel-1, -2, -3, SMAP, SMOS, and preparing for

EarthCARE

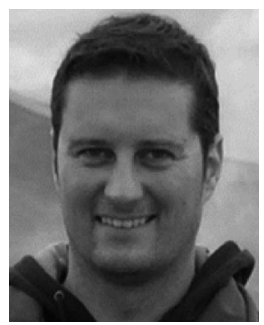

Carsten Montzka (Member, IEEE) received the $\mathrm{Ph} . \mathrm{D}$. degree in geography from the University of Bonn, Bonn, Germany, in 2007.

$\mathrm{He}$ is currently with the Institute of Bio- and Geosciences: Agrosphere (IBG-3) of the Forschungszentrum Jülich, Juelich, Germany, where he is focusing on hydrological remote sensing.

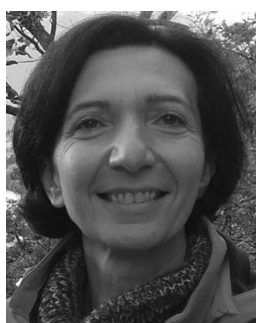

Claudia Notarnicola (Member, IEEE) received the M.S. degree in physics (summa cum laude) and Ph.D. degree in physics from the University of Bari, Bari, Italy, in 1995 and 2002, respectively.

She is currently the Vice-Head of the Institute for Earth Observation at Eurac Research, Bolzano, Italy, and the Leader of Earth Observation for Environmental Monitoring Group. Her research interests include biophysical parameter (soil moisture, vegetation, and snow) retrieval using optical and SAR images, optical and SAR data processing, data fusion, and electro-

magnetic models.

José Martínez-Fernández received the B.S. (Degree Award) degree in physical geography, the M.S. degree in water science and technology, and Ph.D. degree in physical geography from the Universidad de Murcia, Murcia, Spain, in 1985, 1991, and 1992, respectively.

He is currently a Professor of Physical Geography with the Department of Geography, Universidad de Salamanca (USAL), Salamanca, Spain, and the PI of the Water Resources Research Group, Instituto Hispano Luso de Investigaciones Agrarias, USAL.

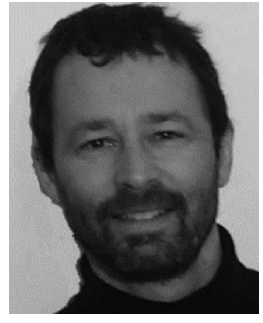

Thierry Pellarin received the M.S. degree in geoscience and the Ph.D. degree in hydrology in 2001.

$\mathrm{He}$ is currently a Senior Scientist (CNRS) with the Institute of Environmental Geosciences, Grenoble, France. His main research interests include microwave remote sensing of soil moisture (particularly in the SMOS mission), field- to regional-scale hydro-geological simulations, rainfall estimates from soil moisture and agricultural applications, and he is the Co-PI of soil moisture measurements in the AMMA-CATCH Observatory in West Africa.

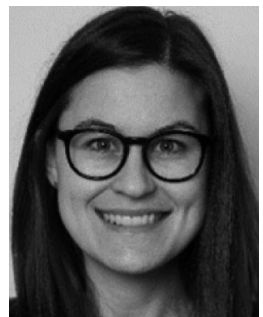

Isabella Greimeister-Pfeil received the B.Sc. and M.Sc. degrees in geodesy and geoinformation, in 2013 and 2016, respectively, from Technische Universität Wien, Vienna, Austria, where she is currently working toward the Ph.D. degree in remote sensing with the Centre for Water Resource Systems and Department of Geodesy and Geoinformation.

She recently joined the Environment Agency Austria as a radar remote sensing expert. Her work focuses on the retrieval and validation of soil moisture and vegetation datasets from active microwave remote sensing observations as well as their application in land surface and drought monitoring projects.
She is a Senior Research Scientist with the Agriculture and Agri-Food Canada, Ottawa, ON, Canada. She has 30 years of research experience in developing mental Studies degree in geography from the UniverM. Guelph, Guelph, ON, Canada, in 1992, and the Ph.D degree in geography from Université Laval, Québec setic aperture radar sensors. 


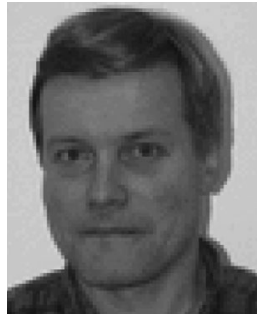

Jouni Pulliainen received the M.Sc. and the D.Sc. in Technology degrees from the Faculty of Electrical Engineering, Helsinki University of Technology (TKK), Espoo, Finland, in 1988 and 1994, respectively.

From 2001 to 2006, he was a Professor of space technology with TKK, specializing in remote sensing. $\mathrm{He}$ is currently a Research Professor with the Finnish Meteorological Institute (FMI), Helsinki, Finland, and the Director of the FMI Space and Earth Observation Centre.

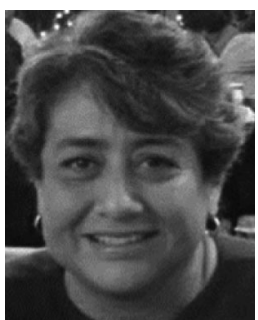

Judith Gpe. Ramos Hernández received the bachelor.s degree in chemical engineering and the M.S. degree in environmental engineering from the Universidad Nacional Autnoma de Mxico (UNAM), Mexico City, Mexico, in 1990 and 1996, respectively, and the Ph.D. degree in water resources management from the University of Wales, Bangor, U.K., in 2004.

She is currently a Technical Academic with the Engineering Institute in the Coordination of Hydraulic, UNAM. She is co-responsible for researches in the area of integrated water management, introducing techniques of remote sensing for irrigation, morphodynamic analysis of rivers and flood plains, identification of the extension and magnitude of floods, and determination and monitoring of organic and inorganic pollutants.

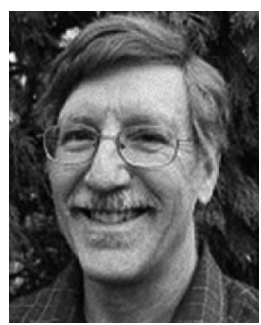

water data since 1993.

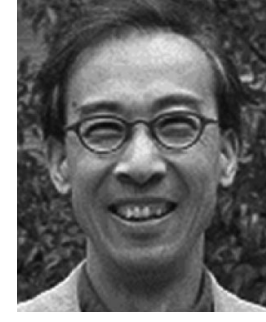

Zhongbo Su received the B.Sc. degree in hydraulic engineering from Taiyuan University of Technology, Taiyuan, China, in 1984, the M.Sc. degree with distinction in hydrological engineering from IHE Delft Institute for Water Education, Delft, The Netherlands, in 1989, and the Ph.D. degree in civil engineering from Ruhr University, Bochum, Germany, in 1996.

He currently holds the chair of Spatial Hydrology and Water Resources Management at the Faculty of Geo-Information Science and Earth Observation of the University of Twente. His current research focuses on integrating radiative transfer, photosynthesis and energy fluxes with simultaneous transfer of energy, mass and momentum in unsaturated soil via the water-soil-plant-atmosphere pathway as a component of earth system model, modelling microwave signature of land surface and retrieval of soil moisture and vegetation properties, and developing data driven machine learning algorithms for digital twin earth. Prof. Su is a member of GEWEX Scientific Steering Group (SSG) and a member of COSPAR Capacity Building Panel.

R. van der Velde, photograph and biography not available at the time of publication.

Yijian Zeng, photograph and biography not available at the time of publication.

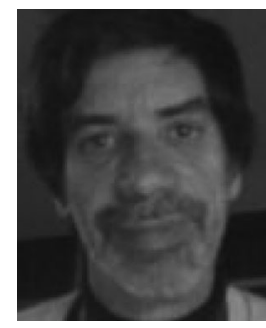

Marc Thibeault received the B.Sc. degree in physics from Laval University, Québec City, QC, Canada, in 1982, the B.Sc. degree in mathematics from the University of Montreal, Montreal, QC, Canada, in 1988, and the D.Sc. degree from the University of Buenos Aires, Buenos Aires, Argentina, in 2004

$\mathrm{He}$ is currently the Assistant Manager in the Earth Observation Management of the Argentinian Space Agency, Buenos Aires, Argentina. His research interests include soil moisture, polarimetry, and SAR calibration.

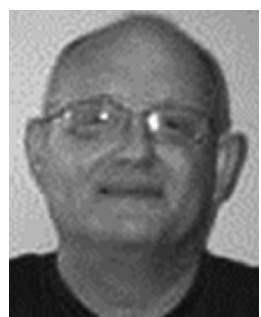

Patrick J. Starks received the B.S. degree in physical geography from the University of Central Arkansas, Conway, AR, USA, in 1979, the M.A. degree in physical geography from the University of NebraskaOmaha, Omaha, NE, USA, in 1984, and the Ph.D. degree in agricultural meteorology and climatology, with emphasis in remote sensing from the Department of Agronomy, University of Nebraska-Lincoln, Lincoln, NE, USA, in 1990.

$\mathrm{He}$ is currently a Research Soil Scientist with the United States Department of Agriculture's Agricultural Research Service, El Reno, OK, USA.

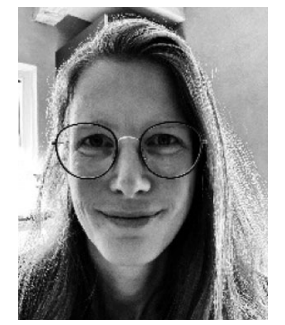

Mariette Vreugdenhil received the B.Sc. and M.Sc. degrees in earth sciences from Vrije Universiteit Amsterdam, Amsterdam, The Netherlands, in 2009 and 2011, respectively, and the Ph.D. degree in remote sensing from Vienna University of Technology (TU Wien), Vienna, Austria, in 2016.

She is currently with TU Wien, working on soil moisture and vegetation monitoring with active microwave observations. 


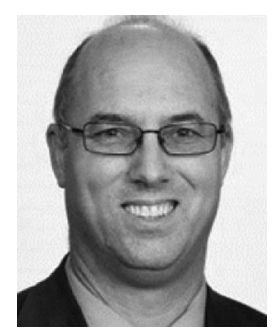

Jeffrey P. Walker (Fellow, IEEE) received the B.E. (Civil) and Bachelor of Surveying degrees with Hons. and the Ph.D. degree in water resources engineering from the University of Newcastle, Callaghan, NSW, Australia, in 1995 and 1999, respectively.

$\mathrm{He}$ is currently a Professor with the Department of Civil Engineering, Monash University, Clayton, VIC, Australia. He is contributing to soil moisture satellite missions at NASA, ESA, and JAXA, as a science team member for the SMAP mission and cal/val team member for the SMOS and GCOM-W, respectively.

Dr. Walker was the recipient of the University Medal from the University of Newcastle.

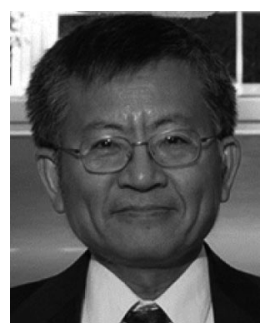

Simon H. Yueh received the Ph.D. degree in electrical engineering from the Massachusetts Institute of Technology, Cambridge, MA, USA, in January 1991.

$\mathrm{He}$ is currently a Senior Research Scientist and SMAP Project Scientist with the Jet Propulsion Laboratory, California Institute of Technology, Pasadena, CA, USA.

Dr. Yueh is the Editor-in-Chief for the IEEE TRANSACTIONS ON GEOSCIENCE AND REMOTE SENSING.

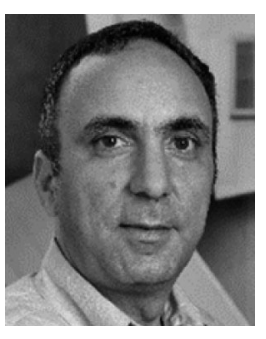

Dara Entekhabi (Fellow, IEEE) received the B.S and M.S. degrees in geography from Clark University, Worcester, MA, USA, in 1983, 1985, and 1988, respectively, and the Ph.D. degree in civil and environmental engineering from the Massachusetts Institute of Technology (MIT), Cambridge, MA, USA, in 1990

He is currently a Professor with the Department of Civil and Environmental Engineering and the Department of Earth, Atmospheric and Planetary Sciences, MIT, and he is the Science Team Lead for the SMAP mission. His research interests include terrestrial remote sensing, data assimilation, and coupled land.atmosphere systems modeling. 